\title{
Tympanal Ears in Nymphalidae Butterflies: Morphological Diversity and Tests on the Function of Hearing \\ by
}

Laura E. Hall

A thesis submitted to the Faculty of Graduate Studies and Postdoctoral Affairs in partial fulfillment of the requirements

for the degree of

Master of Science in Biology

Carleton University

Ottawa, Ontario, Canada

(C) 2014 Laura E. Hall 


\begin{abstract}
Several Nymphalidae butterflies possess a sensory structure called the Vogel's organ (VO) that is proposed to function in hearing. However, little is known about the VO's structure, taxonomic distribution or function. My first research objective was to examine VO morphology and its accessory structures across taxa. Criteria were established to categorize development levels of butterfly VOs and tholi. I observed that enlarged forewing veins are associated with the VOs of several species within two subfamilies of Nymphalidae. Further, I discovered a putative light/temperature-sensitive organ associated with the VOs of several Biblidinae species. The second objective was to test the hypothesis that insect ears function to detect bird flight sounds for predator avoidance. Neurophysiological recordings collected from moth ears show a clear response to flight sounds and chirps from a live bird in the laboratory. Finally, a portable electrophysiology rig was developed to further test this hypothesis in future field studies.
\end{abstract}




\section{Acknowledgements}

First and foremost I would like to thank David Hall who spent endless hours listening to my musings and ramblings regarding butterfly ears, sharing in the joy of my discoveries, and comforting me in times of frustration. Without him, this thesis would not have been possible.

I thank Dr. Jayne Yack for being an amazing supervisor and going above and beyond what was necessary to help me, inspire me, and encourage me.

I would like to thank Dr. Jeff Dawson for always being there to listen to my technical difficulties and providing solutions and for continuously nudging me in the right direction.

I thank Amanda Lindeman for always being an amazing friend and fellow researcher; her helping hands in my experiments were much appreciated.

I would like to thank Ross Layberry and Ed Bruggink who helped with collecting and caring for butterflies

There were so many people that helped me along the way that I would like to thank, including committee member Dr. John Lewis, my lab mates, and the undergraduate teaching coordinators Glen Kit and Joan Mallet who made my time at Carleton amazing.

Finally, I would like to thank my family. My mother and father, Susan and Eric McMillan, for their guidance and encouragement, which has led me to become who I am today. My sister Aimee for challenging me and helping me realize my potential and finally my granddad Jim Laird who always encouraged me to think outside the box. 


\section{Table of Contents}

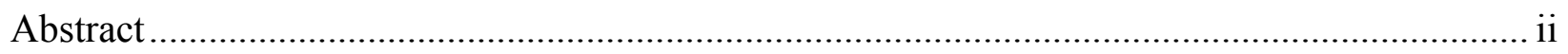

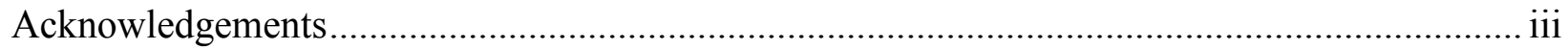

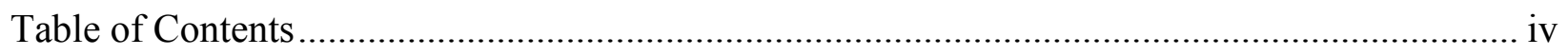

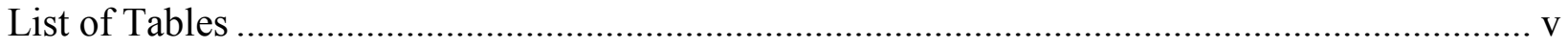

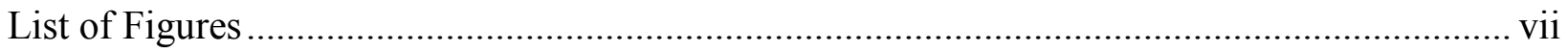

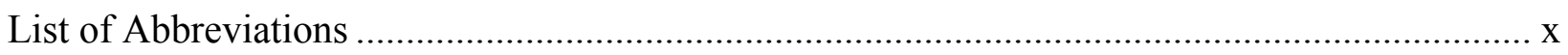

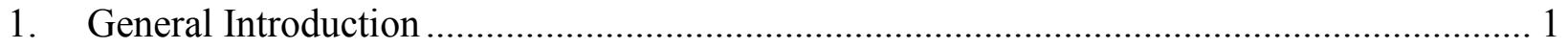

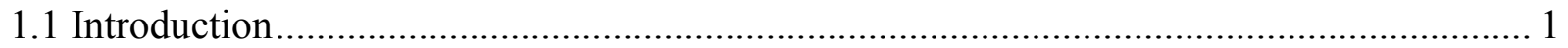

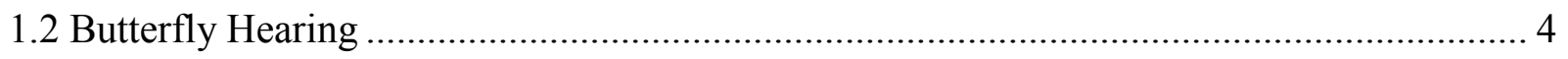

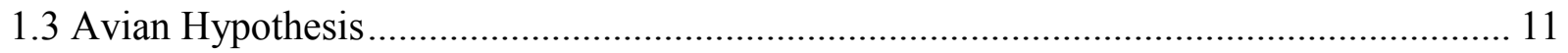

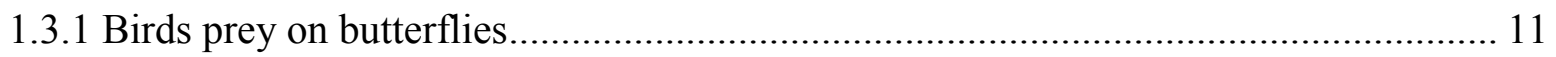

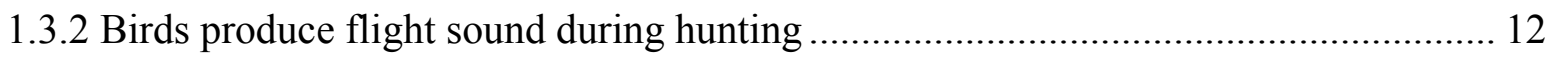

1.3.3 Butterflies preyed upon by birds have ears that can detect bird sounds ..................... 12

1.3.4 Butterfly ears will respond to bird flight sounds in a natural setting .......................... 13

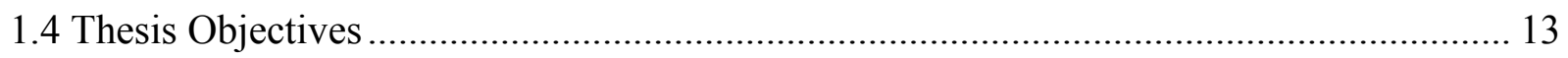

2. External Morphological Diversity of the Hearing and Accessory Organs in Nymphalidae 15

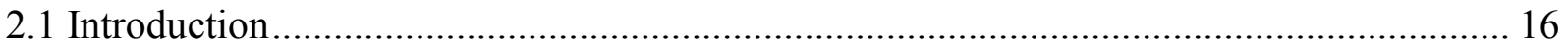

2.1.1 What is the morphological variation of butterfly hearing organs and associated

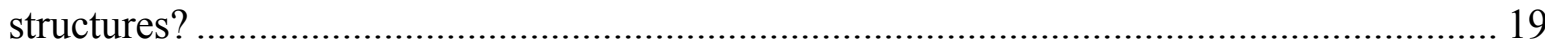

2.1.2 How are the variations of butterfly hearing organs distributed in the family

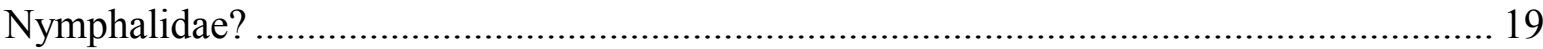

2.1.3 Is there sexual dimorphism in butterfly hearing organs or the associated structures?. 20

2.1.4 What is the morphological variation of hearing organs and associated structures within

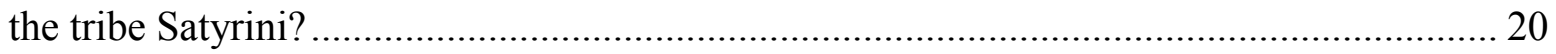

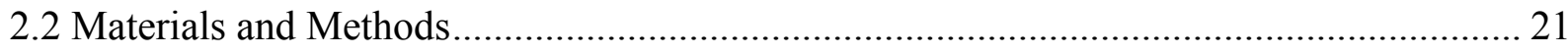

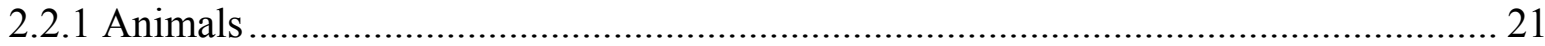

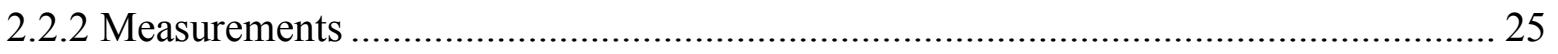

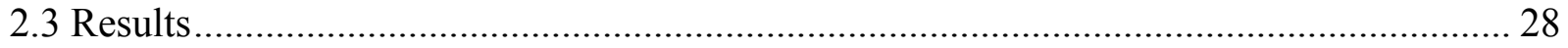


2.3.1What is the morphological variation of butterfly hearing organs and associated structures?

2.3.2 How are the variations of butterfly hearing organs distributed in the family

Nymphalidae? 54

2.4 Discussion

2.4.1 What is the observed morphological variation of Vogel's organ and its accessory structures?

2.4.2 How are the variations of butterfly hearing organs distributed in the family

Nymphalidae? 74

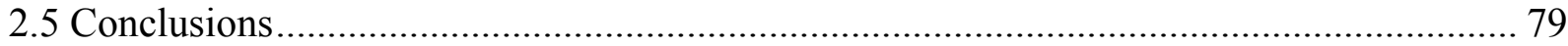

3. Neurophysiological Investigations into the Avian Hypothesis..................................... 81

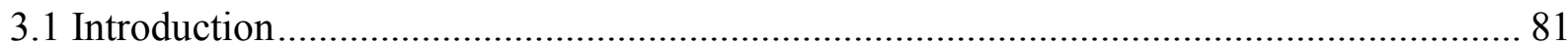

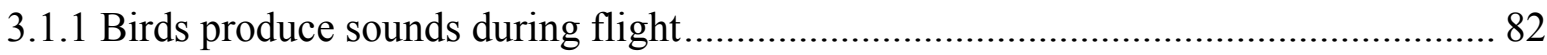

3.1.2 Insects are capable of hearing bird flight sounds.............................................. 83

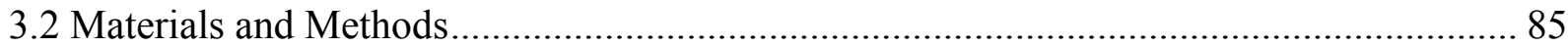

3.2.1 Objective 1: Recording bird flight sounds in the laboratory................................... 85

3.2.2 Objective 2: Neurophysiological response of moth ears to a bird in flight ............... 86

3.2.3 Objective 3: Constructing and testing a portable extracellular neurophysiology rig... 90

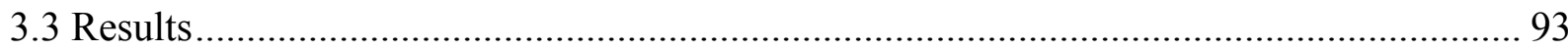

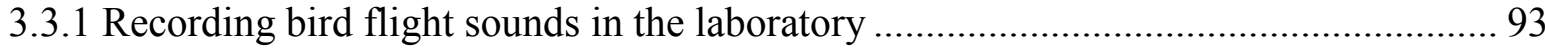

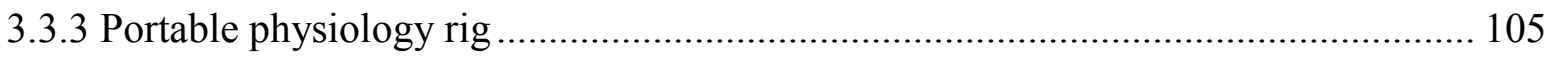

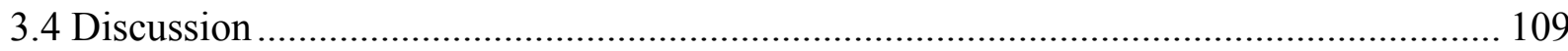

3.4.1 Objective 1: Recording bird flight sounds in the laboratory ................................. 110

3.4.2 Objective 2: Recording the physiological response of moths to a bird in flight....... 111

3.4.3 Objective 3: Constructing and testing an outdoor physiology rig ......................... 113

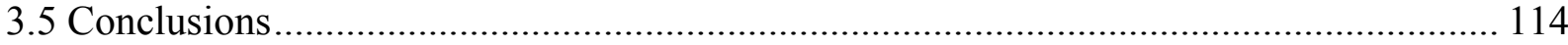

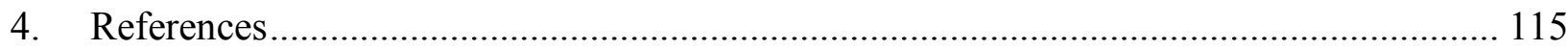

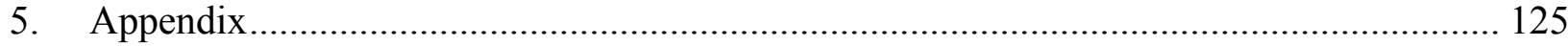

5.1 Full List of Qualitative Descriptions of the Vogel's Organs ...................................... 125 


\section{List of Tables}

Table 2.1 List of specimens in this work sorted by species name ...................................... 23

Table 2.2 Summary of VO development in the butterfly species studied in this work .......... 32

Table 2.3 Summary of the tholus development of the eared species (those with a VO) studied

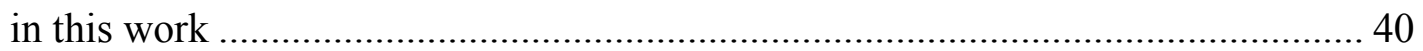

Table 2.4 Summary of the level of development of the hearing organs of Satyrini species.... 62

Table 3.1 The neural response of the A1 cell of Trichoplusia ni recorded during flybys ..... 101 


\section{List of Figures}

Figure 1.1 A phylogeny of the Lepidoptera .............................................................. 3

Figure 1.2 Ventral view of the forewing of Erebia dislocalis with the hindwing removed to

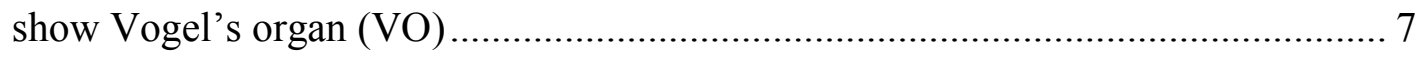

Figure 2.1 Representative images of Ariadne ariadne and Megisto cymela demonstrating how

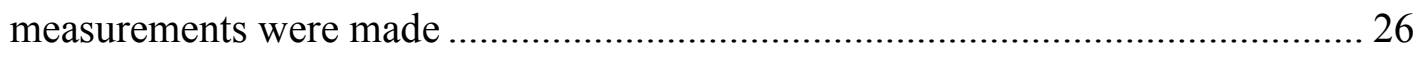

Figure 2.2 External morphology of the VO in Coenonympha tullia ..................................... 29

Figure 2.3 Representative specimens showing the categories of VO 'development': Absent,

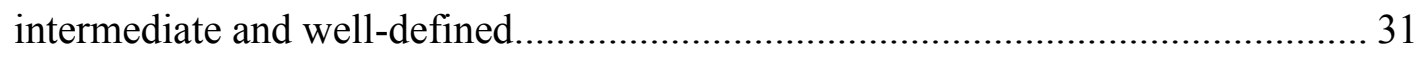

Figure 2.4 Non-linear regression between the size of the femur, as an indicator of body size,

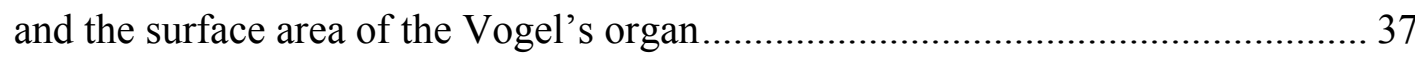

Figure 2.5 Representative specimens illustrating the observed variation in the tholus: Absent,

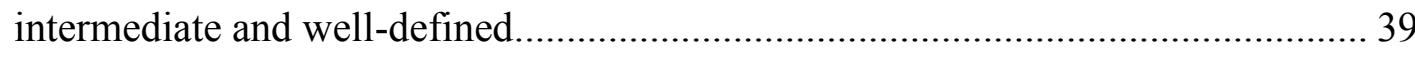

Figure 2.6 Representative species illustrating the different forewing vein inflation conditions used in this work: No inflation, inflation of the subcostal forewing vein only, and inflation of the subcostal, cubital and anal veins

Figure 2.7 A plot demonstrating forewing to hindwing ratio of the subcostal veins against hindleg femur length as an indicator of body size ........................................ 46

Figure 2.8 A regression between body size and anal vein inflation................................. 48

Figure 2.9 A scatter plot showing the instances of inflated and non-inflated forewing anal veins 49 
Figure 2.10 Ventral surface of the forewing of Myscelia cyaniris with the light and temperature sensitive regions, the $\mathrm{VO}$ and the membranous ampulla indicated ...................... 51

Figure 2.11 Phylogeny of the family Nymphalidae with VO development levels indicated...... 56

Figure 2.12 Phylogeny of the family Nymphalidae with tholus development levels indicated.. 57

Figure 2.13 Absolute VO sizes of males and females in Cercyonis pegala, Coenonympha tullia and Enodia anthedon 59

Figure 2.14 Subcostal vein size of males and females in Cercyonis pegala, Coenonympha tullia and Enodia anthedon. 60

Figure 3.1 Schematic diagram of the portable electrophysiology rig. ................................. 92

Figure 3.2 Sound levels of cockatiel flight at various distances ...................................... 94

Figure 3.3 A frame-grab from the video of the cockatiel in flight, the audio waveform of one flyby and the power spectrum of cockatiel flight sounds. 96

Figure 3.4 The hearing thresholds of Morpho peleides and Trichoplusia ni. The power spectrum of bird flight sounds is shown for comparison 98

Figure 3.5 The electrical signal from the auditory nerve of Trichoplusia $n i$ in response to the flight sounds of the cockatiel 100

Figure 3.6 The audio waveform, spectrogram and power spectrum a cockatiel chirp and the respondant electrical signal from the auditory nerve of Trichoplusia $n i$. 103

Figure 3.7 The audio waveform, spectrogram and a 'snapshot' of a single cockatiel chirp ... 104

Figure 3.8 The portable electrophysiology rig.... 106

Figure 3.9 Neural response of the Trichoplusia ni auditory nerve recorded on the portable rig constructed in this study. 107

Figure 5.1 External morphology of the VO in Mycelia cyaniris..................................... 126 
Figure 5.2 External morphology of theVO in Siproeta epaphus

Figure 5.3 External morphology of the VO in Caligo memnon

Figure 5.4 External morphology of the VO in Caligo eurilochus.

Figure 5.5 External morphology of the VO in Morpho microthalmus 135

Figure 5.6 External morphology of the VO in Morpho polyphemus 137

Figure 5.7 External morphology of the VO in Megisto cymela 139

Figure 5.8 External morphology of the VO in Coenonympha nipisquit

Figure 5.9 External morphology of the VO in Enodia anthedon..... 143

Figure 5.10 External morphology of the VO in Satyrodes appalachia. 145

Figure 5.11 External morphology of the VO in Oeneis bore

Figure 5.12 External morphology of the VO in Oeneis chryxus. 149

Figure 5.13 External morphology of the VO in Oeneis jutta 151

Figure 5.14 External morphology of the VO in Oeneis polixenes..... 153

Figure 5.15 External morphology of the VO in Erebia mackinleyensis 155

Figure 5.16 External morphology of the VO in Erebia manicus . 157

Figure 5.17 External morphology of the VO in Erebia rossii. 159

Figure 5.18 External morphology of the VO in Erebia youngi. 161

Figure 5.19 External morphology of the VO in Cercyonis pegala 163 


\section{List of Abbreviations}

$\begin{array}{ll}\text { A } & \text { Absent } \\ \mathrm{An} & \text { Anal } \\ \mathrm{Cu} & \text { Cubital } \\ \text { LPS } & \text { Intermediate } \\ \text { MA } & \text { Membranous ampulla } \\ \text { NWT } & \text { Northwest Territories } \\ \text { Sc } & \text { Subcostal } \\ \text { VO } & \text { Vogel's organ } \\ \text { WD } & \text { Well-defined }\end{array}$




\section{General Introduction}

\subsection{Introduction}

Acoustic communication is widespread in the class Insecta. Acoustic signals can be used for social interactions, for detecting environmental cues, in predator-prey dynamics, and during mate selection (Yack and Dawson 2008). There exists a wide diversity of acoustic receptors although in a broad sense they all function by detecting vibration. Insect acoustic receptors include four main types: trichoid sensilla and Johnston's organs, which detect near-field sounds, subgenual organs, which detect solid-borne vibrations and tympanal hearing organs, which detect far-field sounds. The types of acoustic receptors have been reviewed extensively (Romer and Tautz 1992; Hoy and Robert 1996; Yager 1999; Yack 2004; Yack and Dawson 2008). The focus of this thesis will be on the form and function of tympanal ears in butterflies.

Tympanal hearing organs have evolved independently at least 17 times in the class Insecta and can be found in at least 7 of the 26 neopteran orders (Yack 2004; Yack and Dawson 2008). The organs range in complexity and can be found on many different parts of the body. Despite their diversity, they all share three morphological components: (1) A tympanal membrane that vibrates in response to sound; (2) a tracheal air sac, which serves as a reverberation chamber and over which the tympanal membrane is stretched; and (3) an associated chordotonal organ that detects the vibrational movement of the membrane and produces bioelectric signals (Yack and Fullard 1993a; Yager 1999; Yack 2004). Within the order Lepidoptera, tympanal ears have been identified in eight superfamilies (Fig. 1) (Minet and Surlykke 2003) and range from simple tympanal organs, with only one acoustic sensory cell (e.g. 
certain noctuoid moths), to more complex structures, with multiple sensory cells (Minet and Surlykke 2003).

The order Lepidoptera comprises 3 superfamilies of butterflies and 43 superfamilies of moths. Most studies on lepidopteran hearing have focused on moths (Spangler 1988; Cook and Scoble 1992; Minet and Surlykke 2003). In moths, tympanal hearing organs are found in a diversity of anatomical positions, including the mouthparts, abdomen, and thorax (Minet and Surlykke 2003; Yack 2004; Faure et al. 2009), and function primarily in the detection of bat echolocation calls (Fenton and Fullard 1979). However, in some species, such as the diurnal tiger moth, they also function secondarily in conspecific communication (Spangler 1988). Butterflies, comprising the remaining 3 superfamilies of Lepidoptera, i.e. Papilionoidea, Hedyloidea and Hesperioidea (Kristensen and Skalski 1999; Kristensen 2003; Wahlberg et al. 2005; Kristensen et al. 2007), have also been shown to possess tympanal hearing organs in certain species. Significantly less is known about hearing in butterflies than in moths. In the remainder of the general introduction I will discuss past research into butterfly hearing followed by a statement of my thesis objectives. 


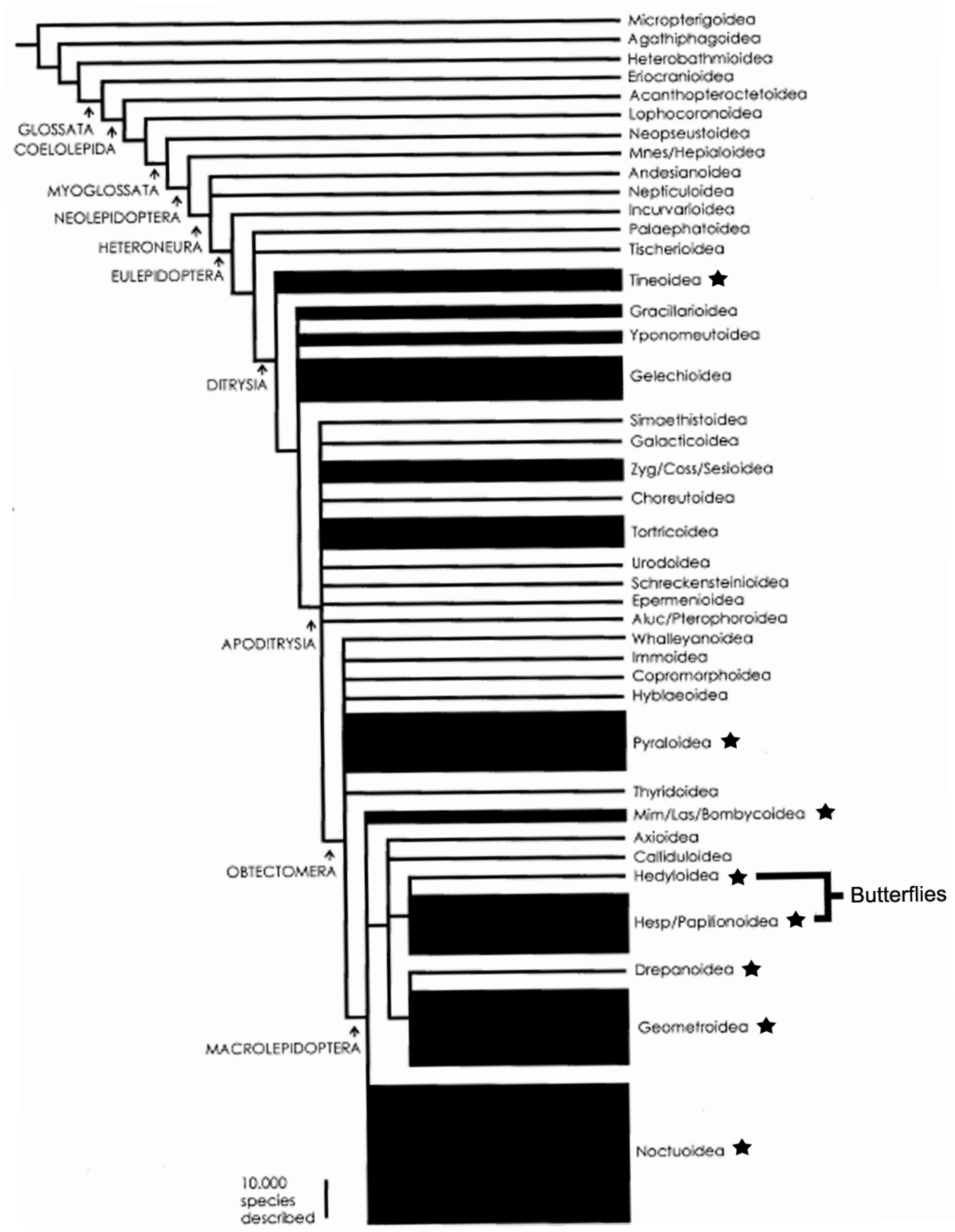

Figure 1.1 A phylogeny of the Lepidoptera. Superfamilies in which tympanal ears have been identified are indicated by stars $(\star)$. Phylogeny adapted from Kristensen (2003). Width of clade bars reflect estimated number of described species. Scale bar: 10000 species. 


\subsection{Butterfly Hearing}

The three butterfly superfamilies, Papilionoidea, Hedyloidea and Hesperioidea, evolved from their nocturnal relatives, the moths (Kristensen 2003; Wahlberg et al. 2005; Kristensen et al. 2007). Hedyloidea are nocturnal and thought by some, e.g., Scoble and Aiello (1990), to be ancestral to the two other superfamilies, Papilionoidea and Hesperioidea, which are primarily diurnal, although this is currently disputed. A recent phylogeny based on morphological and molecular characteristics suggests that Hesperioidea and Hedyloidea are not, in fact, superfamilies, but rather they are sister families that should be part of the Papilionoidea superfamily (Heikkilä et al. 2012). However, the presence of three superfamilies is prevalent in the current literature. As such, I have adopted the phylogenetic scheme of Kristensen (2003) throughout this work. However, it is important that any further progress in this field be monitored in the future. Tympanal ears occur in the Hedyloidea and some Papilionoidea. Hedyloidea hearing is ascribed to bat detection (Yack and Fullard 2000; Yack et al. 2007); however the function of hearing in Papilionoidea is unclear. Unlike the Hedyloidea, most species of Papilionoidea are diurnal. Ears in diurnal butterflies are likely to serve one of two general functions: They may function to detect diurnal predators or they may be used for conspecific communication. I will now summarize what is known about hearing in the two superfamilies of butterfly: Hedyloidea and Papilionoidea.

\section{Hedyloidea}

Hedyloidea possess tympanal hearing organs that function in defence against predation by insectivorous bats. The paired tympanal ears in hedylids are 
located at the base of their forewings on the ventral wing surface and are formed by

modifications to the cubital and subcostal veins which form the tympanal cavity in which a thin membrane resides (Yack and Fullard 2000; Yack et al. 2007). Each ear consists of a thin chitinous membrane stretched over an air sac, to which three chordotonal organs are attached. Through extracellular neurophysiological recordings conducted on the auditory nerve branch IIN1c of Macrosoma heliconiaria, it was determined that this hedylid was sensitive to ultrasonic frequencies, $40-80 \mathrm{kHz}$ with a best threshold at $60 \mathrm{~dB}$ (Yack et al. 2007). Upon exposure to sounds at these frequencies during flight, the butterflies are observed to initiate evasive manoeuvres, which supports the hypothesis that Hedyloidea use hearing for bat detection (Yack and Fullard 2000; Yack et al. 2007).

\section{Papilionoidea}

Interestingly, several species of Papilionoidea butterflies in the Nymphalidae family possess hearing organs (Vogel 1912; LeCerf 1926; Yack et al. 2000; Minet and Surlykke 2003). The Nymphalidae comprise around 6,000 species of the Papilionoidea superfamily (Ackery et al. 1999). Certain species within this family have a tympanal hearing organ at the base of the forewing on the ventral surface located at the base of the cubital vein (Vogel 1912; LeCerf 1926; Minet and Surlykke 2003). Such organs were first described morphologically in 1912 and have since come to be commonly called Vogel's organ (VO) after their discoverer (Vogel 1912; Minet and Surlykke 2003). In general, a thin tympanal membrane is attached to a chitinous ring, which is formed by the branching of the cubital vein as it approaches the base of the forewing (Minet and Surlykke 2003). An example is shown in Figure 1.2. Although little is known of the morphology of the VO within or between Nymphalidae taxa, studies of the external 
morphology in a range of different species shows that there exists variation in the external morphology, from those with no ears, to those with very well developed ears (Otero 1990; Minet and Surlykke 2003). This variation will be studied and discussed in more detail in the next chapter of this thesis. Since the discovery of the VO, there have been few studies that have attempted to categorize butterflies based on this feature (LeCerf 1926; Otero 1990). Despite morphological evidence for ears in these butterflies, there is little information about their physiology or their function. Behavioural and/or physiological responses to sound have now been studied for a few species within the genera Hamadryas, Manataria, Erebia, Morpho, Caligo and Pararge. I will briefly review this literature. 


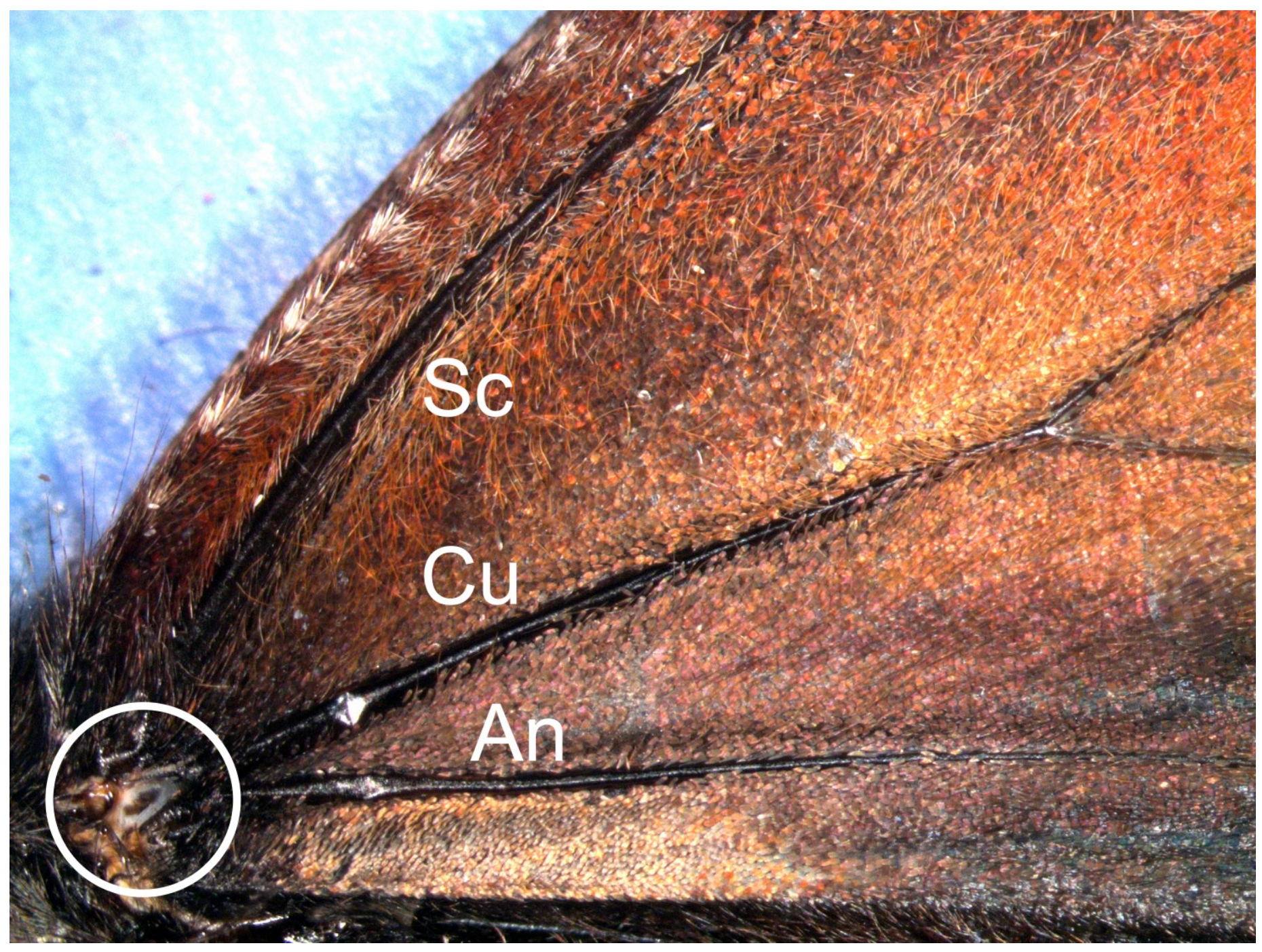

Figure 1.2 Ventral view of the forewing of Erebia dislocalis with the hindwing removed. Vogel's organ is circled and is located at the base of the forewing, where the wing attaches to the body. The subcostal $(\mathrm{Sc})$, cubital $(\mathrm{Cu})$ and anal $(\mathrm{An})$ veins are labeled. 
Hamadryas sp. (Nymphalidae: Biblidinae: Ageroniini) ears: conspecific communication?

Hamadryas feronia, commonly called the blue cracker butterfly, is a neotropical nymphalid that ranges from the southern United States to Brazil and possesses a Vogel's organ (Yack et al. 2000). Through neurophysiology conducted on the mesothoracic IINIc NII nerve branch, $H$. feronia was found to respond to broadband signals with an optimal frequency of $1.75 \mathrm{kHz}$ at $68 \mathrm{~dB}$ SPL. For frequencies above $6 \mathrm{kHz}$ the threshold increased to $90 \mathrm{~dB}$ SPL (Yack et al. 2000). It is also observed that males of this species engage in territoriality and produce audible clicks to conspecifics that can lead to chasing behaviour (Monge-Najera et al. 1998; Yack et al. 2000). This morphological, physiological, and behavioural evidence supports the hypothesis that these butterflies could use their ears to listen for the sounds produced by conspecifics (Yack et al. 2000). There is however a mismatch between the best hearing of these butterflies and the clicks they produce. Yack et al. (2000) showed that the peak frequencies of the clicks being emitted by the males of this species were between 13 and $15 \mathrm{kHz}$. This large discrepancy in the frequencies best heard and those produced suggests that there is possibly a secondary use for hearing, such as predator avoidance.

Manataria (Nymphalidae: Satyrinae: Melanitini) ears: Bat echolocation detectors?

Manataria maculata is a neotropical nymphalid that exhibits crepuscular flight behaviours similar to those of moths (Rydell et al. 2003). Using ultrasonic pulses (26 kHz, 110 dB SPL at 1m) generated from an electric dog whistle, Rydell et al. (2003) showed that during their crepuscular flight times $90 \%$ of M. maculata tested would display evasive flight manoeuvres in response to a stimulus up to $10 \mathrm{~m}$ away. The behavioural hearing threshold of this species was calculated to be $70 \mathrm{~dB}$ SPL. The authors suggest that predation by bats could have 
driven the development of ultrasound sensitive ears in M. maculata (Rydell et al. 2003).

Manataria maculata does possess a VO but the physiology has not been studied, and although assumed that the $\mathrm{VO}$ is causing the behavioural response to sound, this was not tested directly.

Other Nymphalidae butterflies: Avian flight or call detectors?

There have been studies performed on different species of Nymphalidae in the past to determine if the $\mathrm{VO}$ was functional in these species. These nymphalids are all diurnal, and there has been no evidence to date of sound production or conspecific communication. Due to these factors the function of these VOs is as of yet unexplained.

The neotropical Morpho peleides (Satyrinae) is a mute diurnal butterfly that possesses a well- developed Vogel's organ (Lane et al., 2008). Extracellular recordings of the N.II and N.III nerve branches of IIN1c show that M. peleides responds to low frequency sounds ranging from $500 \mathrm{~Hz}$ to $20 \mathrm{kHz}$ with best frequencies ranging from $1 \mathrm{kHz}-6 \mathrm{kHz}$ (Lane et al., 2008; Lucas et al., 2009).

Caligo eurilochus is a neotropical butterfly that has a similar geographical range as $M$. peleides (DeVries 1987). This butterfly is in the subfamily Satyrinae, which is largely composed of diurnal butterflies. However, this particular species has become crepuscular and possesses adapted sensory organs to accommodate this change, such as its specialized eyes that allow it to thrive in low-light conditions (Frederiksen and Warrant 2008). It was noted that moving temporally into crepuscular flight alleviates predation pressures. Hence, it was hypothesized that if the Caligo uses its VO to detect predators, such as birds, its VO should have deteriorated after it shifted its flight behaviour. Lucas (2008) first did a morphological assessment and found that the ear of C. eurilochus was not as well-developed as that of M. peleides. Perhaps the most 
interesting results were from the physiological tests. Lucas (2008) found that although $C$. eurilochus responded to the same range of sounds $(\sim 1-23 \mathrm{kHz})$ the thresholds of these frequencies were approximately $10 \mathrm{~dB}$ higher than those in $M$. peleides. The best frequency of hearing in C. eurilochus was found to be $3 \mathrm{kHz}$ at $74 \mathrm{~dB}$ SPL, whereas the threshold at the same frequency in M. peleides was $65 \mathrm{~dB}$ SPL. This is an interesting case of a possible degenerating VO in a butterfly species moving from diurnal to crepuscular in nature.

Ribaric and Gogala (1996) conducted behavioural research on two species of diurnal butterfly, Erebia manto and Erebia euryale (Satyrinae), and concluded that these species possess functional hearing organs. The researchers observed wing twitches and entry into escape flight when the butterflies were exposed to low frequency sounds. The lowest behavioural threshold, the threshold at which a startle response was achieved, was determined to be $1.0 \mathrm{kHz}$ at $49 \mathrm{~dB}$ SPL. When the Vogel's organs are covered in wax and the specimens are subject to identical testing, they no longer demonstrate these behaviours, which the authors conclude are in response to sounds detected by the Vogel's organs. The authors of this study suggest that these ears function in predation avoidance as bird call detectors. There is no reported empirical evidence, such as neurophysiological testing, that supports these findings.

Pararge aegeria is a small wood nymph that was found to possess a VO. Mahony (2006) provided morphological, physiological, and behavioural evidence that it was a functional tympanal hearing organ. $P$. aegeria responds to frequencies over the range $3-18 \mathrm{kHz}$ and its best hearing threshold is $56 \mathrm{~dB}$ SPL at the frequency $6.5 \mathrm{kHz}$ (Mahony 2006).

There is a limited amount of evidence that $P$. aegeria responds behaviourally to acoustic stimuli. Using tethered specimens wing twitches and cessation of movement was observed, similar to previous behavioural accounts (Ribaric and Gogala 1996; Mahony 2006). The 
behavioural threshold was found to be $88 \mathrm{~dB}$ SPL for a frequency of $3 \mathrm{kHz}$. The author suggests that more behavioural trials should be conducted.

\subsection{Avian Hypothesis}

At present, the function of hearing in most nymphalid butterflies -which includes those that are diurnal and mute- is unknown. One hypothesis is that butterflies use their ears to detect bird flight sounds and/or calls (Ribaric and Gogala 1996; Mahony 2006; Lane et al. 2008). From this hypothesis, certain predictions arise which can be tested. Some of these predictions are discussed below.

\subsubsection{Birds prey on butterflies}

The fact that a wide variety of insectivorous birds prey upon butterflies and, thus, impose a large selective pressure has been well documented (Marshall 1909; Chai and Srygley 1990; Chai 1996; Pinheiro 1996; Langham 2004, 2006). The selection pressure by birds is thought to influence butterfly colouration, wing morphology, and behaviours concerning flight and reproduction (Chai and Srygley 1990). Because there are several birds that hunt butterflies, and because they utilize various predation strategies, butterflies are not safe from predation during flight or rest. A few known examples of neotropical birds that prey upon butterflies are Jacamars (Genus: Galbula), Kingbirds (Genus: Tyrannus) and Neotropical jays (Genus: Cyanolyca) (Chai 1996; Pinheiro 1996; Langham 2006). There are many known species of insectivorous birds native to Canada, including Eastern Kingbirds (Genus: Tyrannus), the Eastern Phoebe (Genus: Sayornis), and the common tree swallow (Genus: Tachycineta) (Bird 
2010). It is known that some insectivorous birds in other regions eat certain species of butterflies (Pough and Brower 1977; Pinheiro 1996) and so it is reasonable to assume that diurnal butterflies in Canada face predation by birds. This assumption is supported by my personal experiences, in which I have observed certain butterflies, including the common ringlet, (Coenonympha tullia inornata) preyed upon by birds.

\subsubsection{Birds produce flight sound during hunting}

The ears of several butterflies are tuned to low-frequency broadband sounds, usually between 2-5 kHz (Mahony 2006; Lane et al. 2008; Lucas 2008). It has been shown that birds produce flight sounds that are also low-frequency and broadband (Mahony 2006; Lane et al. 2008). Further studies on the Eastern Phoebe (Sayornis phoebe) and the Black-Capped chickadee (Poecile atricapillus) confirm that birds produce flight sounds in their natural environments when hunting a prey item (Fournier 2011; Fournier et al. 2013). The Eastern Phoebe's flight

sounds were found to be broadband ( $>50 \mathrm{kHz}$ at $-20 \mathrm{~dB}$ ) with most of the power in the range $1-$ $5 \mathrm{kHz}$, which is well within the hearing range of the butterfly ear.

\subsubsection{Butterflies preyed upon by birds have ears that can detect bird sounds}

Vogel's organ is widely distributed in the family Nymphalidae; furthermore, the morphological development of ears can vary substantially within subfamilies (King, 2007). Although the ears of some species have been described morphologically, most remain undocumented. Even fewer have been tested physiologically and behaviourally to determine whether they are functional. Assuming that a given butterfly possesses the morphological features of a tympanal ear, physiological evidence, such as neural responses to playbacks of 
recorded bird flight sounds, is required to demonstrate that an ear is functional, i.e., that the ear exhibits a neural response to an auditory stimulus.

\subsubsection{Butterfly ears will respond to bird flight sounds in a natural setting}

Although playing back recorded sounds through speakers is useful for understanding how an insect responds to environmental sounds, the removal of the animal from its natural habitat introduces variables that may affect how the specimen perceives signals. It is generally agreed that insects experience sounds in their natural environments quite differently than the same sounds presented in that of a laboratory setting due to natural attenuations and obstacles (Forrest, 1994; Romer, 1993). As such, it is important to complement laboratory studies by conducting physiological and behavioural experiments outdoors, or indoors, using more natural sound sources such as live conspecifics or predators (Gilbert and Elsner, 2000; Kostarakos and Romer, 2010; Rheinlaender and Romer, 1986; Romer and Bailey, 1986).

\subsection{Thesis Objectives}

The original objective of my thesis was to develop an outdoor physiology rig so that I could test the hearing of local Satyrinae (wood nymph) butterflies in an outdoor setting, to assess what they could hear and whether they responded to bird flight. I chose to work with local Satyrinae rather than tropical Nymphalidae species, since environmental laws would not allow me to take the tropical species outdoors. This led me to begin a morphological survey of the external anatomy of local Satyrinae species, and this survey expanded to looking at a collection of Canadian Satyrinae that was offered to me. Since none of these species had been examined, 
and this rare collection was available to me, I took advantage of this opportunity and began an in-depth study of their hearing organs. In the meantime, for various reasons, my original project took a turn, and it was not possible to complete my original goals with respect to testing live butterflies outdoors. My goals therefore were changed to focusing on comparative morphology of butterfly ears, and developing techniques that will ultimately aid in testing hypotheses on the function of hearing in butterflies.

The two general objectives for my thesis are:

1) To perform a comparative study of the external morphology of hearing organs in butterflies. Most Nymphalidae butterfly species have not previously been examined, yet preliminary studies from the Yack research group (King 2007) and the existing literature suggest that there is a wide diversity of external morphology. I have chosen to focus on local Satyrinae and species that were both readily available and that represent previously unreported taxa. This is the subject of chapter 2 .

2) To develop and to test the experimental techniques for an investigation of butterfly response to bird flight sounds. This involved measuring the physiological response of moths to a live bird indoors to determine whether insects can detect a flying bird and whether we can record their response. This subsequently involved building an outdoor physiology rig and testing its functionality with moths. This is the subject of chapter 3. 


\section{External Morphological Diversity of the Hearing and Accessory Organs in Nymphalidae}

Parts of the work contained in this chapter are being adapted into manuscripts for submission to peer-reviewed journals:

1. Hall, L.E., R. Layberry, and J.E. Yack, Diversity of Vogel's organ and accessory structures found within the Canadian Satyrinae Population (In preparation for submission to Canadian Entomologist)

2. Preston, K., L.E. Hall, A. Kawahara, J. King and J.E. Yack, Morphological diversity and evolutionary origins of tympanal hearing organs in brush-footed butterflies (Lepidoptera: Nymphalidae). (In preparation for Journal of Arthropod Structure and Development) 


\subsection{Introduction}

Presently, not a lot is known about the taxonomical diversity, the evolution or the function of butterfly ears. However, there have been numerous published investigations of hearing organs in butterflies. Therefore, the overarching objective of this research is to build upon the current body of published literature in order to gain a better understanding of the morphological diversity between and within taxonomical groups. Ultimately, this will provide information to address questions regarding the evolution of hearing organs, the function of hearing in butterflies and the functions of specific hearing structures.

To begin, I will present a brief review of previous research of butterfly hearing. In 1912, Vogel first described his eponymous tympanal organ (Vogel 1912). He described a scleritized membrane situated at the base of the cubital vein, which was split into two branches. This description has been affirmed in other reports (LeCerf 1926; Minet and Surlykke 2003; Lane et al. 2008). Although Vogel initially hypothesized that it was a tympanal organ, this view was not shared by his contemporaries. Publishing papers after Vogel had announced his findings, Kennel and Eggers (1933) as well as Debaisieux (1935) both stated that no tympanal organs had been found in butterflies. LeCerf (1926) agreed with Vogel in as much as he located the same organ at the base of the forewing. The two differed however in what they thought the function of the organ could be. LeCerf (1926) did not think the organ was suited to detecting sound, although years later Ribaric and Gogala (1996) provided some support for sound reception. To be classified as a tympanal hearing organ, a structure must possess certain characteristics (Yack and Fullard 1993b). First, a tympanal membrane, which is usually comprised of a thinned layer of exo-skeleton stretched over a chitinous ring, must be present. The second characteristic of 
tympanal hearing organs is the tracheal air chamber. Generally, this chamber is a cavity over which the membrane is stretched. Finally, there must be chordotonal organs present to detect the vibrations of the tympanal membrane. These organs can either be directly or indirectly associated with the membrane (Yager 1999, Yack 2004). Vogel's organ, as described by Vogel (1912), LeCerf (1926), and Otero (1990) is now known to fit these criteria and, as I will discuss later has been shown to function in sound detection, thus, can be described as a tympanal hearing organ (Yack and Fullard 1993b).

LeCerf conducted a survey of the VO in selected species, although he disbelieved that it could be a tympanal hearing organ because he believed that the membrane would not transmit vibrations (LeCerf 1926). LeCerf (1926) categorized the VOs based on the morphological appearance of the cubital veins and the chitinous rings. Species that he described as lacking this organ had no forewing vein swellings, no bifurcation of the Cubital vein and no outer-membrane. In those that possessed a VO he described a bifurcation of the Cubital vein in which there was an irregularly circular chitinous ring. The membrane itself also is irregularly circular with an asymmetric chitinous plate located on the anterior edge. The most highly specialized, as he called them, were bounded on three sides by the Cubital and Anal veins, had a chitinous ring with a distinctly ovular shape, a symmetric outermembrane, and the chitinous plate previously mentioned manifested as a membranous dome. He also noted that in tympanate species, the veins can be either inflated or non-inflated without impacting the development of the VO. There were no described cases of atympanate species possessing inflated veins. More recently, Minet and Surlykke (2003) observed that this membrane possesses a unique character because, in some cases, it is heterogeneous with an inner membrane that appears distinctly coloured and elevated from the outer membrane. The authors termed this structure as the 'tholus,' which is Latin for 
'dome' (Minet and Surlykke 2003). When examined under a scanning electron microscope (SEM), it was discovered that both the outer membrane and the tholus are covered with tiny unsocketed filaments known as microtrichs (Lane et al. 2008). Otero (1990) also used the VO to categorize nymphalids. His categories are as follows: Absent, in which no membrane is present at the base of the cubital vein on the forewing; precursorial, in which there is a membrane at the base of the cubital vein that lacks clear definition, but is associated with a chordotonal organ; and present, in which the outer membrane, tholus and supporting ring are present (Otero 1990).

From the literature discussed above, there appears to be some interesting diversity of the VO and its associated structures within the family Nymphalidae. However, there is still a lot of missing information regarding which species do or do not possess these characteristics. It is demonstrated that comparative morphology can provide invaluable information on the function and evolution of structures in the biological sciences, whether the specimens are plants (Zavadad 1983), animals (Reid 1989) or even fossils (Gingerich 1984). Therefore, this chapter will focus on using the comparative morphology of butterfly ears to provide information about the function and evolution of these hearing organs.

Tympanal hearing organs have been previously used to classify certain types of moths in the past. For example, the location of tympanal hearing organs on the metathorax is a decisive tool for classifying noctuoid moths (Otero 1990). Moths belonging to Pyraloidea and Geometroidea have been classified by the position of their abdominal tympana (Nielson and Common 1991). For butterflies, LeCerf (1926) reported the total absence of any VO structures or membranes in Danaidae, Lycaenidae, Libytheidae, and Papilionidae. The only family in which he found the VO was Nymphalidae, within which he reported considerable variation. He described the most highly developed VO in Morpho menelaus whereas he reported that certain 
other nymphalids, e.g. Melitaea cinxia, do not have VOs at all. Otero also suggested that the VO is a nymphalid trait (Otero 1990). Although the previous works provided novel information on VOs, they were not comprehensive surveys. The present work seeks to expand the available knowledge of the variations that exist between the VOs of butterflies.

2.1.1 What is the morphological variation of butterfly hearing organs and associated structures?

Previous investigations into the hearing organs of butterflies have been limited in scope to relatively few species in the family Nymphalidae, which contains over 6000 species. Therefore the objectives of this work are twofold: To search for VOs in representative species in as many subfamilies as possible within Nymphalidae, and to examine the morphological variations of VOs that manifest. This objective would add to the scientific knowledge base as a survey of subfamilies has not been done.

\subsubsection{How are the variations of butterfly hearing organs distributed in the family Nymphalidae?}

By examining how VOs are distributed over an established phylogeny, it may be possible to gain insight regarding the selection pressures, history, and evolution of hearing in butterflies. Ultimately this knowledge may help to identify the function of hearing in the family Nymphalidae. Therefore, this work considers how the existence and the morphological variations of butterfly hearing organs and associated structures are distributed across the taxonomical groups. 


\subsubsection{Is there sexual dimorphism in butterfly hearing organs or the associated structures?}

The presence or absence of sexual dimorphism in the morphology of butterfly hearing organs may provide clues regarding the function of hearing. For example, if the VOs in males are different than those of females then it could be inferred that butterflies participate in conspecific communication. Alternatively, such sexual dimorphism may indicate that males and females are under differing selection pressures. In contrast, if the hearing organs of males and females are identical then it may be concluded that the function of hearing is conserved between sexes. Since the presence or absence of sexual dimorphism in the morphology of butterfly hearing organs has not been investigated, to date, the present work includes results to consider these possibilities.

2.1.4 What is the morphological variation of hearing organs and associated structures within the tribe Satyrini?

One ultimate goal of this research project is to discover clues that may help to determine the function of hearing in butterflies. In order to achieve this goal, I wanted to examine the selection pressures, history and evolution of VOs and the associated structures between closely related species with very different life histories. Therefore, the final component of this chapter presents the morphological variations observed in Canadian species within the tribe Satyrini. This tribe was chosen for two reasons. First, these species are closely related, phylogenetically, and yet they have a wide geographical distribution that includes a variety of different habitats (coniferous forests, grassy meadows, permafrost plains, etc.). Second, there is the practical consideration that many of these species are readily available in Canada. 


\subsection{Materials and Methods}

\subsubsection{Animals}

Live butterflies were either reared from commercially purchased pupae or collected as adults in the wild. The live pupae were obtained from London Pupae Supplies Ltd. (Horspath Oxford, UK: Permit numbers: P-2011-01618, P-2011-04393). At Carleton University, the pupae were reared in mesh enclosures inside a greenhouse with $90 \%$ humidity, temperature fluctuation between $25-35^{\circ} \mathrm{C}$, and normal light conditions for the season (Fall: $11 \mathrm{~h}$ light $13 \mathrm{~h}$ dark, Spring: $12 \mathrm{~h}$ light, $12 \mathrm{~h}$ dark). Upon eclosure the butterflies were fed a diet of oranges and bananas until experimentation (1-3 days post eclosure). The live specimens that were captured as adults were collected from multiple locations within Southern Ontario [Preservation Park,

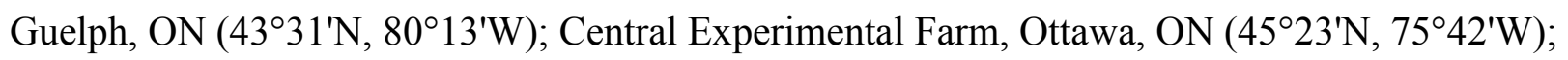
Rideau River Pathway by Hurdman Station, Ottawa, ON (452 $\left.25^{\prime} \mathrm{N}, 75^{\circ} 40^{\prime} \mathrm{W}\right)$; and Carleton University wildlife reserve, Ottawa, ON $\left.\left(45^{\circ} 11^{\prime} \mathrm{N}, 75^{\circ} 36^{\prime} \mathrm{W}\right)\right]$. The captured specimens were stored in individual glassine envelopes until experimentation. The live specimens were euthanized using $\mathrm{CO}_{2}$ immediately prior to measurement. This work also used dried specimens that were obtained from the private collection of Ross Layberry and the collection of the Government of the Northwest Territories (contact: Suzanne Carriere). The dried specimens were stored in individual glassine envelopes. The species studied in this work and how the specimens were obtained are summarized in Table 2.1. The species in this work were selected by three general criteria: i) several species were selected to represent taxa that have not been previously studied for their VOs; ii) to consider the effects of phylogenetic relationships and life history, 
this work examines several closely related Canadian species within the tribe Satyrini from a broad geographical range of habitats. 
Table 2.1 List of specimens in this work sorted by species name. The specimens were either reared from pupae obtained from London Pupae Supplies (LPS), obtained as dried specimens from the private collection of Ross Layberry (RL), captured as adults (by myself, LM), obtained as or obtained as dried specimens from the collection of the Government of the Northwest Territories (NWT). The location and geographical coordinates where wild-caught specimens were captured are listed.

\begin{tabular}{|c|c|c|c|c|c|c|}
\hline Genus & Species & N Male & N Female & Collected by & Location & Coordinates \\
\hline Ariadne & ariadne & 2 & 0 & London Pupae Supply (LPS) & - & - \\
\hline Archaeoprepona & demophon & 2 & 0 & LPS & - & - \\
\hline Biblis & hyperia & 2 & 0 & LPS & - & - \\
\hline Baeotus & japetus & 2 & 0 & LPS & - & - \\
\hline Cymothoe & beckeri & 1 & 0 & LPS & - & - \\
\hline Charaxes & brutus & 1 & 0 & LPS & - & - \\
\hline Cethosia & cyane & 0 & 1 & LPS & - & - \\
\hline Caligo & eurilochus & 2 & 0 & LPS & - & - \\
\hline Caligo & memnon & 0 & 2 & LPS & - & - \\
\hline Catacore & kolyma & 1 & 0 & LPS & - & - \\
\hline \multirow[t]{4}{*}{ Cercyonis } & pegala & 1 & 2 & Ross Layberry (RL) & King's Co., PEI & $46^{\circ} 3.554^{\prime},-62^{\circ} 33.631^{\prime}$ \\
\hline & & 2 & 1 & $\mathrm{RL}$ & Alliston, PEI & $46^{\circ} 3.585^{\prime},-62^{\circ} 36.339^{\prime}$ \\
\hline & & 2 & 1 & RL & Seal Cove, PEI & $46^{\circ} 2.948^{\prime},-62^{\circ} 31.554^{\prime}$ \\
\hline & & 0 & 2 & RL & Dwyer Hill, ON & $45^{\circ} 7.659^{\prime},-75^{\circ} 56.820^{\prime}$ \\
\hline Colias & philadice & 1 & 0 & Laura McMillan (LM) & Ottawa, ON & $45^{\circ} 21.604^{\prime},-75^{\circ} 36.996^{\prime}$ \\
\hline Cirrochroa & regina & 0 & 2 & LPS & - & - \\
\hline Coenonympha & nispisquit & 2 & 0 & RL & Bathurst, NB & $47^{\circ} 34.597^{\prime},-65^{\circ} 39.025^{\prime}$ \\
\hline \multirow[t]{2}{*}{ Coenonympha } & tullia & 4 & 3 & LM & Ottawa, ON & $45^{\circ} 25.248^{\prime},-75^{\circ} 39.884^{\prime}$ \\
\hline & & 2 & 7 & LM & Guelph, ON & $43^{\circ} 30.693^{\prime},-80^{\circ} 13.361^{\prime}$ \\
\hline \multirow[t]{3}{*}{ Enodia } & anthedon & 1 & 2 & RL & Prescott, ON & $45^{\circ} 32.316^{\prime},-75^{\circ} 1.557^{\prime}$ \\
\hline & & 2 & 2 & LM & Sharbot Lake, ON & $44^{\circ} 46.149^{\prime},-76^{\circ} 41.391^{\prime}$ \\
\hline & & 3 & 2 & LM & Ottawa, ON & $45^{\circ} 21.604^{\prime},-75^{\circ} 36.996^{\prime}$ \\
\hline Elymniopsis & bammakoo & 1 & 0 & $\mathrm{RL}$ & - & - \\
\hline \multirow[t]{7}{*}{ Erebia } & dislocalis & 0 & 2 & RL & Horton River, NWT & $68^{\circ} 46.101^{\prime},-121^{\circ} 46.857^{\prime}$ \\
\hline & fasciata & 1 & 0 & RL & Esker, NWT & $64^{\circ} 50.712^{\prime},-111^{\circ} 33.082^{\prime}$ \\
\hline & mackinleyensis & 1 & 0 & RL & Alliston, PEI & $46^{\circ} 3.585^{\prime},-62^{\circ} 36.339^{\prime}$ \\
\hline & manicus & 1 & 0 & RL & Jawbone, NWT & \\
\hline & & 0 & 1 & RL & Horton River, NWT & $68^{\circ} 46.101^{\prime},-121^{\circ} 46.857^{\prime}$ \\
\hline & rossii & 2 & 0 & RL & $\begin{array}{c}\text { Mackenzie } \\
\text { Mountains, NWT }\end{array}$ & $63^{\circ} 43.231^{\prime},-127^{\circ} 21.624^{\prime}$ \\
\hline & youngi & 0 & 2 & RL & $\begin{array}{c}\text { Mackenzie } \\
\text { Mountains, NWT }\end{array}$ & $63^{\circ} 43.231^{\prime},-127^{\circ} 21.624^{\prime}$ \\
\hline Euripus & nyctelius & 1 & 0 & LPS & - & - \\
\hline
\end{tabular}




\begin{tabular}{|c|c|c|c|c|c|c|}
\hline Genus & Species & N Male & N Female & Collected by & Location & Coordinates \\
\hline Euphaedra & xypete & 1 & 0 & LPS & - & - \\
\hline Glaucopsyche & couperi & 1 & 0 & LM & Ottawa, ON & $45^{\circ} 25.248^{\prime},-75^{\circ} 39.884^{\prime}$ \\
\hline \multirow[t]{2}{*}{ Hypolimnas } & alimena & 1 & 0 & LPS & - & - \\
\hline & bolina & 2 & 2 & LPS & - & - \\
\hline Limenitis & arthemis & 1 & 0 & LM & Ottawa, ON & $45^{\circ} 25.248^{\prime},-75^{\circ} 39.884^{\prime}$ \\
\hline Megisto & cymela & 19 & 5 & LM & Guelph, ON & $43^{\circ} 30.693^{\prime},-80^{\circ} 13.361^{\prime}$ \\
\hline \multirow[t]{3}{*}{ Morpho } & microthalmus & 1 & 1 & LPS & - & - \\
\hline & peleides & 2 & 0 & LPS & - & - \\
\hline & polyphemus & 0 & 2 & LPS & - & - \\
\hline Myscelia & cyaniris & 5 & 5 & LPS & - & - \\
\hline Napeocles & jucunda & 1 & 0 & LPS & - & - \\
\hline \multirow[t]{4}{*}{ Oeneis } & bore & 0 & 2 & RL & $\begin{array}{c}\text { Mackenzie } \\
\text { Mountains, NWT }\end{array}$ & $64^{\circ} 44.048^{\prime},-127^{\circ} 20.606^{\prime}$ \\
\hline & chryxus & 2 & 0 & RL & $\begin{array}{c}\text { Mackenzie } \\
\text { Mountains, NWT }\end{array}$ & $64^{\circ} 44.048^{\prime},-127^{\circ} 20.606^{\prime}$ \\
\hline & jutta & 0 & 2 & RL & $\begin{array}{c}\text { Mackenzie } \\
\text { Mountains, NWT }\end{array}$ & $64^{\circ} 44.048^{\prime},-127^{\circ} 20.606^{\prime}$ \\
\hline & polixenes & 1 & 1 & RL & $\begin{array}{c}\text { Mackenzie } \\
\text { Mountains, NWT }\end{array}$ & $64^{\circ} 44.048^{\prime},-127^{\circ} 20.606^{\prime}$ \\
\hline Opsiphanes & tamirindi & 0 & 2 & LPS & - & - \\
\hline Palla & $s p$. & 1 & 0 & LPS & - & - \\
\hline Phyciodes & batesii & 0 & 1 & LM & Ottawa, ON & $45^{\circ} 10.780^{\prime},-75^{\circ} 36.532^{\prime}$ \\
\hline Prothoe & franck & 1 & 0 & LPS & - & - \\
\hline Polygonia & interrogationis & 1 & 0 & LM & Ottawa, ON & $45^{\circ} 10.780^{\prime},-75^{\circ} 36.532^{\prime}$ \\
\hline Precis & lemonias & 1 & 0 & LPS & - & - \\
\hline Pseudacraea & lucretia & 1 & 0 & LM & Ottawa, ON & $45^{\circ} 10.780^{\prime},-75^{\circ} 36.532^{\prime}$ \\
\hline Satyrodes & appalachia & 0 & 1 & RL & Prescott, ON & $45^{\circ} 32.316^{\prime},-75^{\circ} 1.557^{\prime}$ \\
\hline \multirow[t]{2}{*}{ Siproeta } & epaphus & 1 & 0 & LPS & - & - \\
\hline & stelenes & 2 & 2 & LPS & - & - \\
\hline Vanessa & rubria & 1 & 0 & LM & Ottawa, ON & $45^{\circ} 10.780^{\prime},-75^{\circ} 36.532^{\prime}$ \\
\hline
\end{tabular}




\subsubsection{Measurements}

Digital photographs of the butterflies in their natural resting positions were taken using a Nikon d300 DSLR camera (Nikon corporation, Tokyo, Japan). After this initial documentation the hindwing of each specimen was removed in order to expose the base of the forewing where Vogel's organ is found. Using forceps the protective scales covering the VO cavity were carefully removed. Digital photographs were taken using an Olympus SZX12 microscope (Olympus, Tokyo, Japan) equipped with a Zeiss AxioCamMRc5 camera (1.4 megapixels, $1388 \mathrm{x}$ 1040) at various stages of unveiling the VO including, post-hindwing removal, pre and post scale removal and low magnification image of entire forewing and hindwing veins.

The length, width, and the geometric surface area (i.e., the projection of the surface area onto a two-dimensional plane) of each VO were measured using AxioVision AC Software version 4.6, as illustrated in Figure 2.1(a)-(c), and considered relative to each specimen's body size in order to survey the variation in VOs and accessory structures that was present. The widths of the forewing and hindwing veins were measured using the same software, as illustrated in Figure 2.1(d). In order to further investigate and quantify forewing vein inflation, ratios were calculated between the forewing veins and their associated hindwing veins. A forewing vein was classified as inflated if the ratio of forewing vein size to hindwing vein size was equal to or greater than 3:1. Three of the species I collected locally, Coenonympha tullia, Enodia anthedon, and Cercyonis pegala were chosen to investigate sexual dimorphisms. These three species were chosen because they have well-defined Vogel's organs, I had collected enough of both sexes, and because they were local, abundant and easy to find. Within each of these species, the measurements were compared between sexes using unpaired, two-tailed Student's t-tests that were conducted using OriginPro 8.5 software. 

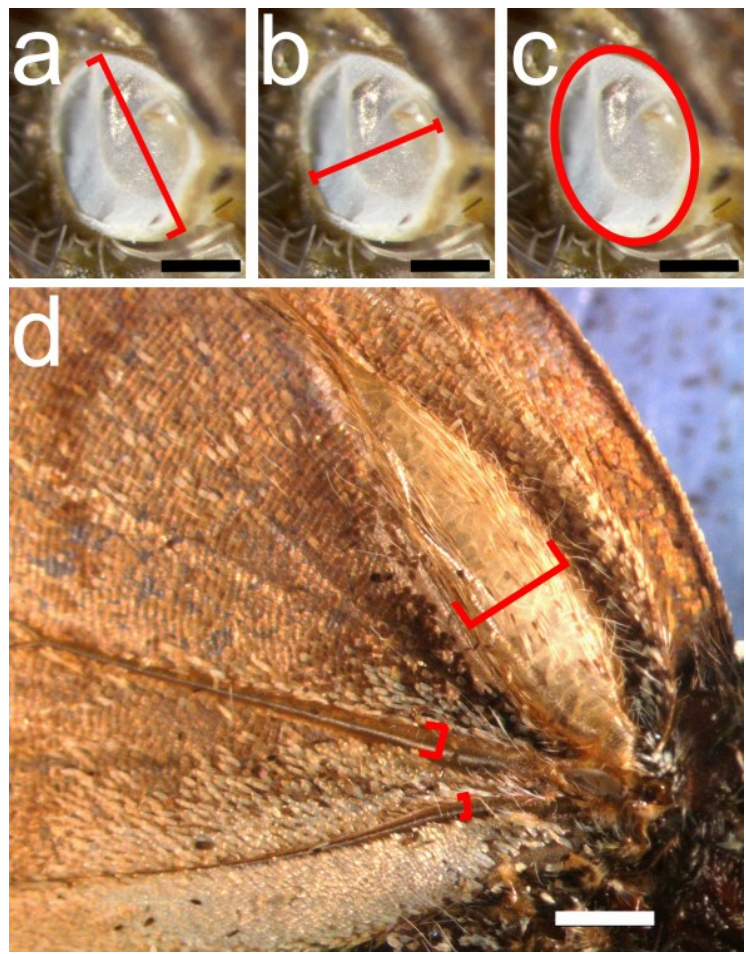

Figure 2.1 Representative images of Ariadne ariadne (a-c) and Megisto cymela (d) demonstrating how measurements were made. (a) Length measurement from proximal edge to distal edge of the VO, in this image from the bottom of the image to the top. (b) Width measurement from anterior edge to posterior edge of the VO, in this image from left edge to right edge. (c) Surface area measurement, all membrane within the indicated circle was measured. (d) Width measurements of the ventral forewing wing veins, the widest section located near the base of the forewing. Scale bars (a-c): $250 \mathrm{um}$. Scale bar (d): $1000 \mathrm{um}$. 


\subsubsection{Temperature and light sensitivity of the membranous ampulla}

Live specimens of Mycelia cyaniris were obtained from London Pupae Supplies Ltd. (Horspath Oxford, UK: Permit numbers: P-2011-01618, P-2011-04393). At Carleton University, the pupae were reared in mesh enclosures inside a greenhouse with $90 \%$ humidity, temperature fluctuation between $25-35^{\circ} \mathrm{C}$, and normal light conditions for the season (Fall: $11 \mathrm{~h} \mathrm{light,} 13 \mathrm{~h}$ dark; Spring: $12 \mathrm{~h}$ light, $12 \mathrm{~h}$ dark). Upon eclosion, the butterflies were fed a diet of oranges and bananas until experimentation (1-3 days post eclosion). A series of experiments were conducted to assess the effects of various stimuli on the membranous ampulla.

For the experiments, a live butterfly was mounted with its wings closed in "resting position" using strips of paper pinned to modeling clay to keep the butterfly immobilized. The hindwing of the butterfly was tucked behind the forewing to expose the membranous ampullae structure, herein denoted the 'MA.' A Sylvania 72288 LED magnetic flexible work light was used as a cold light source. A blunt metal dissecting probe was used for mechanical stimulation. Finally, a Mastercraft 25W soldering iron was used as a source of heat without light. See results section for more details.

Video recordings of the MA were taken using a Sony Handycam HDR-HC7. Videos were imported onto an iMac station and viewed using iMovie. 


\subsection{Results}

In organizing my results to illustrate the morphological variation, a series of photographs was taken for each specimen in this work, following the same procedure that is shown for $C$.

tullia as shown in Figure 2.2. First, a low magnification photograph of the butterfly, showing the ventral surface of the forewing was taken for identification and total body measurement (Figure 2.2A). Second, the forewing veins were examined to study variations in relative size between species (Figure 2.2B). Third, high magnification images of the VOs were taken with their

protective scales intact. These scales form a cavity over the tympanal membrane, and do not attach to the membrane (Figure 2.2C). Finally, the protective scales were removed and the VOs were photographed (Figure 2.2D). 


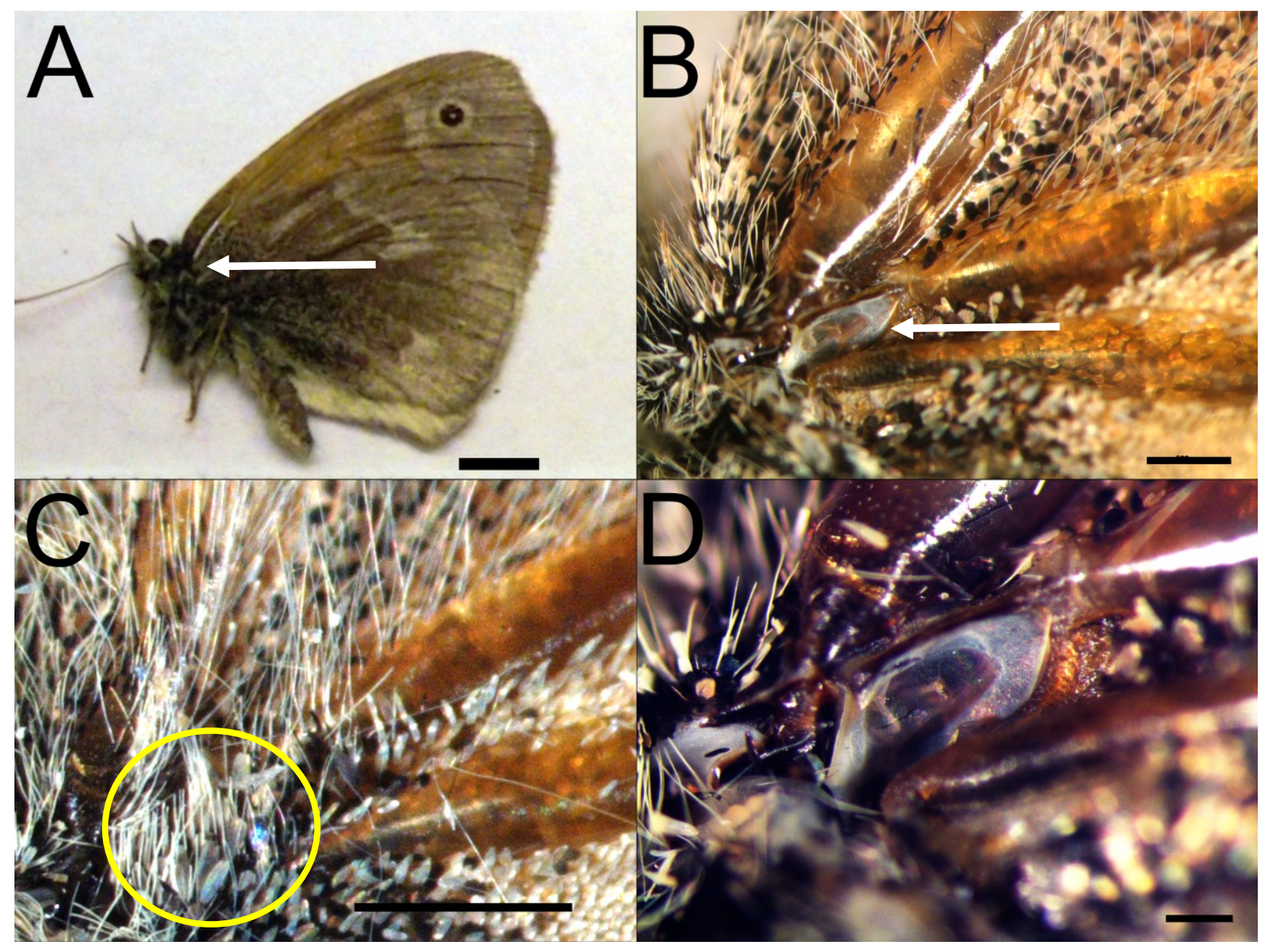

Figure 2.2 External morphology of the VO in Coenonympha tullia. (A) View of ventral wing surface of intact specimen. White arrow indicates location of VO. Scale bar: $5 \mathrm{~mm}$. (B) Ventral surface of the forewing illustrating the venation. White arrow indicates location of VO. Scale bar: $500 \mu \mathrm{m}$. (C) The base of the forewing on the ventral side of the specimen with hindwing removed, but protective scales intact and circled in yellow. Scale bar: $1000 \mu \mathrm{m}$. (D) The base of the forewing on the ventral side with hindwing and protective scales removed to expose the VO. Scale bar: $200 \mu \mathrm{m}$ 
From these measurements, it was observed that $C$. tullia has a rigid, well-defined cuticular ring that supports the transparent outer membrane of the tympanum. Its tholus is well defined and convex with clear margins and distinct colouration. All three forewing veins in $C$. tullia are inflated. Fusiform and flattened scales arising from the three inflated veins completely obscure the VO from view. The specific results all of the other species in this work are presented in Appendix 1. The tabulated and plotted results presented in this section allow one to consider the variations between species of the VO, the forewing veins and the hearing organ accessory structures.

2.3.1 What is the morphological variation of butterfly hearing organs and associated structures?

Vogel's Organ

To study the variations of the VOs between species, the specimens were categorized as follows: Absent, intermediate and well-defined. These are described below. An example of each category is shown in Figure 2.3. The observed variation of the VOs for the specimen studied in this work is summarized in Table 2.2. 


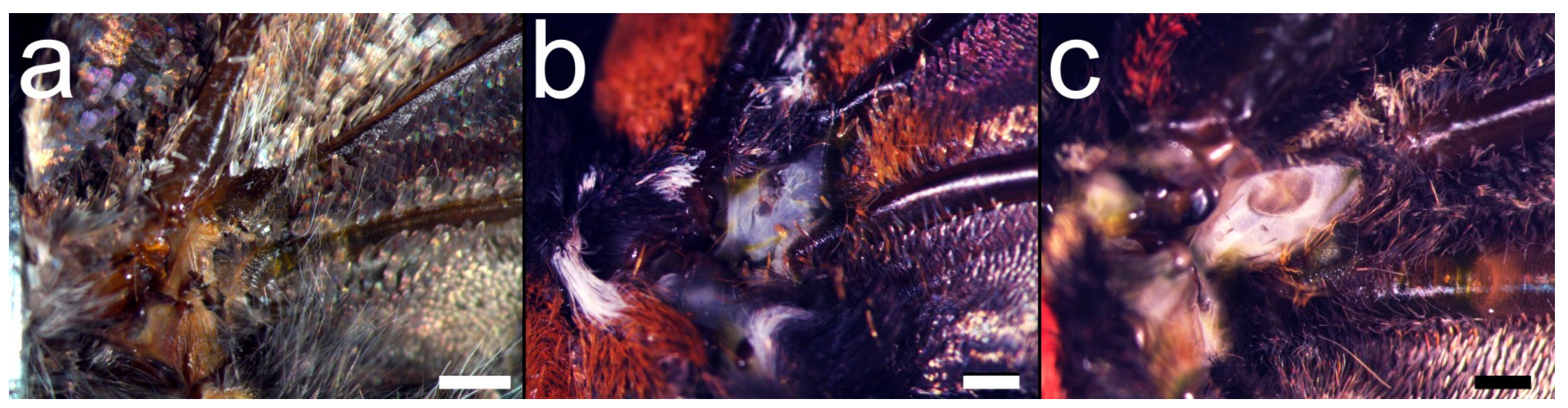

Figure 2.3 Representative specimens showing the categories of VO 'development'. Scales have been removed at the base of the forewing on the ventral side. (A) Absent: Vanessa rubria. Scale bar $=500 \mu \mathrm{m}$ (B) Intermediate: Siproeta epaphus. Scale bar $=500 \mu \mathrm{m}$. (C) Well-defined: Morpho microthalmus. Scale bar $=500 \mu \mathrm{m}$ 


\begin{tabular}{|c|c|c|c|c|c|c|}
\hline Family & Subfamily & Tribe & Species & Absent & Intermediate & Well-Defined \\
\hline \multirow[t]{6}{*}{ Papilionidae } & Papilioniinae & Papilionini & Papilio clytia & $\mathrm{X}$ & & \\
\hline & Papilioniinae & Papilionini & Papilio memnon & $\mathrm{X}$ & & \\
\hline & Papilioniinae & Papilionini & Papilio palinurus & $\mathrm{X}$ & & \\
\hline & Papilioniinae & Papilionini & Papilio rumanzovia & $\mathrm{X}$ & & \\
\hline & Papilioniinae & Troidini & Parides iphidamus & $\mathrm{X}$ & & \\
\hline & Papilioniinae & Leptocircini & Graphium agamemnon & $\mathrm{X}$ & & \\
\hline \multirow[t]{2}{*}{ Pieridae } & Pierinae & & Hebomoia glaucippe & $\mathrm{X}$ & & \\
\hline & Coliadinae & & Colias philodice & $\mathrm{X}$ & & \\
\hline \multirow{22}{*}{$\begin{array}{l}\text { Lycaenidae } \\
\text { Nymphalidae }\end{array}$} & Polyommatinae & Polyomatiini & Glaucopsyche lygdamus & $\mathrm{X}$ & & \\
\hline & Libytheinae & & Libythea celtis & $\mathrm{X}$ & & \\
\hline & Libytheinae & & Libytheana carinenta & $\mathrm{X}$ & & \\
\hline & Danainae & Danaini & Danaus plexippus & $\mathrm{X}$ & & \\
\hline & Danainae & Danaini & Danaus chrysippus & $\mathrm{X}$ & & \\
\hline & Danainae & Danaini & Idea leuconoe & $\mathrm{X}$ & & \\
\hline & Danainae & Danaini & Danaus limniace & $\mathrm{X}$ & & \\
\hline & Danainae & Danaini & Ideopsis juventa & $\mathrm{X}$ & & \\
\hline & Heliconiinae & Cethosia & Cethosia penthesilla & $\mathrm{X}$ & & \\
\hline & Heliconiinae & Cethosia & Cethosia cyane & $\mathrm{X}$ & & \\
\hline & Heliconiinae & Vagrantini & Cirrochoa regina & $\mathrm{X}$ & & \\
\hline & Heliconiinae & Heliconiini & Heliconius erato & $\mathrm{X}$ & & \\
\hline & Heliconiinae & Heliconiini & Heliconius melpomene & $\mathrm{X}$ & & \\
\hline & Heliconiinae & Argynnini & Argynnis aphrodite & $\mathrm{X}$ & & \\
\hline & Heliconiinae & Carchrodini & Acraea viola & $\mathrm{X}$ & & \\
\hline & Limentidinae & Limentidini & Pseudacraea lucretia & $\mathrm{X}$ & & \\
\hline & Limentidinae & Limentidini & Limenitis arthemis & $\mathrm{X}$ & & \\
\hline & Limentidinae & Limentidini & Athyma perius & $\mathrm{X}$ & & \\
\hline & Limentidinae & Neptini & Cymothoe beckeri & $\mathrm{X}$ & & \\
\hline & Limentidinae & Adoliadini & Euphadra sp. & $\mathrm{X}$ & & \\
\hline & Limentidinae & Parthenonini & Parthenos sylvia & $\mathrm{X}$ & & \\
\hline & Cyrestinae & & Marpesia chiron & $\mathrm{X}$ & & \\
\hline
\end{tabular}




\begin{tabular}{|c|c|c|c|c|c|c|}
\hline Family & Subfamily & Tribe & Species & Absent & Intermediate & Well-Defined \\
\hline \multirow[t]{27}{*}{ Nymphalidae } & Cyrestinae & & Cyrestis miralis & $\bar{X}$ & & \\
\hline & Biblidinae & Ageroniini & Panacea prola & & & $\mathrm{X}$ \\
\hline & Biblidinae & Ageroniini & Hamadryas amphinome & & & $\mathrm{X}$ \\
\hline & Biblidinae & Catagrammini & Catacore kolyma & & & $\mathrm{X}$ \\
\hline & Biblidinae & Biblidini & Biblis hyperia & & & $\mathrm{X}$ \\
\hline & Biblidinae & Epicaliini & Myscelia cyaniris & & & $\mathrm{X}$ \\
\hline & $\begin{array}{l}\text { Biblidinae } \\
\text { Anaturinae }\end{array}$ & Epicaliini & $\begin{array}{l}\text { Myscelia ethusa } \\
\text { Eurimus nusteliusus }\end{array}$ & & & $\mathrm{X}$ \\
\hline & Apaturinae & & Doxocopa pavon & & & $\mathrm{X}$ \\
\hline & Nymphalinae & Kallimi & Kallima paralekta & $\mathrm{X}$ & & \\
\hline & Nymphalinae & Kallimi & Doleschallia bisaltide & & & $\mathrm{X}$ \\
\hline & Nymphalinae & Victoriniini & Napeocles jucunda & & & $\mathrm{X}$ \\
\hline & Nymphalinae & Victoriniini & Siproeta stelenes & & $\mathrm{X}$ & \\
\hline & Nymphalinae & Victoriniini & Siproeta epaphus & & $\mathrm{X}$ & \\
\hline & Nymphalinae & Coenini & Baeotus japetus & $\mathrm{X}$ & & \\
\hline & Nymphalinae & Meitaeini & $\begin{array}{l}\text { Phyciodes batesii } \\
\text { phyciodina }\end{array}$ & $\mathrm{X}$ & & \\
\hline & Nymphalinae & Junoniini & Hypolimnas bolina & & & $\mathrm{X}$ \\
\hline & Nymphalinae & Junoniini & $\begin{array}{l}\text { Protogoniomorpha } \\
\text { anacardii }\end{array}$ & & & $\mathrm{X}$ \\
\hline & Nymphalinae & Junoniini & Junonia lemonias & $\mathrm{X}$ & & \\
\hline & Nymphalinae & Nymphalini & Colobura dirce & $\mathrm{X}$ & & \\
\hline & Nymphalinae & Nymphalini & Vanessa atalanta & $\mathrm{X}$ & & \\
\hline & Nymphalinae & Nymphalini & $\begin{array}{l}\text { Polygonia } \\
\text { interrogationis }\end{array}$ & $\mathrm{X}$ & & \\
\hline & Calinaginae & & Calinaga davidis & & $\mathrm{X}$ & \\
\hline & Calinaginae & & Calinaga gautama & & $\mathrm{X}$ & \\
\hline & Charaxinae & Charaxini & Charaxes brutus & & $\mathrm{X}$ & \\
\hline & Charaxinae & Preponiini & $\begin{array}{l}\text { Archaeprepona } \\
\text { demophon }\end{array}$ & & $\mathrm{X}$ & \\
\hline & Charaxinae & Pallini & Palla sp. & & $\mathrm{X}$ & \\
\hline & Charaxinae & Anaeini & Consul fabius & & & $\mathrm{X}$ \\
\hline
\end{tabular}




\begin{tabular}{|c|c|c|c|c|c|c|}
\hline Family & Subfamily & Tribe & Species & Absent & Intermediate & Well-Defined \\
\hline \multirow[t]{30}{*}{ Nymphalidae } & Charaxinae & Prothoini & Prothoe franck & & $\mathrm{X}$ & \\
\hline & Satyrinae & Morphini & Morpho & & & $\mathrm{X}$ \\
\hline & & & micropthalamus & & & \\
\hline & Satyrinae & Morphini & Morpho peleides & & & $\mathrm{X}$ \\
\hline & Satyrinae & Morphini & Morpho polyphemus & & & $X$ \\
\hline & Satyrinae & Brassolini & Caligo memnon & & & $\mathrm{X}$ \\
\hline & Satyrinae & Brassolini & Caligo iloneus & & & $\mathrm{X}$ \\
\hline & Satyrinae & Brassolini & Caligo eurilochus & & & $X$ \\
\hline & Satyrinae & Brassolini & Opsiphanes tamarindi & & $X$ & \\
\hline & Satyrinae & Zethyrini & Zethera musa & $\mathrm{X}$ & & \\
\hline & Satyrinae & Satyrini & Cercyonis pegala & & & $\mathrm{X}$ \\
\hline & Satyrinae & Satyrini & Coenonympha nipisquit & & & $\mathrm{X}$ \\
\hline & Satyrinae & Satyrini & Coenonympha tulia & & & $\mathrm{X}$ \\
\hline & Satyrinae & Satyrini & Elymniopsis banmakoo & & & $\mathrm{X}$ \\
\hline & Satyrinae & Satyrini & Enodia anthedon & & & $\mathrm{X}$ \\
\hline & Satyrinae & Satyrini & Erebia discoldalis & & & $\mathrm{X}$ \\
\hline & Satyrinae & Satyrini & Erebia fasciata & & & $\mathrm{X}$ \\
\hline & Satyrinae & Satyrini & Erebia mackinleyensis & & & $X$ \\
\hline & Satyrinae & Satyrini & Erebia mackinleyensis & & & $\mathrm{X}$ \\
\hline & Satyrinae & Satyrini & Erebia mancinus & & & $\mathrm{X}$ \\
\hline & Satyrinae & Satyrini & Erebia rossii & & & $X$ \\
\hline & Satyrinae & Satyrini & Erebia youngi & & & $\mathrm{X}$ \\
\hline & Satyrinae & Satyrini & Megisto cymela & & & $\mathrm{X}$ \\
\hline & Satyrinae & Satyrini & Oeneis bore & & & $X$ \\
\hline & Satyrinae & Satyrini & Oeneis chryxus & & & $\mathrm{X}$ \\
\hline & Satyrinae & Satyrini & Oeneis jutta & & & $\mathrm{X}$ \\
\hline & Satyrinae & Satyrini & Oeneis polixenes & & & $\mathrm{X}$ \\
\hline & Satyrinae & Satyrini & Pedaliodes phanias & & & $\mathrm{X}$ \\
\hline & Satyrinae & Satyrini & Pierella astyoche & & & $\mathrm{X}$ \\
\hline & Satyrinae & Satyrini & Satyrodes appalachia & & & $\mathrm{X}$ \\
\hline
\end{tabular}


Well-defined VO: A well-defined VO is bordered on three out of four sides by the base of anterior and posterior branches of the cubital vein, as well as the anal vein on the proximate end of the forewing. The cuticular ring is rigid and a symmetrical oval in shape with the long axis traveling from proximal towards distal and the short axis from anterior to posterior. The outer tympanal membrane is ovular as well and clearly bordered by the cuticular ring (Figure 2.3). It can vary between translucent and opaque.

Intermediate VO: In this condition the $\mathrm{VO}$ must be bordered on at least two sides by either the anterior and posterior branches of the cubital vein and/or the anal vein. The shape of the cuticular ring manifests as an irregular circle. The membrane itself is asymmetric and the borders of the chitinous ring are not apparent (Figure 2.3). The membrane can vary between translucent and opaque.

Absent VO: Finally, the VO is completely absent in some species. There is no bifurcation of the cubital vein at its proximate end. In some cases there is a structure known as the cubital plate at the base of the cubital vein, but no tympanal membrane is present (Figure 2.3).

Are morphological variations linked to size?

In addition to the overall level of VO development, I looked for variations in the relative VO sizes. I examined a wide variety of specimens in this study that ranged in size from small (femur length $\approx 2,500 \mu \mathrm{m}$ ) to large (femur length $\approx 10,000 \mu \mathrm{m}$ ). In order to see if a correlation exists between a specimen's body size and the size of its VO, I conducted an ANOVA between the body size, represented by the length of the femur on the hindleg, and the overall surface area of the Vogel's organ using sex as a covariate. This ANOVA showed no significant differences 
between the sex of the butterflies and their size in any of the three species examined $\left(F_{1,2}=\right.$ $0.213, p=0.65$. The non-linear regression using a quadratic equation shows a significant relationship $\left(R^{2}=0.91, F_{1,34}=156.19, p<0.001\right)$ between the size of the butterflies and their VOs which demonstrates that the size of the VO is linked to the size of the butterfly (Figure 2.4). 


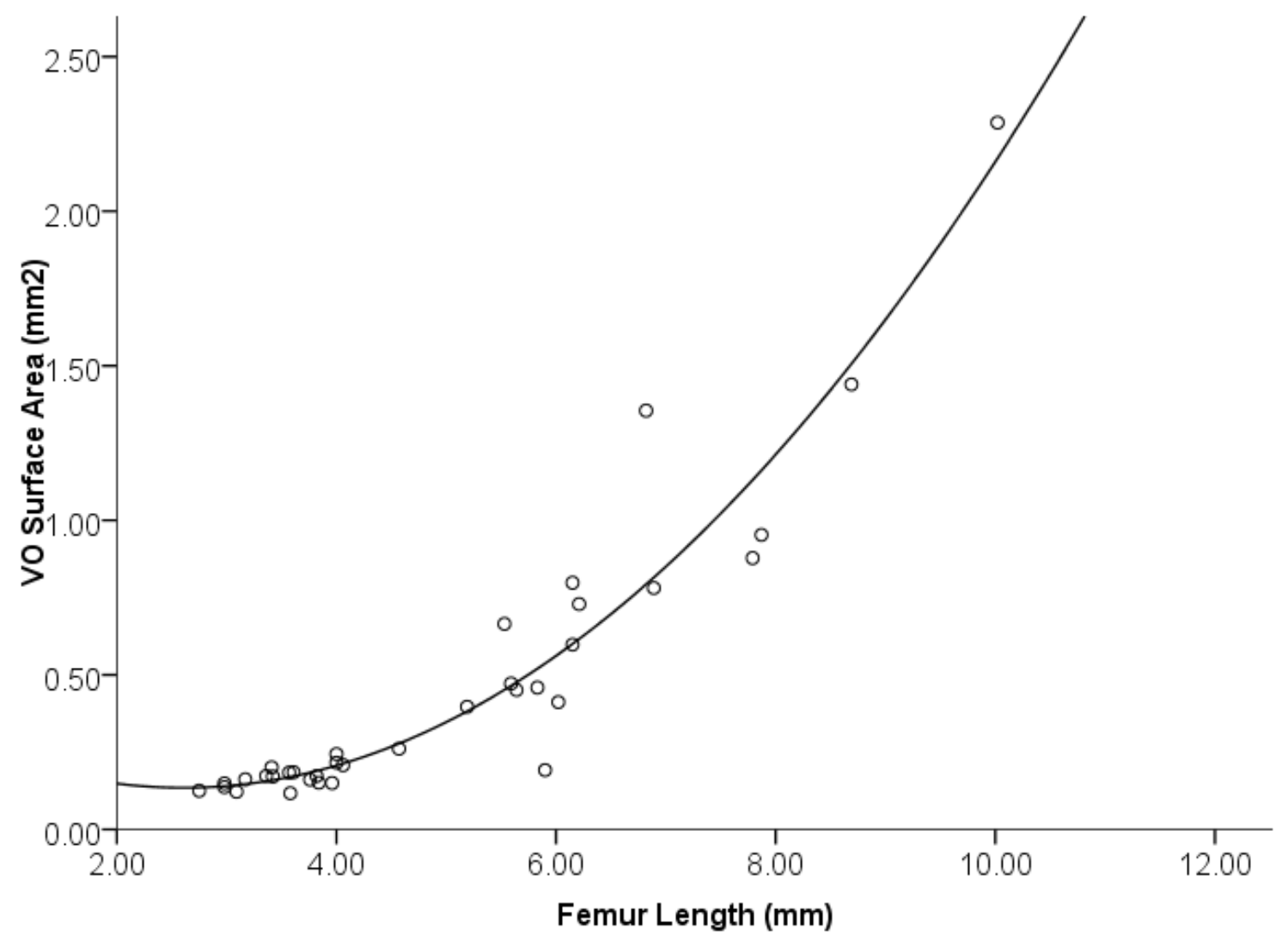

Figure 2.4 Non-linear regression using a quadratic function indicates a significant correlation $\left(R^{2}=0.91\right.$, $\left.F_{1,34}=156.19, \quad p<0.001\right)$ between the size of the femur, as an indicator of body size, and the surface area of the Vogel's organ. 


\section{Tholus}

I also categorized the tholus as absent, intermediate, or well defined. The tholus, or inner membrane, is a structure that appears in some of the butterfly species that possess VOs. It has been suggested that the tholus is derived from a fragment of the anterior basal branch of the bifurcation of the cubital vein. Most of the species examined in this study were found to have a well-defined tholus and only one completely lacked a tholus. The observed variation in the level of tholus development is shown in Figure 2.5 and summarized in Table 2.3. 


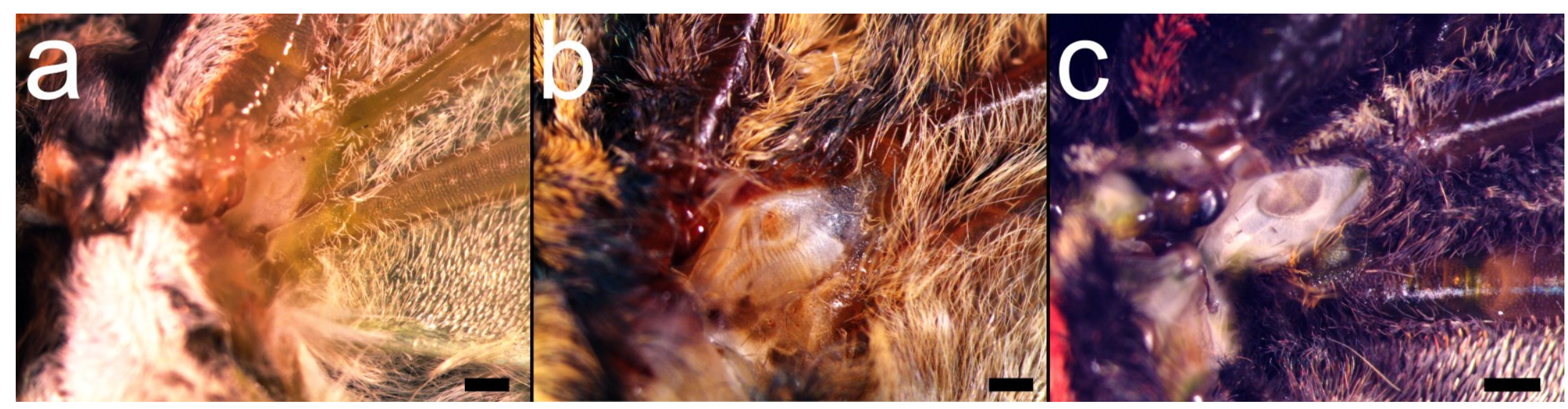

Figure 2.5 Representative specimens illustrating the observed variation in the tholus. Scales at the base of the forewing on the ventral side have been removed to expose the VO. (A) Light micrograph of Morpho polyphemus. In this specimen the membrane appears homogeneous and the tholus is absent. (B) Light micrograph of Caligo memnon. The membrane has some discolouration. This specimen possesses an intermediate tholus. (C) Light micrograph of Morpho microthalmus. In this specimen a clear distinction is present in the membrane both in terms of topography and colouration. This specimen possesses a well-defined tholus. Scale bars: $500 \mu \mathrm{m}$. 
Table 2.3 Summary of the tholus development of the eared species (those with a VO) studied in this work.

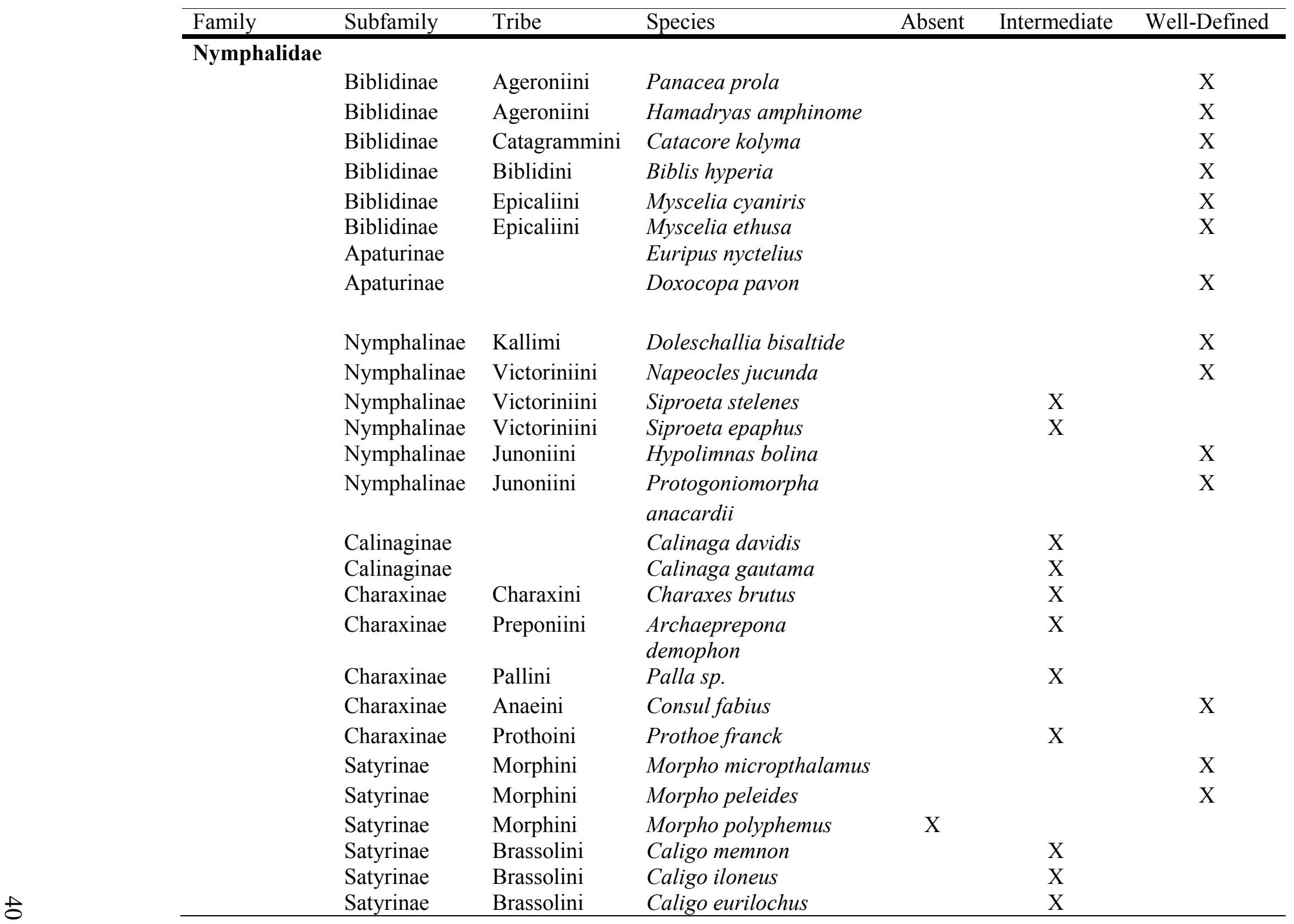




\begin{tabular}{|c|c|c|c|c|c|c|}
\hline Family & Subfamily & Tribe & Species & Absent & Intermediate & Well-Defined \\
\hline & Satyrinae & Brassolini & Opsiphanes tamarindi & & $\mathrm{X}$ & \\
\hline & Satyrinae & Satyrini & Cercyonis pegala & & & $\mathrm{X}$ \\
\hline & Satyrinae & Satyrini & Coenonympha nipisquit & & & $\mathrm{X}$ \\
\hline & Satyrinae & Satyrini & Coenonympha tulia & & & $\mathrm{X}$ \\
\hline & Satyrinae & Satyrini & Elymniopsis banmakoo & & & $\mathrm{X}$ \\
\hline & Satyrinae & Satyrini & Enodia anthedon & & & $\mathrm{X}$ \\
\hline & Satyrinae & Satyrini & Erebia discoldalis & & & $\mathrm{X}$ \\
\hline & Satyrinae & Satyrini & Erebia fasciata & & & $\mathrm{X}$ \\
\hline & Satyrinae & Satyrini & Erebia mackinleyensis & & & $\mathrm{X}$ \\
\hline & Satyrinae & Satyrini & Erebia mancinus & & & $X$ \\
\hline & Satyrinae & Satyrini & Erebia rossii & & & $\mathrm{X}$ \\
\hline & Satyrinae & Satyrini & Erebia youngi & & & $\mathrm{X}$ \\
\hline & Satyrinae & Satyrini & Megisto cymela & & & $\mathrm{X}$ \\
\hline & Satyrinae & Satyrini & Oeneis bore & & & $\mathrm{X}$ \\
\hline & Satyrinae & Satyrini & Oeneis chryxus & & & $\mathrm{X}$ \\
\hline & Satyrinae & Satyrini & Oeneis jutta & & & $\mathrm{X}$ \\
\hline & Satyrinae & Satyrini & Oeneis polixenes & & & $\mathrm{X}$ \\
\hline & Satyrinae & Satyrini & Pedaliodes phanias & & & $\mathrm{X}$ \\
\hline & Satyrinae & Satyrini & Pierella astyoche & & & $X$ \\
\hline & Satyrinae & Satyrini & Satyrodes appalachia & & & $\mathrm{X}$ \\
\hline
\end{tabular}


Well defined tholus: A well-defined tholus is a brown symmetrical ovular dome with varying degrees of transparency and with clear margins that separate it from the peripheral membrane. Its appearance is membranous in nature. In these species, the tholus is a clear attachment zone for at least one chordotonal organ (Figure 2.5).

Intermediate tholus: An intermediate tholus appears reduced and does not possess clearly defined margins or shape. In these specimens, the tholus appears brown in colouration, is asymmetric, appears more chitinous, and is not elevated from the peripheral membrane (Figure 2.5).

Absent tholus: Finally, the tholus is completely absent in some species. There are no areas of different colouration present or elevation on the membrane (Figure 2.5).

Forewing Veins Associated with the VO

The variation of the three major forewing veins, i.e., the subcostal, the cubital and the anal veins (labelled in Figure 2.6), was examined. These veins surround the VO at the proximate base of the forewing. The cubital vein borders the VO anteriorly and posteriorly as well as the anal vein. At the base of the forewing, the air chamber associated with the VO is connected to the rest of the alar venation system directly (subcostal, radial, cubital and anal veins). In some species, I observed that one or more of these veins are enlarged. The inflation existed at the proximate end of the forewing vein, enlarging from anterior to posterior. The enlargement could vary in length, but always tapered to a non-inflated size before the median of the forewing. To determine whether a forewing vein would be considered inflated, I took measurements of the serial homologue veins from the forewing and hindwing. The vein widths were compared to 
establish the condition for forewing vein inflation because there is no ear associated with the hindwing. The non-eared species examined in this portion of the study all have ratios that range from 1 , meaning in no cases were the hindwing veins found to be larger than the forewing veins, to under 3, which means they are all uninflated. Based on previous studies (LeCerf 1926; Bourgogne 1951) as well as my own observations of atympanate species, I conclude that none of the atympanate specimens examined in this study display any forewing vein inflation. Thus, any forewing-to-hindwing ratio greater than 3 is herein considered inflated whereas a ratio below 3 is denoted non-inflated. The specimens that do possess VOs show variation in their degree of forewing vein inflation. 

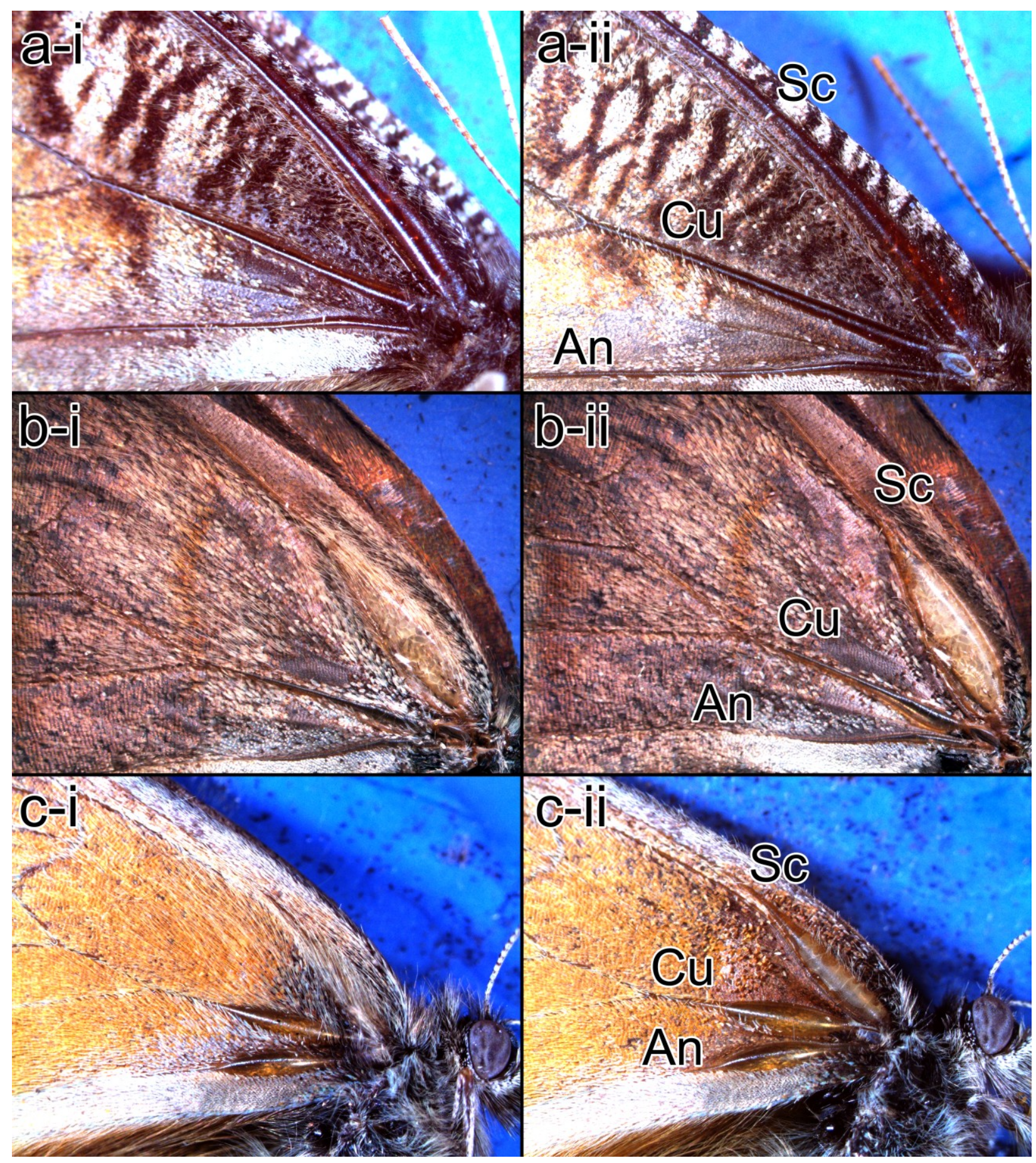

Figure 2.6 Representative species illustrating the different forewing vein inflation conditions used in this work. Light micrographs of the ventral side of the forewing of Oeneis chryxus with scales intact (a-i) and after the scales have been removed to fully expose the veins (a-ii). No forewing vein inflation is observed. Light micrographs of the ventral side of the forewing of Megisto cymela, with scales intact (b-i) and after the scales have been removed (b-ii). In this specimen the subcostal vein is inflated. Light micrographs of the ventral side of the forewing of Coenonympha tullia with scales intact (c-i) and after the scales have been removed (c-ii). Three forewing veins are inflated in this case. $\mathrm{Sc}=\mathrm{Subcostal}, \mathrm{Cu}=$ Cubital, A = Anal. 
I also considered whether any correlations exist between the subcostal and anal vein widths with the size of the animal, as measured by hindleg femur length. The results I found were very intriguing. When all of the cases were considered together (atympanate, tympanate, inflated, non-inflated) for a regression, there was no relationship present between body size and the width of the subcostal vein $\left(R^{2}=0.001, F_{1,49}=0.05, p=0.82\right)$ which could mean that subcostal vein width is independent of body size. When those cases were plotted based on subcostal forewing ratio to hind wing ratio an interesting trend appeared. For those categorized as atympanate, as well as the cases that were non-inflated the ratios generally fall within the range of $1-3$ (Figure 2.7). This implies that no matter the size of the butterfly, if there is no conspicuous inflation the forewing to hindwing ratio of the subcostal vein is consistent. Although there was no such trend present for the inflated species, it is noted that no butterfly examined with a femur size greater than $4 \mathrm{~mm}$ had inflated subcostal veins (Figure 2.7). When a regression was conducted on atympanate species alone, a positive correlation was seen between increasing body size and increasing subcostal vein width $\left(R^{2}=0.3, F_{1,14}=5.58, p<0.05\right)$. These results indicate that the subcostal forewing vein width is only correlated with overall body size for atympanate species, whereas for tympanate species it is not. 


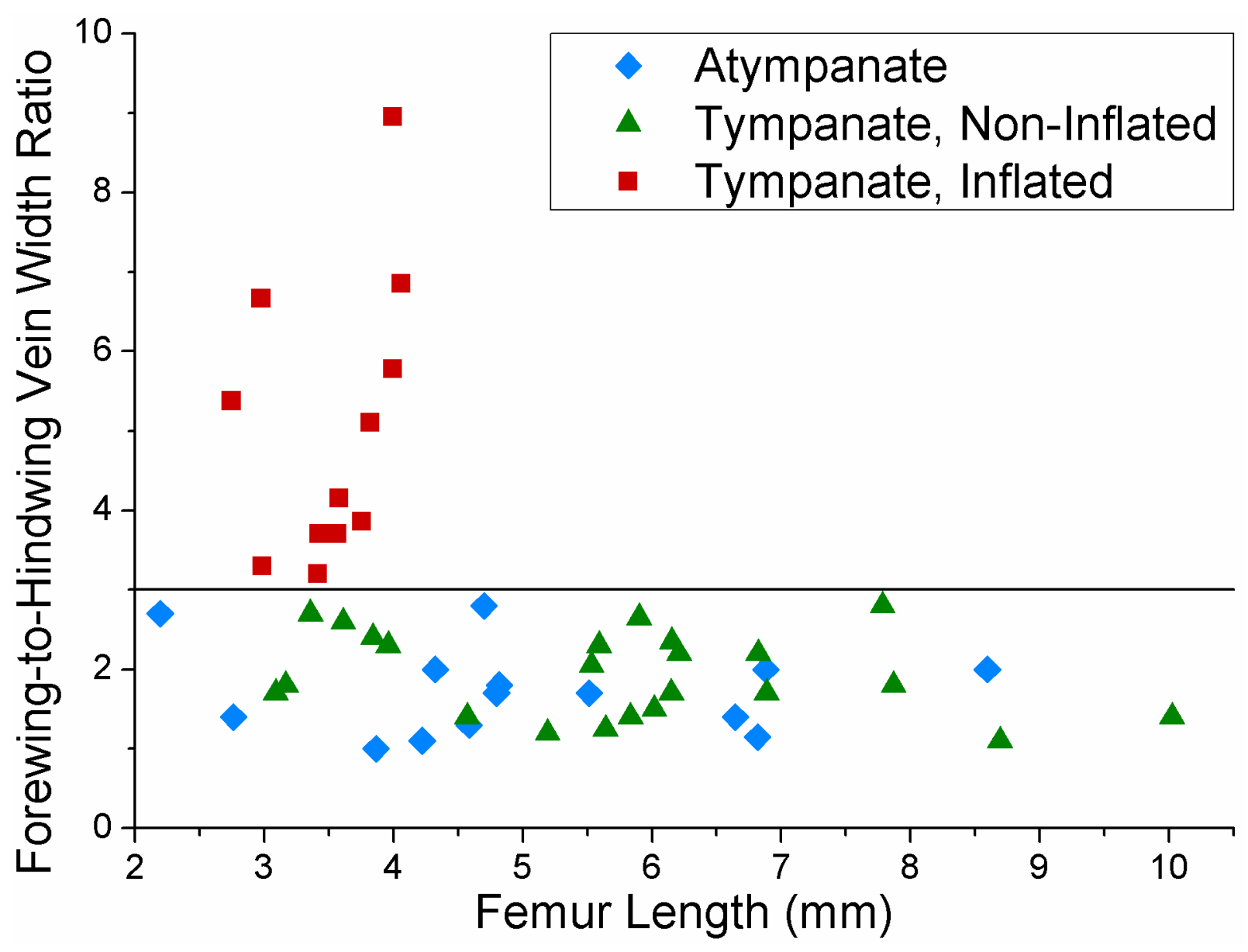

Figure 2.7 A plot demonstrating forewing to hindwing ratio of the subcostal veins against hindleg femur length as an indicator of body size. The black line at 3 indicates the cut-off between inflated and uninflated forewing veins. 
As for the anal vein, when all cases are considered together (tympanate, atympanate, inflated and non-inflated), a significant correlation exists between width of the anal vein and a butterfly's body size, as indicated by its femur length $\left(R^{2}=0.42, F_{1,48}=34.75 p<0.001\right)$. This is shown in Figure 2.8. When they were plotted based on forewing to hindwing anal vein width ratio, with the exception of two species that were inflated, there seemed to be an ideal, or average ratio of 1.5 (Figure 2.9). In general, these results suggest that the width of the anal forewing vein is correlated with the overall body size, including most of the tympanate species in this work. This is in contrast with the results from the subcostal forewing vein, for which the vein width is only correlated with body size for the atympanate species. 


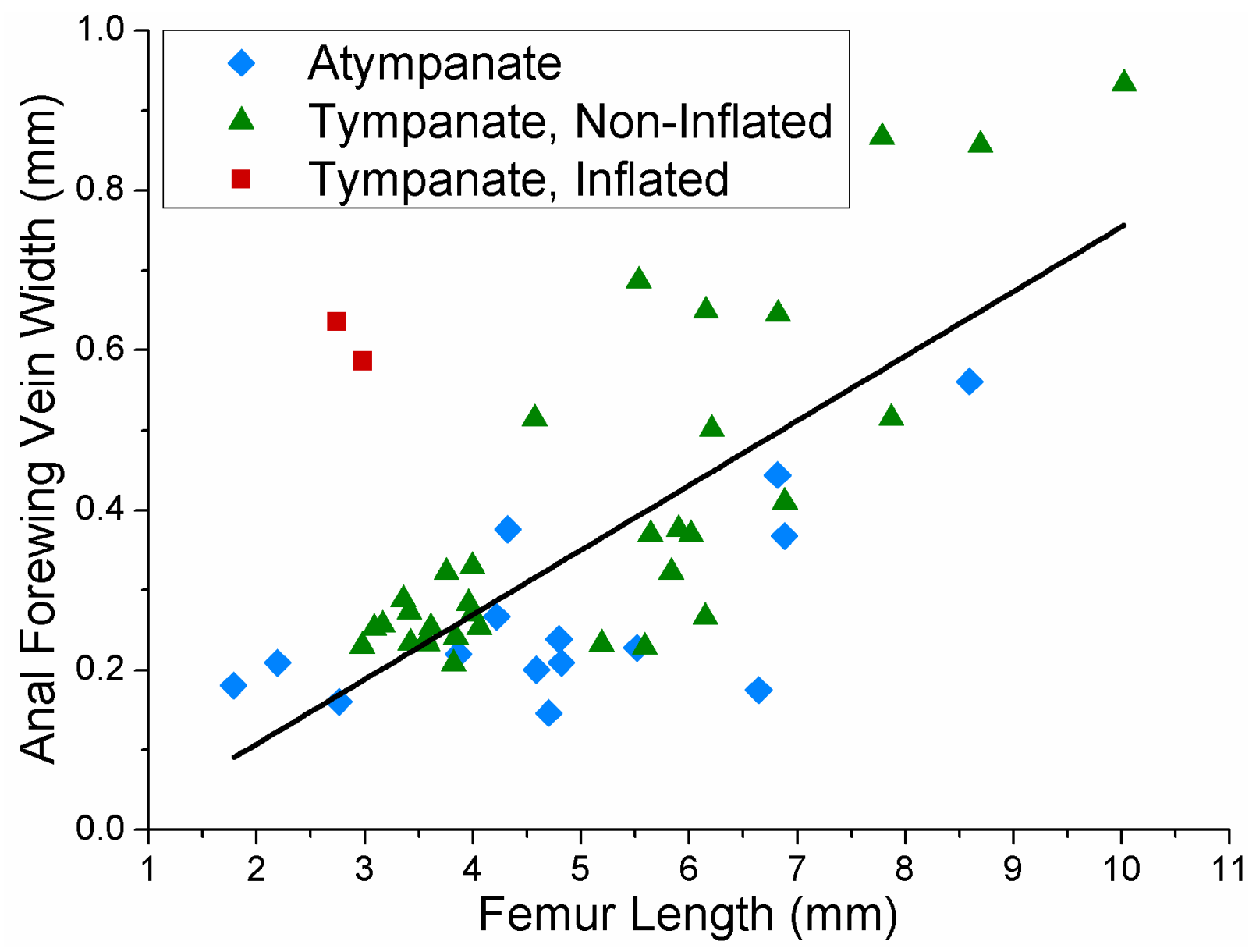

Figure 2.8 A regression showing significant correlation $\left(R^{2}=0.42, F_{1,48}=34.75, p<0.001\right)$ between body size and anal vein inflation. The ratio of the width of the forewing anal vein and the width of the hindwing anal vein is plotted against the length of the hindleg femur. 


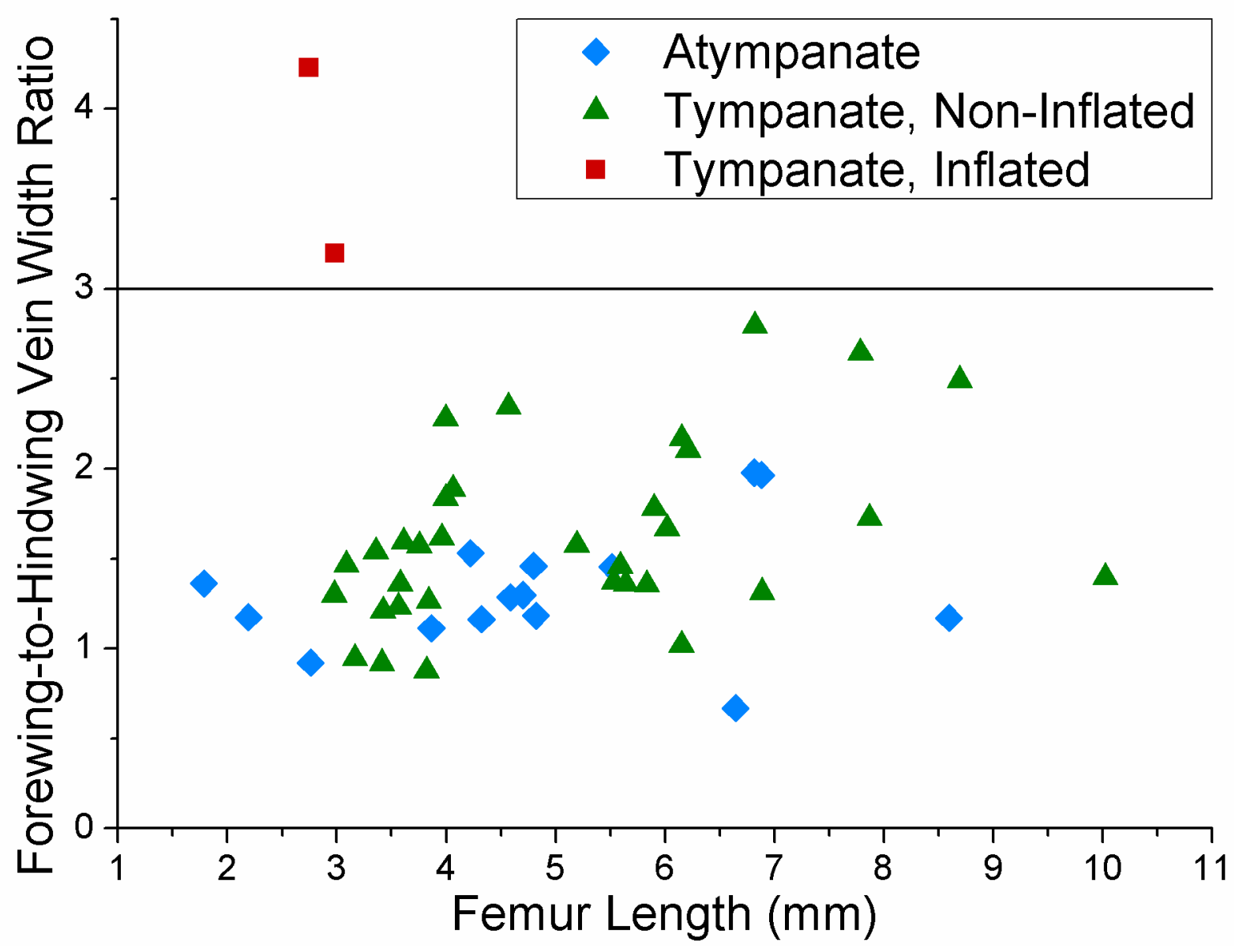

Figure 2.9 A scatter plot showing the instances of inflated and non-inflated forewing anal veins. All of the atympanate as well as most of the tympanate fall below the cut-off ratio of 3 . 


\section{Membranous Ampulla}

\section{Preliminary observations}

In this work, I observed membranous ampullae (MAs) in Myscelia cyaniris and Myscelia ethusa (Figure 2.10), which has not been previously reported for either species. The membrane is opaque and highly wrinkled, which indicates that it has a large surface area. It is obscured from view by a covering of flat scales, which are similar to those found elsewhere on the costal cell. I further observed that changes in the room's ambient lighting conditions affect the observed size and shape of this membranous structure. Since there are no other examples of a photosensitive forewing structure and since the membrane is physically connected to the $\mathrm{VO}$, I decided to further investigate this novel observation and the results of those measurements are presented in this section. 


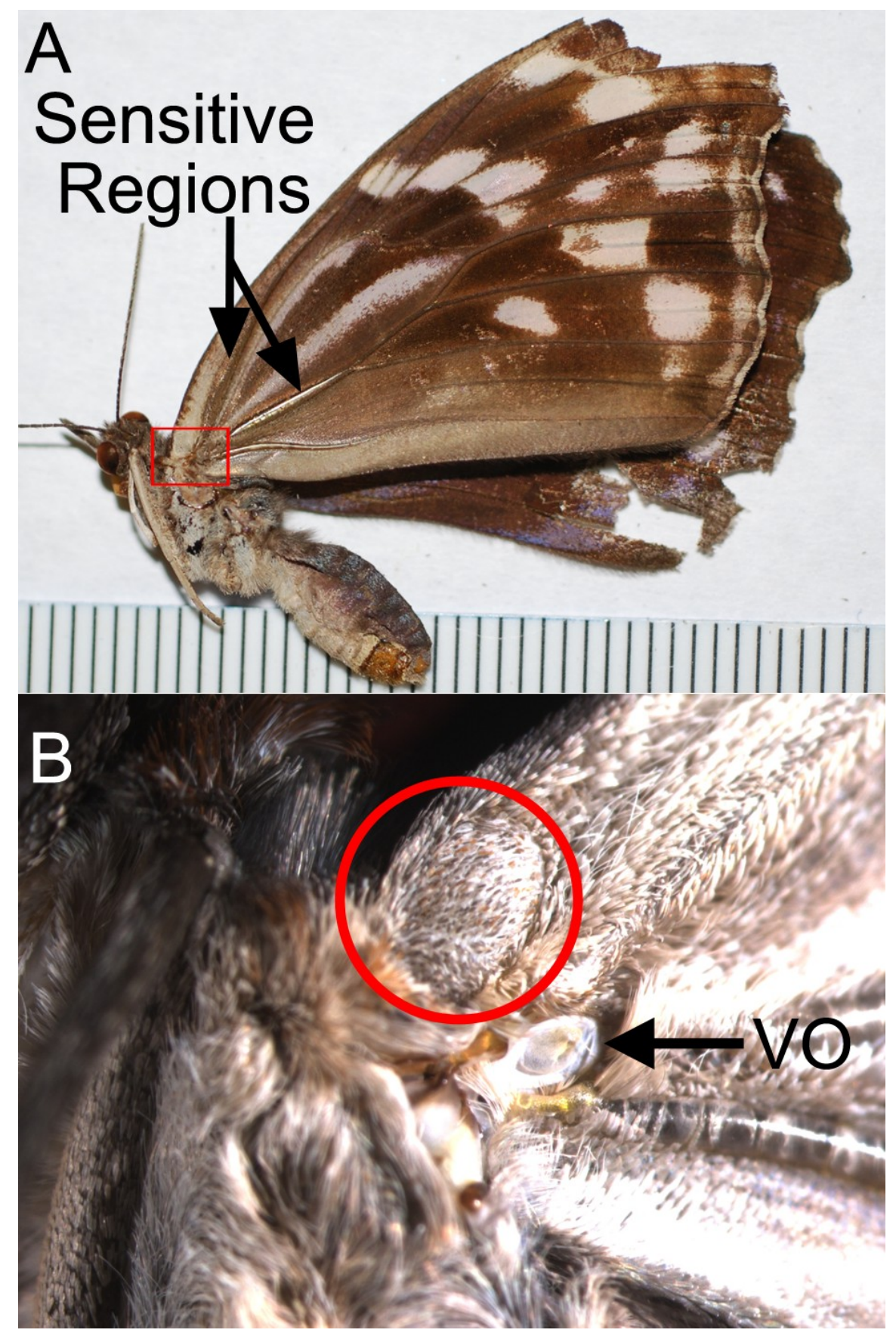

Figure 2.10 Ventral surface of the forewing of Myscelia cyaniris with the light and temperature sensitive regions indicated with arrows in (A). Scale marks are spaced $1 \mathrm{~mm}$ apart. The rectangular region is enlarged. (B) The MA is circled and the VO is indicated by an arrow. 
I observed that when the MA is physically disturbed, e.g., when prodded with a blunt tool, the membrane of the VO responds by moving. For instance, when I depressed the MA, the VO inflated outward. From this, I conclude that the two membranes are physically linked, likely by a trachea. I further observed that the MA responds to certain stimuli by rapidly inflating outward. Upon inflation, the volume of the tracheal air cavity increases. Preliminary trials showed that only the MA in living specimens responded to stimuli, while ethanol preserved specimens, freshly sacrificed, and dried specimens did not. I then conducted a series of experiments to determine what individual stimuli (light and heat) cause this response. These pilot experiments are described below.

Does the MA in Myscelia respond to light?

I observed that in ambient room lighting, the MA in Myscelia cyaniris and Myscelia ethusa is moderately inflated, whereas in a dark room the MA is recessed into the forewing cell and is concave in shape. When I illuminated the forewings with a LED specimen light, the MA fully inflated outward, adopting a convex shape. To determine the location of the receptive region, I shone the light at specific parts of the specimens' forewings, using pieces of modelling clay to block the light from reaching portions of the wing by either casting shadows or by physically attaching the clay to the wing. I ultimately located the photosensitive areas on ventral side of the forewing, which are indicated in Figure 2.10. I was able to rule out the dorsal surface of the wing as the sensitive surface by mounting the butterfly on a glass petri dish and shining light on the dorsal surface while watching for a response on the ventral surface. If light was shone on the MA itself, with the forewing veins obstructed, no response was elicited. Further, illumination of one forewing elicits a response of only the MA on the ipsilateral forewing, i.e., 
the MA on the contralateral wing does not respond. Thus, I observe that this structure responds to external light stimuli, which is detected by apparently photosensitive regions on the ventral side of the forewing at regions between approximately 3 and $6 \mathrm{~mm}$ from the wing base.

Does the MA in Myscelia respond to temperature?

Although the LED is marketed as a 'cool' light, it does produce some heat. Thus, I separately considered whether the MA responds to temperature changes. To accomplish this, I used a soldering iron, set to its lowest setting, as an external heat source. At this setting, the iron is approximately $35^{\circ} \mathrm{C}$. For all temperature experiments, I set the ambient room lighting such that the MA was in its basal condition, i.e., approximately in plane with the rest of the forewing. I held the iron parallel to the forewing, anterior to posterior in order to get the smallest heat point possible, $1.5 \mathrm{~cm}$ from the surface. By slowly moving the iron along the surface, I determined that when the heat source is near certain locations on the forewing, the MA fully inflates. These heatsensitive regions are the same as the photosensitive region identified previously and indicated in Figure 2.10. I also froze a $10 \mathrm{~mL}$ syringe, filled with saline solution, to determine whether the MA responds to cold stimuli. Following the same procedure as for the hot stimuli, I observed that when the cold syringe is near the temperature-sensitive regions the MA fully depresses inward and adopts a concave shape. Thus, I find that MA is indeed a temperature-sensitive structure.

The observation that the MA physically responds to an external heat source leads to the question of whether this structure indeed responds to light or whether the LED was heating the specimens during the above experiment. To further investigate this, I simultaneously exposed 
specimens to the frozen syringe and a bright light. This elicited an oscillating response between full inflation and depression into the forewing at an approximate frequency of $1-3 \mathrm{~Hz}$. This may indicate that the MA actively responds to light and low temperature signals through separate pathways. I then exposed specimens to the heated iron under dark ambient conditions, which caused the MA to fully inflate. This demonstrates that low light is not an active cue, whereas heat is. Thus, it is consistent with my results that the MA in Myscelia responds to temperature and light stimuli. While the oscillations in the MA were occurring there was negligible movement of the VO's membrane. Alternatively, when Morpho peleides was used as a control (does not possess a MA) the membrane of the VO varied drastically in response to light and heat stimuli. When heat or light was applied, the membrane would bulge out from the chitinous ring. When the cold treatment was applied, the membrane of the VO would recess into the tympanal air cavity.

In addition to temperature and light, I considered whether the MA responds to tactile or acoustic stimuli. I was unable to elicit a response by prodding the specimens, in either the putatively sensitive regions, or the MA itself with a blunt tool. I was similarly unable to elicit a response to sound using an electronic dog whistle as a source. In both experiments, I observed behavioural responses, by twitching, which indicates that the specimens were able to feel and hear the stimuli. Thus, I conclude that the MA does not inflate in response to tactile or acoustic stimuli.

\subsubsection{How are the variations of butterfly hearing organs distributed in the family Nymphalidae?}

In order to gain insight into how widespread the VO characters and its associated structures were, I plotted my character groups onto a recently published comprehensive 
phylogeny that utilized both morphological characters from all stages of development and genetic data from eight different gene regions (Heikkilä et al. 2012). From plotting this information onto a phylogeny I was able to discern if trends existed in the location and developmental stage of the VO (Figure 2.11) and the tholus (Figure 2.12). From this phylogeny we see that the sub-families of Nymphalidae can be split into two clades. The presence and absence of VO as well as the condition of the VO seems to be sporadic. 


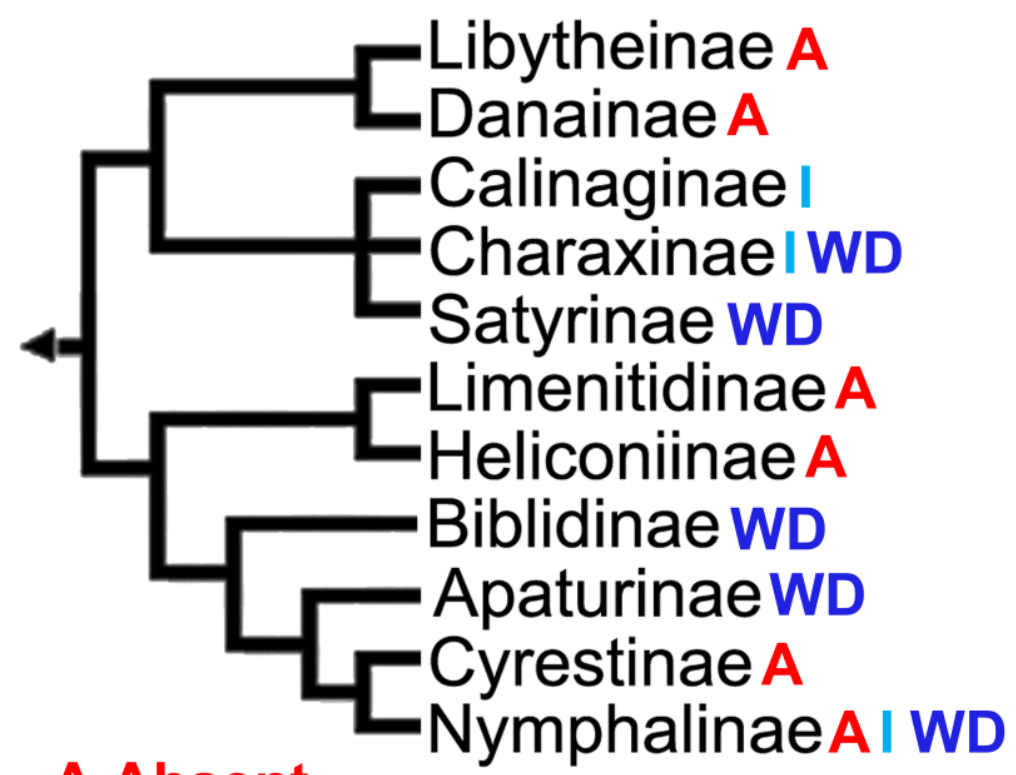

A Absent

I Intermediate

WD Well Defined

Figure 2.11 Phylogeny of the family Nymphalidae. The level of VO development is indicated next to the family name (note: not all species within each subfamily has been examined). Phylogeny adapted from (Heikkilä et al. 2012). 


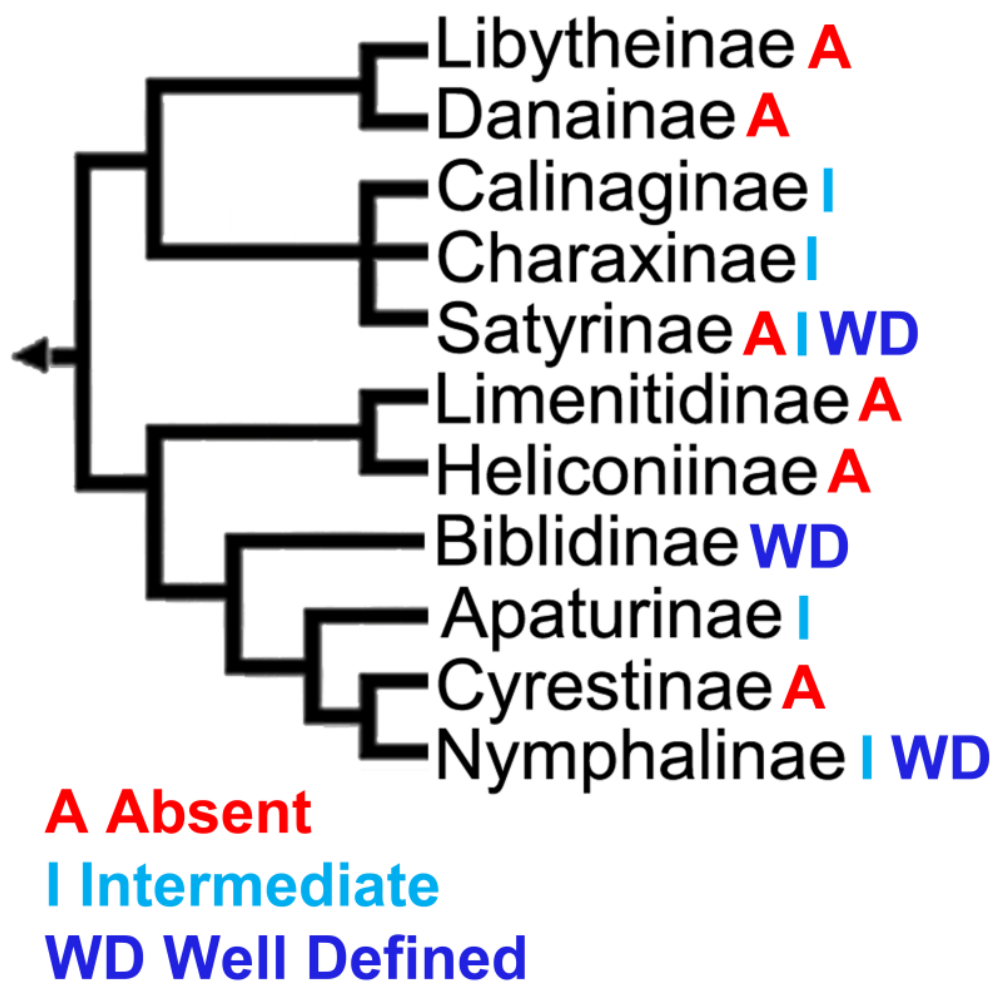

Figure 2.12 Phylogeny of the family Nymphalidae. The level of tholus development is indicated next to the family name (note: not all species within each subfamily have been examined). Phylogeny adapted from (Heikkilä et al. 2012). 
Inflated forewing veins were only found in two out of eleven sub-families, Satyrinae and Biblidinae. According to this phylogeny they belong to different clades within Nymphalidae which would seem to imply this trait developed twice. Within the sub-family not all representatives examined were found to have forewing vein inflation. Even on the tribal level there was variation as to who had inflated forewing veins and who did not. This would seem to imply perhaps different selection pressures on different species of each tribe impact whether the trait developed more so than the proximity of the relationships.

\subsubsection{Is there sexual dimorphism in butterfly hearing organs or the associated structures?}

To determine whether sexual dimorphism occurs in the VOs of Nymphalidae, three representative species were selected: Megisto cymela, Coenonympha tullia, and Enodia anthedon. These species were chosen for their high specimen availability, such that sufficiently high sample sizes could be collected and examined. Sizes of the butterflies were compared between males and females to confirm there was no sexual dimorphism in size. In all cases, no sexual dimorphism in terms of body size was found (Enodia anthedon $\mathrm{p}=0.54$, Coenonympha tullia $\mathrm{p}=0.3$, Cercyonis pegala $\mathrm{p}=0.08$ ). The sizes of the VOs were measured by their surface areas. From a one-way paired t-test, it was found that there are no significant differences $(p>$ 0.05 ) between the males and females in any of the three species for their VO surface areas (Figure 2.13) or the widths of the forewing subcostal veins (Figure 2.14). 


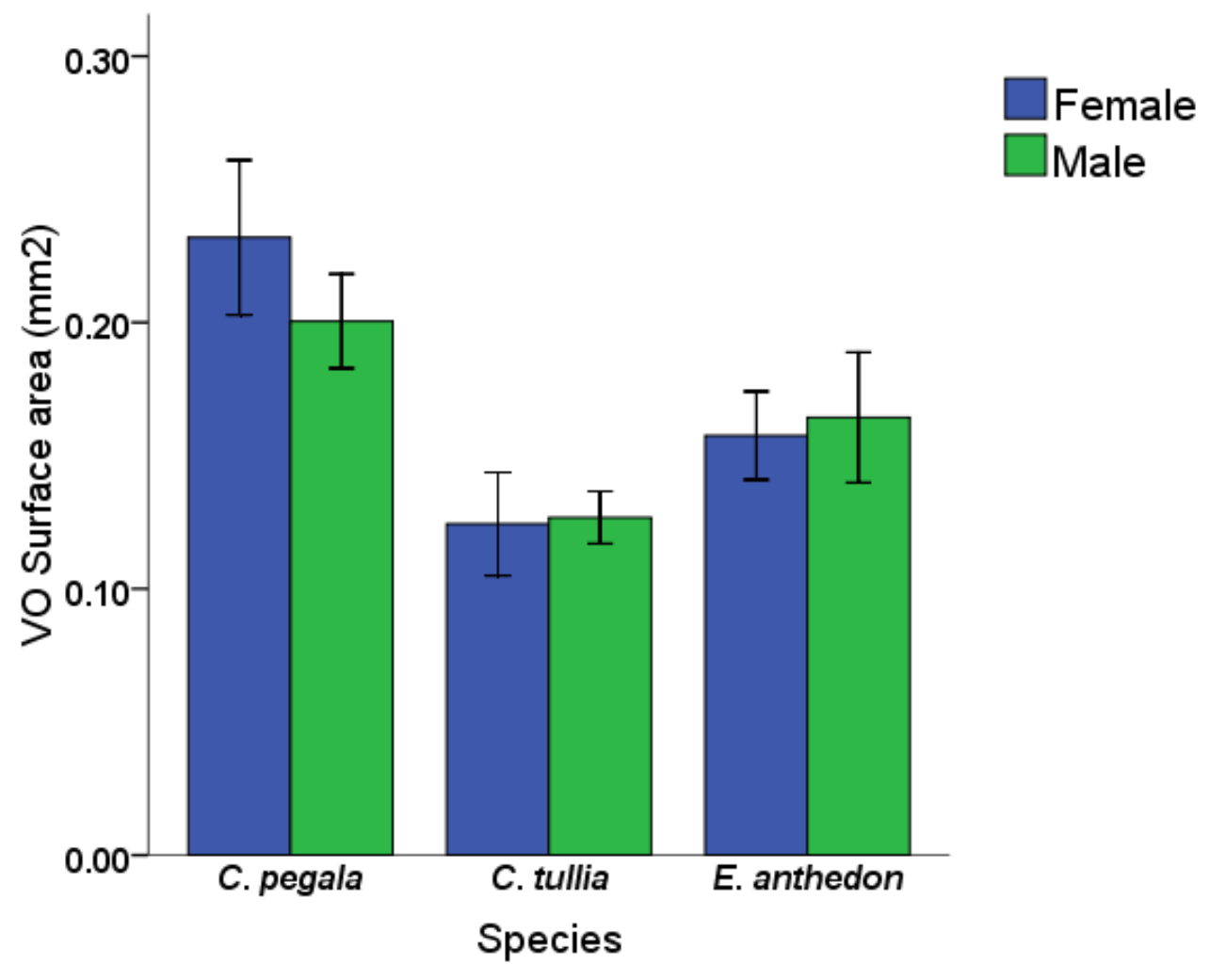

Figure 2.13 Absolute VO sizes of males and females in three species. Error bars represent one standard deviation. Cercyonis pegala $\mathrm{n}=6,6$, Coenonympha tullia $\mathrm{n}=10,6$, Enodia anthedon $\mathrm{n}=6,6$. 


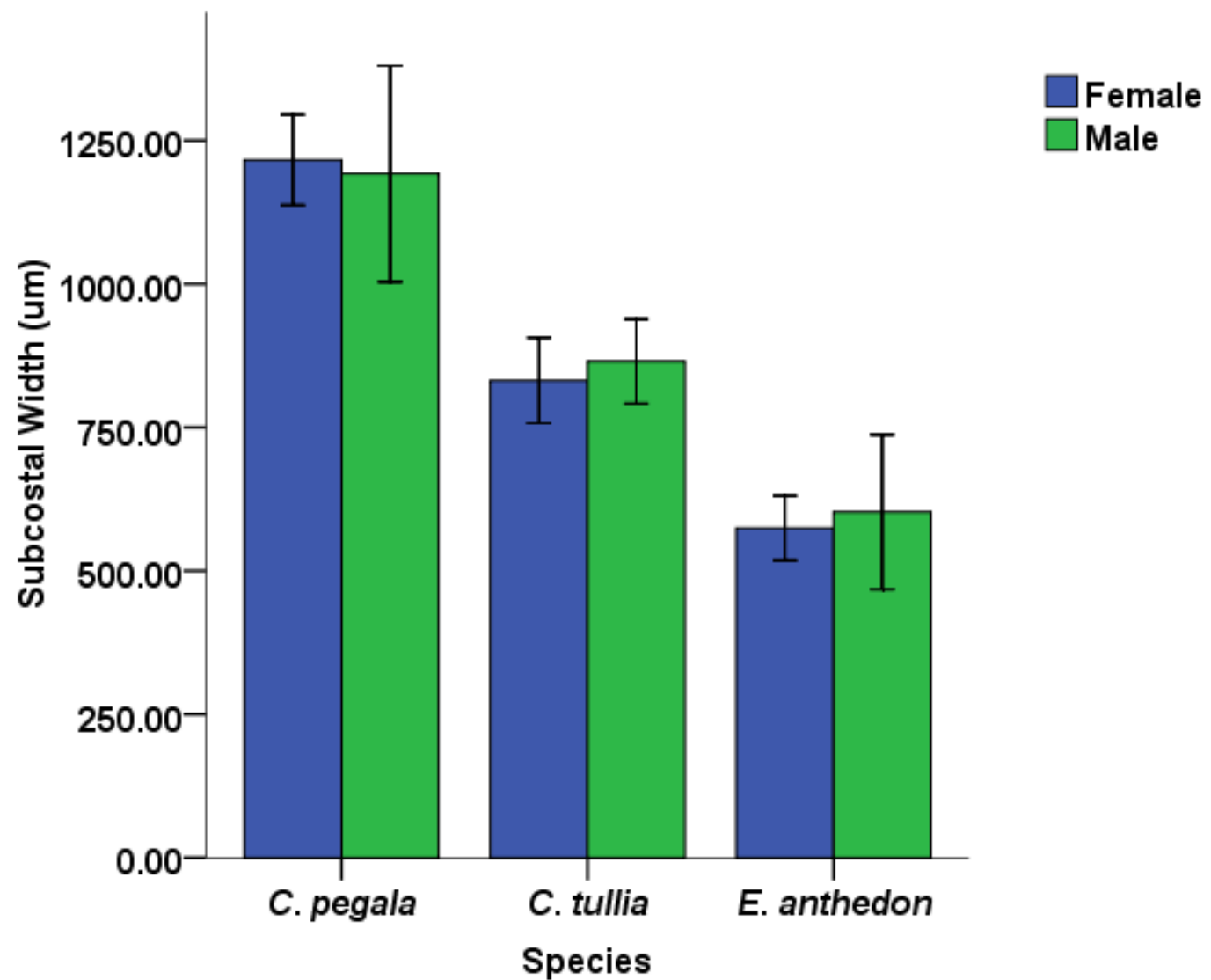

Figure 2.14 Subcostal vein size of males and females in three species. Error bars represent one standard deviation. Cercyonis pegala $\mathrm{n}=6,6$, Coenonympha tullia $\mathrm{n}=10,6$, Enodia anthedon $\mathrm{n}=6,6$. 
2.3.4 What is the morphological variation of hearing organs and associated structures within the tribe Satyrini?

Having broadly examined the morphological variation of the VOs, tholus and forewing veins in the family Nymphalidae, I considered the variation within a smaller taxonomical distribution. I chose to further scrutinize Satyrini because of previously reported evidence of highly developed VOs in this tribe (Mahony 2006; Lane et al. 2008). All of the eighteen species examined in this work possess well-defined VOs (Table 2.4). 
Table 2.4 Summary of the level of development of the hearing organs of Satyrini species. The VO and tholus are well-defined (WD) for all the Satyrini species in this study. Species that exhibit inflation of the subcostal, cubital and forewing veins are marked with an ' $\mathrm{X}$ '.

\begin{tabular}{lllllll}
\hline \multicolumn{1}{c}{ Subtribe } & \multicolumn{1}{c}{ Species } & VO & Tholus & \multicolumn{2}{c}{ Forewing Vein Inflation } \\
Subcostal & Cubital & Anal \\
\hline Cercyonis (genus) & Cercyonis pegala & WD & WD & X & & \\
Coenonymphina & Coenonympha nipisquit & WD & WD & X & X & X \\
& Coenonympha tullia & WD & WD & X & X & X \\
Erebiina & Erebia mackinleyensis & WD & WD & X & & \\
& Erebia manicus & WD & WD & & \\
& Erebia rossii & WD & WD & X & \\
Euptychiina & Erebia youngi & WD & WD & X & \\
Lethina & Megisto cymela & WD & WD & X & \\
& Enodia anthedon & WD & WD & X & & \\
Satyrina & Satyrodes appalachia & WD & WD & & & \\
& Oeneis bore & WD & WD & & & \\
& Oeneis chryxus & WD & WD & & \\
& Oeneis jutta & WD & WD & X & & \\
& Oeneis polixenes & WD & WD & & & \\
\hline
\end{tabular}




\subsection{Discussion}

2.4.1 What is the observed morphological variation of Vogel's organ and its accessory structures?

\section{Vogel's Organ}

To accomplish the goal of categorizing the morphological variations of the VOs examined in this study, I first had to form a basis on what I considered the basal, or atympanate form. In order to do this I considered the findings of LeCerf and of Otero, who previously had formed classifications themselves.

For the basal condition, LeCerf postulated that there was no enlargement or swelling at the base of the forewing veins, and no bifurcation of the cubital vein was present. Wing sclerites are present but there is no chitinous ring or membrane present (LeCerf 1926). There can be varying degrees of atympanate, as he described certain species such as Tellervo moorei (Nymphalidae: Danainae) as having no differentiation of the cubital vein, although there were others, such as Dione dido (now: Philaethria dido, Nymphalidae: Heliconiinae), which had a swelling at the base of the radial and cubital vein that formed what LeCerf called a chitinous plate. Although this structure exists, the VO is not present and so the representatives are still described as atympanate. Otero similarly suggested that in atympanate species there is no differentiation in the base of the forewing (Otero 1990). As such, I adopted an absent, or atympanate, category. I found that this category is populated by species from the families Pieridae and Lycaenidae, which is in agreement with previous literature evidence (Vogel 1912; 
LeCerf 1926; Otero 1990). Further, I only observed VOs for species within the family Nymphalidae, which is consistent with previous reports.

My categorization of what I considered to be an intermediate stage was also based largely on previous reports by (LeCerf 1926) in addition to my own observations. An intermediate VO had a bifurcation of the cubital vein and the base of the forewing. As LeCerf (1926) noted, the overall shape of the chitinous ring surrounding the outer membrane was that of an irregular or asymmetric circle. The intermediate stage in my work also was characterized by the lack of bordering on at least three sides by the cubital and anal veins which is present in well-defined VOs (Minet and Surlykke 2003). Again, as with the atympanate, there could be variations between intermediate stages, for instance in absolute shape of the organ.

Finally, the well-defined category was defined by having an enlargement to the proximate base of the cubital vein that resulted in a bifurcation of the vein. The VO was bordered on all three sides by the cubital and anal vein, with the most proximate edge of the membrane being defined by a fold in the base wing membrane (Minet and Surlykke 2003). LeCerf (1926) described this state as having a symmetrical ovular chitinous ring with nicely rounded edges. The membrane itself is symmetric with clearly defined borders that lie at an angle to the plane of the wing.

Therefore, using previous literature, as well as my own observation, I was able to define the above three categories of Vogel's organs. Further, I examined and classified over 85 species into these categories. I hypothesize that the differing categories of VO correspond to different stages, or levels of ability of hearing. In the case of atympanate species, I do not believe that they can detect air-borne sounds with this region, based on the lack of tympanal organ. The 
intermediate VOs may be capable of detecting sounds, but perhaps a smaller range of frequencies or at a lower sensitivity than those with a well-defined VO. To understand the influence of membrane geometry on sound detection, I considered man-made diaphragms for electronic microphones, which are analogous to the VO membrane. Although circular diaphragms are common because they are the easiest to make, several microphone manufacturers also produce non-circular designs. Available geometries include rectangular (2700 rectangular capsule, Milab Microphones; ELM-C, Pearl Mikrofonlaboratorium; and CC22, Pearl Mikrofonlaboratorium), triangular (EHR-M, Ehrlund Microphones) and elliptical (507, Bock Audio). The manufacturers' information all supports that circular diaphragms always have a single fundamental frequency, which results in an uneven response to different frequencies as a result of constructive and destructive interference (Cardas 2006). This is analogous to the intermediate VOs, which are circular in shape. In the case of rectangular diaphragms, there are two fundamental frequencies (one associated with the length and one associated with the width) and for triangular diaphragms, there are none. Finally, elliptical diaphragms have a range of fundamental frequencies (ranging between the width and length), which theoretically provides high sensitivity with a smooth response over a wide range of frequencies (Cardas 2006). Elliptical diaphragms are analogous to the membranes of well-defined VOs. Therefore, it is possible that the observed geometry differences of the VOs correspond to the sensitivities and frequency ranges of these hearing organs. It is noted that physiological investigation is necessary to support or disprove these hypotheses, which are solely based on morphology.

Next, I considered the variation of VO size between species. To this end, I conducted a regression of VO size, as measured by surface area, against the size of the butterfly itself, as represented by the femur length. The purpose of this statistical analysis is to consider whether 
there is an optimal VO size that is independent of the specimen body size or whether the VO scales with the overall body size. I find that there is a significant relationship between the size of a butterfly and the size of its VO. This supports that the VO size is linked to the size of the butterfly, rather than adopting an optimal absolute size.

\section{Tholus}

The tholus, also referred to as the inner membrane, is a brown convex protrusion that sits on the outer membrane, usually in a central anterior position. The tholus has been described as a small sclerite that varies in its membranous properties depending on the degree of development of the VO in which it is found (Otero 1990). Minet and Surlykke (2003) claim that the tholus is derived from a fragment of the anterior branch of the cubital vein surrounding the VO that has been enveloped by the outer membrane. The tholus is contacted by a chordotonal organ that crosses the tholus from anterior to posterior and is visually manifested as a scar. This chordotonal organ is innervated by the N.II branch of the main wing nerve IIN1c (Vogel 1912; Lane et al. 2008). The properties of the heterogeneous membrane were investigated in 2006 by Katie Lucas. Using Doppler laser vibrometry, Lucas (2008) showed that the VO of Morpho peleides vibrates at two frequency-dependent modes. The outer membrane vibrates in response to stimuli below $5 \mathrm{kHz}$, while the tholus remains still. Both membranes vibrate in response to stimuli over $5 \mathrm{kHz}$.

Frequency discrimination is found in other insect tympanal hearing organs such as those possessed by the Mediterranean cicada. In this example, when the tympanal hearing organ is stimulated by sound, a heterogenous membrane propagates a travelling wave in response. 
Different areas of the membrane respond to different frequencies in the sound stimuli. This information is conserved into the central nervous system where a cicada gleans information on what frequencies are being detected (Sueur et al. 2006). Frequency discrimination has also been shown to exist in the ears of locusts. Exposing the ear to different frequency stimuli will cause different areas of the membrane to vibrate. Each area of the membrane is innervated by different scolopidia, which means frequency discrimination is determined by which scolopidia on the membrane are receiving the signal and transmitting it to the central nervous system (Windmill et al. 2005). Thus, the tholus may be very important for frequency discrimination in some species of butterfly.

In this work, I categorize the level of tholus development to consider the variations of the tholus between species. In previous literature the appearance and development of the tholus has been grouped in with the overall stage of the VO (LeCerf 1926; Otero 1990). In this work, however, I recommend that the two traits should be considered independently. For example, consider two hypothetical species that both possess well-defined outer membranes. If the tholus indeed is used for frequency discrimination in hearing, then it is possible that these two different species may possess tholi at different developmental stages. This difference could arise if the selection pressures are such that frequency discrimination is more or less important for these two hypothetical species. Hence, I believe that it is prudent to consider the tholus and the VO separately.

I only found one instance of a tholus being absent in this work. In Morpho polyphemus (Satyrinae: Morphini) no such structure is present. The outer membrane appears consistent across the entire surface and the colour across the entire structure is homogenous. That the tholus 
is absent may imply that this particular species is incapable of the proposed frequency discrimination (or whatever other function the tholus may serve).

The intermediate tholus was defined to be an irregularly shaped dark brown area on the outer membrane with jagged edges and has an irregular circular shape. It is not necessarily elevated from the outer-membrane and appears more rigid and only semi-membranous in nature (LeCerf 1926). Minet and Surlykke (2003) suggest that the tholus is a fragment of the anterior cubital vein that has been enveloped by the outer membrane. If this is indeed the case, then I would postulate that the intermediate form of the tholus represents a stage at which the transition from a fragment of the cubital vein to a secondary vibrating membrane has simply not fully developed. Perhaps this allows for minimal frequency discrimination as previously mentioned its irregular shape would not be ideal for standing wave vibrations. A well-defined tholus has an ovular shape with both the outer, inner (tholus), and chitinous ring all possessing rounded edges which may serve to decrease interference in a standing wave. It ranges in location on the inner membrane from a more anterior position, which is true in most cases, to a more centered location. The tholus appears more membranous and the chordotonal attachment scar is much more visible (LeCerf 1926; Minet and Surlykke 2003).

\section{Forewing Veins}

In this work, I considered the inflation of three veins: The cubital vein, the subcostal vein and the anal vein, although the focus was on the subcostal vein as it was the most common of the inflated veins and often had a much higher ratio of inflation. In general, the inflated veins are directly associated with the VO via the tympanal air chamber underlying the outer membrane 
and tholus at the base of the forewing (LeCerf 1926; Bourgogne 1951; Minet and Surlykke 2003) and it is therefore I propose they play a role in hearing.

LeCerf (1926) postulated that for the basal condition of VO, the cubital vein is both uninflated and a single unit, similar to the other forewing veins. Otero (1990) also concurred that in atympanate species there was no enlargement of the cubital of subcostal veins. I used these previous studies, as well as observations of my own and I applied this definition to my basal condition, all three veins must be uninflated. For my second condition, only the subcostal vein is enlarged, as determined by the forewing-to-hindwing vein width ratio. I established a cut-off ratio of three. This value was chosen by observing the forewing-to-hindwing vein width ratios in atympanate species. Only tympanate species have a ratio greater than three, as shown in Figure 2.7. For my final category, all three forewing veins are enlarged, in that the widths of all three forewing veins are at least three times the widths of the respective hindwing veins. The difference between my categories and those LeCerf established is that he only examined the inflation of the cubital vein and did so only as a means to deduce the stage of development of the VO itself. Instead, I examined all three forewing veins and considered their sizes separately from the VO's development. Otero (1990) examined forewing vein inflation of the subcostal and cubital veins. However, his criteria for classification were unclear.

Because the far most common inflation seen in my study was the subcostal vein, I sought to determine if there was any physical connection between the VO itself and the apparent bulging of the subcostal vein. By injecting the subcostal vein using toluidine blue dye (tolonium chloride) it was determined that this vein is continuous with the VO. This is corroborated with previous findings that state that the tympanal air chamber is continuous with the subcostal, cubital and anal veins (Minet and Surlykke 2003). Thus, it is necessary to consider the possibility 
that this vein is relevant for hearing in butterflies. Further, for the specimens that exhibit cubital vein inflation, I observed that the subcostal and anal veins were similarly enlarged. Thus, it is my opinion that the variations of all three veins should be considered for their possible roles in butterfly hearing.

In 2006, Murillo-Hiller put forward the hypothesis that the inflated subcostal vein present in Ypithimoides castrensis (Nymphalidae: Satyrinae) acts as an amplifier to a small structure called the callus that produces clicking sounds. Inside of the inflated subcostal veins is a network of trachea, or scleritized divisions, that the author suggests vibrate to amplify sounds being produced. They hypothesized the more chambers the vein possesses, the more the sound is amplified (Murillo-Hiller 2006). To consider the possibility of this hypothesis, I conducted SEM imaging (Tescan Vega-II XMU VPSEM) on Au-coated specimens, utilizing their description of the callus appearance and location. However, the callus was not found on any of the satyrines with inflated veins in this work. Also, most butterflies are not known to produce sounds. Therefore, I considered alternative possibilities for the role of inflated forewing veins in satyrines.

Butterflies have been shown to listen to lower frequency sounds in the sonic range (Yack et al. 2000; Mahony 2006; Lane et al. 2008). Insects have an inherently difficult problem when it comes to sound detection at lower frequency because of their small size, localization can be problematic when the body size of the insect is smaller than the incoming sound (Bennet-Clark 1998; Michelsen 1998; Robert 2005). In order to optimize call reception, it would be beneficial to somehow match the detectors auditory system with a frequency response matched to the carrier frequency of the call. For this reason, I hypothesize that the inflated forewing veins are acting as sound receivers, or resonators, to help detect biologically relevant sounds. It has been 
shown in other insects that associated trachea can act as band-pass filters, behaving as resonating cylindrical tubes with a resonance frequency inversely proportional to the length of the inflation (Nocke 1975). The size and shape of associated trachea with the auditory system in bushcrickets can range from having little impact on the tuning and directionality, to being the most important factor concerning these traits (Heinrich et al. 1993; Shen 1993; Kalmring et al. 1995; Rajaraman et al. 2013). The interaural distance of some of the butterflies studied is shorter than the wavelengths of the sounds they are purportedly listening to. The inflated pockets of the subcostal vein could act to increase interaural distance to extend the hearing range to lower frequencies, in a similar way to bushcrickets (Heinrich et al. 1993). This hypothesis is supported by the observation that the largest of the butterflies, such as Caligo, do not possess inflated subcostal veins. Although it is possible to calculate the resonance frequencies of the inflated forewing veins of the specimens in this study, these calculations are beyond the scope of the present work.

Another possible function is that the forewing vein inflations are acting as Helmholtz resonators. Even if the incoming frequency is low, the harmonic transient should be detectable if the auditory system had a component that could act as a high quality resonator (Hartley and Stephen 1992). In the Hemisaga genus of tettigoniids it is proposed that the slit cavities associated with the tympanal ears found on their tibia act as coupled Helmholtz resonators. Helmholtz resonators are known for having a high quality (or high Q) factor. This means that the rate at which the oscillations from the sound diminish is slow (Stephen and Bailey 1982; Hartley and Stephen 1992). If the forewing vein inflation acted as Helmholtz resonators, they would extend the overall duration of the incoming sound, increase the number of cycles in each transient frequency (which would be detectable by the VO) and perhaps improve frequency discrimination. In this possible function of vein inflation, the subcostal veins act as resonators to 
amplify the sounds being detected. Although the results in this work suggest that forewing vein inflation is important for hearing, further work is necessary to more thoroughly consider the possible function.

\section{Membranous ampulla}

In this work, I observed the membranous structure, which I denoted the "MA," in two species of Myscelia. Although this structure has been previously observed in Hamadryas, I observed this structure in a mute species for the first time. Further, this is the first report of a photo- or temperature-sensitive structure associated with an ear in a butterfly. As such, the function of this structure is wholly unknown and only the results in the present work are available to support or oppose any hypotheses of its function. Thus, I now present some possibilities for the function of the MA and discuss whether my results support or oppose these hypothetical roles.

There is evidence that tympanal hearing organs in both cicadas and locusts are affected by changes in temperature. In both examples, with increased temperature the frequency of maximum hearing sensitivity is shifted to higher frequencies (Oldfield 1988; Fonseca and Correia 2007). Therefore, I considered the possibility that the function of the MA in Myscelia is to regulate the change in pressure in the tympanal cavity of the VO caused by either a change in ambient temperature or by local heating caused by direct sunlight. For example, in the Cloud Forest of Monteverde, Costa Rica, the difference in ambient temperature between the canopy and above the tree-line can exceed $25^{\circ} \mathrm{C}$. This is approximately a $10 \%$ increase in absolute temperature, which would result in a pressure increase of $10 \%$ (ideal gas law). Thus, I propose 
that when a butterfly detects bright light or high temperatures, the MA outwardly inflates to increase the tympanal cavity volume by an appropriate amount (10\% in this example), thereby keeping the pressure constant. Similarly, I postulate that a rapid decrease in ambient temperature could cause a rapid decrease in tympanal pressure. Hence, when a butterfly detects a cold stimulus, the MA depresses into the forewing to decrease the cavity volume and maintain the tympanal pressure. Finally, the absence of any light does not pose any risk of an acute pressure change, which is consistent with my observation that low light is not an active cue. Thus, I find that it is a reasonable possibility that the function of the MA is to prevent ambient temperature or local heating-induced, rapid pressure changes to tympanal cavity.

Another possible function of the MA in Myscelia is to extend the hearing range to lower frequencies by acting as a resonance chamber. This is similar to the hypothesized role of vein inflation discussed in section 2.4.1. It is possible that the MA inflates during periods of bright light and higher temperature, i.e., during the daytime, because that is when the butterflies require this extended hearing range. For instance, if butterflies use their hearing to avoid predation by birds during the day, then it is unnecessary to listen for bird flight sounds at night. However, the advantage of deflating the structure at night, rather than having a permanently inflated MA, is not immediately clear. As such, it remains uncertain whether the role of the MA is to regulate the tympanal cavity pressure, to extend the hearing frequency range or, perhaps, some other function. However, it is clear that further research on this novel structure is required to consider its observed temperature and photosensitivity. 


\subsubsection{How are the variations of butterfly hearing organs distributed in the family Nymphalidae?}

Libytheinae and Danainae as well as Limenitinae and Heliconiinae all had no instances of VO found in the species examined. These four subfamilies may represent the basal condition of their respective clades. Plotting these traits onto a phylogeny also indicates that different subfamilies possess different stages of VO condition. For example, the Nymphalinae sub-family has representatives that are atympanate, have intermediate VOs and some well-defined VOs. In certain sub-families like Satyrinae, where there were over twenty species examined, all had welldefined VOs. When the traits were looked at on the scale of tribe (as can be seen in the table presented earlier in this chapter) the state of the VO was much more consistent (Table 2.2). When the tholus classifications were plotted onto the same phylogeny the results were similar in that the different appearances of the traits were sporadic but not necessarily in the same distribution we saw for the VO itself (figure 2.7). For example, the sub-family Satyrinae, which we previously saw had only well-defined VOs, has all stages of development for the tholus, that is, absent, intermediate and well-defined. From these phylogenies we can see there is no clear trend for the presence of absence of VOs and its structures, at least at this scale.

Forewing vein inflation is a trait by which the Satyrinae subfamily has been characterized and recognized (Kristensen 2003). However, I now find that this is a large misconception since there are entire tribes within Satyrinae that do not possess inflated veins, such as Morphini and Brassolini. In addition to this, I have shown multiple cases from the subfamily Biblidinae that possess this feature in the extreme. In particular, forewing vein inflation is widespread in the tribe Satyrini. Although inflated forewing veins were only found in two out of eleven subfamilies (Satyrinae and Biblidinae), this is a radical change from the previous assertion that this trait is characteristic of satyrines only. According to the most recent phylogeny, the subfamilies 
belong to different clades within Nymphalidae. Therefore the parsimonious interpretation appears to be that this trait developed twice. Within the subfamily, not all representatives examined were found to have forewing vein inflation. Even on the tribal level there was variation as to who had inflated forewing veins and who did not. This would seem to imply that perhaps different pressures on different members of each tribe impact whether the trait developed more so than the proximity of the relationships.

\subsubsection{Does sexual dimorphism occur in the Vogel's organs of Nymphalidae?}

If sexual dimorphism is present in the VOs of Nymphalidae, it would support the hypothesis that males and females listen to different acoustic stimuli. Such variation could arise from differences in predators or from gender-linked conspecific communication behaviours. For example, if one sex typically calls while the other listens, then the ears should differ by gender. Conversely, in a case where there is no conspecific communication and where both sexes face the same predation threats, then we would expect to observe that the tympanal hearing organs are conserved between males and females. There are two ways in which sexual dimorphism in auditory systems can manifest. The first is a mismatch between the calling frequency of the sender and the frequency of best detection of the receiver. The second, on which I will focus, is a difference in gross morphology. Both types of sexual dimorphism can be observed simultaneously, such as has been reported for the tettigoniid (Bailey and Romer 1991). In this example, females possess an associated tracheal structure to enhance the reception of certain frequencies. This tracheal structure is not present in male tettigoniids. Further, the females are able to detect a wider range of frequencies with lower thresholds than their male counterparts (Bailey and Romer 1991). Female tettigoniids also have a mismatch in best hearing versus the 
calling frequency of the males. The reason for this mismatch remains uncertain, but one possible explanation is that it may assist with predator avoidance (Bailey and Romer 1991). As another example, certain praying mantids possess a single tympanal hearing organ on their metathorax. Both the gross morphology and the tuning of these organs vary significantly between males and females (Yager 1990, 1999). Another example of sexual dimorphism of ears is seen in the gypsy moth. Male gypsy moths face predation by echolocating bats whereas the females do not (Cardone and Fullard 1988). As a result of their varied predation pressures, the females' optimum detection frequency is much lower than that of the males. Furthermore, the females' ears have much lower sensitivities, which indicates that there has been a degeneration of their ears (Cardone and Fullard 1988). Hence, both gross morphology and physiological measurements can provide information on sexual dimorphism. In this section, I consider the morphological variation between the hearing organs of male and female butterflies.

This work examined the relative sizes of the VOs of Cercyonis pegala, Coenonympha tullia, and Enodia anthedon. There was no significant difference found in the size of the VOs between males and females in these species. This is further supported by Mahony (2006) who found no sexual dimorphism in the VO of Cercyonis pegala. These species have never been shown to use conspecific communication, nor is there any evidence that they occupy different habitats (Layberry et al. 1998). Thus, my result that no gross morphological sexual dimorphism is present is consistent with the present understanding of communication behaviours and habitats for these species. However, it remains to be tested whether sexual dimorphism is present in the tuning or the sensitivities of their VOs. There exists some species of satyrines such as Oeneis chryxus that exhibit sexual dimorphism, not in size, but in colouration (Layberry et al. 1998). More interestingly perhaps is they also display differing preferred habitats between sexes. Males 
prefer rocky high elevation ridge tops near tree lines, whereas females prefer grassy meadows (Clayton and Petr 1992). Also interesting is that males participate in territoriality behaviours while females do not (Clayton and Petr 1992). In this study, I only had access to two males of this species and so no exploration into sexual dimorphism in this species was possible. It would be interesting in the future to examine whether this species, who displays sexual dimorphisms in appearance and life history, also displays sexual dimorphism in its VO.

\subsubsection{What is the morphological variation of hearing organs and associated structures within the tribe Satyrini?}

In order to investigate the $\mathrm{VO}$ on a smaller scale than across the entire family of Nymphalidae I chose to examine the tribe Satyrini which exists in the subfamily Satyrinae. In particular I chose to examine those of the tribe Satyrini which are found within Canada. As these butterfly species all exists within the tribe Satyrini we know they are closely related phylogenetically (Peña and Wahlberg 2008). The Satyrini that exist within Canada also are distributed into a wide variety of habitats, and exhibited markedly different life histories. For example, Coenonympha nipisquit commonly known as the Maritime ringlet, only resides in saltwater marshes in Quebec and New Brunswick at latitudes within $46^{\circ} \mathrm{N}$ and elevations near sea level (Layberry et al. 1998). Another example would be Oeneis polixenes which has most populations living in northern Canada at latitudes above $55^{\circ} \mathrm{N}$. This species has populations which inhabit alpine meadows in elevations ranging from 1300-2500 $\mathrm{m}$ above sea level (Troubridge and Parshall 1988). Oeneis chryxus displays an interesting life history difference in that it displays biennialism (It takes two summers to reach maturity) which can be explained by its high altitude living and relatively short summers compared to its temperate counterparts (Clayton and Petr 1992). The variations between occupying grasslands and meadows or 
coniferous forests also exists, as well as the strata they occupy (grassland species tend to fly near the ground as adults, while forest dwelling species rarely fly or land below $2 \mathrm{~m}$ ) so there is much diversity in terms of the habitat being exploited with the Canadian Satyrini (Brussard and Ehrlich 1970; Troubridge and Parshall 1988; Layberry et al. 1998). Finally, Canadian Satyrini were more easily accessible to me for this research.

Despite the differences that were found in terms of habitat, elevation, temperatures experiences etc. there were no differences found in terms of $\mathrm{VO}$ development or tholus development. All of the Satyrini examined had well-defined VO and tholus. Though some variation was found in terms of forewing vein inflation, as I talked about in the forewing vein section, I believe this could have more to do with overall body size than other factors. From my observations in this study, it would seem that the development of VO is not necessarily related to habitat. The Canadian Satyrini that were examined belong to a wide range of elevations, temperatures, and habitat, which would expose them to all kinds of different selection pressures, both in terms of environmental stressors and predators. Even so, they exhibit very similar VOs. In the exact same meadows and forests in which I caught some of my specimen, I also caught completely atympanate butterflies as well. This is confirmed through outside reports of butterfly habitat of atympanate species (Layberry et al. 1998). This indicates that these atympanate butterflies are exposed to similar selection pressures, and yet they lack ears. Therefore, any explanation of the function of hearing in butterflies must account for this observation that these closely related species all have well-defined hearing organs, whereas cohabitant species from other taxa do not. 


\subsection{Conclusions}

This work examined the morphological variation of butterfly hearing organs and associated structures. Criteria have been established to categorize the levels of development of VOs and tholi as absent, intermediate or well-defined. The forewing veins associated with the VO are enlarged, relative to the respective hindwing veins, for some tympanate species. This work establishes three categories of forewing vein inflation: non-inflated, subcostal vein inflation and inflation of all three forewing veins (subcostal, cubital and anal veins). In general, forewing vein inflation is only observed in smaller specimens. Further, the MA, discussed in this chapter, is the first known example of a temperature- or light-sensitive accessory to a butterfly hearing organ.

Next, this chapter discussed how the variations of butterfly hearing organs are distributed in the family Nymphalidae. Certain subfamilies, such as Lybithinae and Danainae may represent the basal condition and others, including Satyrinae and Bilidinae, represent more derived hearing organs. Although more than one level of VO or tholus development were present in certain subfamilies, the results were more consistent on a tribe level.

This work did not find evidence of sexual dimorphism of the hearing organs or the associated structures in the family Nymphalidae. However, this component of the research was limited to three species. Since there over 6000 species in this family, these should be considered only as preliminary results.

Between closely related Canadian species in the tribe Satyrini there was no observed variation in the VOs or the tholi of the specimens examined in this work. There was some observed variation in the forewing vein inflation. However, these variations are likely linked to 
total body size, since only small butterflies show forewing vein inflation. The species in this work have very different life histories and habitats and yet possess very similar hearing organs. This may indicate that Satyrini species have hearing organs from a common ancestor and that hearing organs are sufficiently useful that they are conserved under a variety of selection pressures. 


\section{Neurophysiological Investigations into the Avian Hypothesis}

\subsection{Introduction}

Insect ears have been shown to function in conspecific communication, predator avoidance, and host detection (Yack and Hoy 2003; Yack and Dawson 2008). Hearing organs are typically identified based on three criteria: morphology, behaviour and physiology (Yack and Fullard 1993b). With respect to hearing in Nymphalidae, the VO morphologically resembles a tympanal ear because it possess the necessary characteristics, membrane capable of vibration, underlying air sac, and affiliated chordotonal organs (Yack and Fullard 1993b). Behaviourally we do not have much evidence for hearing as of yet, at least within Nymphalidae (Frings and Frings 1956; Ribaric and Gogala 1996; Mahony 2006). Physiologically we know that certain butterflies, such as $M$. peleides respond to low frequency sounds in the range of $0.5-10 \mathrm{kHz}$ with optimum hearing at $2 \mathrm{kHz}$ (Yack et al. 2000; Mahony 2006; Lane et al. 2008; Lucas 2008; Lucas et al. 2009).

Presently, the hearing organs in Nymphalidae butterflies are known to fit the morphological data (see Chapter 2). There are a few studies that have recorded a neurophysiological response to auditory stimuli from various butterfly species (Ribaric and Gogala 1996; Lane et al. 2008; Lucas et al. 2009). Therefore, further investigation is required to conclusively identify VOs in butterflies as true hearing organs and to ascertain the function of hearing in butterflies. Since diurnal butterflies such as M. peleides are not under predation stress from bats and since there is no evidence of conspecific communication, one must consider what sounds are present in its natural environment that match this hearing range. One hypothesis is that butterflies (and other insects) use their ears to detect bird flight sounds and/or calls (Ribaric 
and Gogala 1996; Mahony 2006; Lane et al. 2008). There are 3 predictions that can be tested to support this hypothesis:

1. Birds produce sound during flight

2. Insect ears are capable of detecting these sounds

3. Insects respond behaviourally to bird flight

The purpose of this chapter is to explore the first two predictions by building upon previous studies. I will briefly explain the previous research that has been conducted and then explain my goals.

\subsubsection{Birds produce sounds during flight}

My first prediction is that predatory birds produce sounds during flight. If insects such as butterflies use their ears to detect birds, then insectivorous birds must produce sounds as a by product of their movements when capturing an insect. Jacobs et al. (2008) speculated that the rustling sounds produced by foraging birds falls within the $5-20 \mathrm{kHz}$ range. They observed a variety of attack styles on birds such as ground gleaning where the bird actually dives into a bush which would produce rustling sounds (Jacobs et al. 2008). It has been shown that birds produce flight sounds that are also low-frequency and broadband (Mahony 2006; Lane et al. 2008). Further studies on the Eastern Phoebe (Sayornis phoebe) and the black-capped chickadee (Poecile atricapillus) confirmed that birds produce flight sounds in their natural environments when hunting an insect prey item (Fournier 2011; Fournier et al. 2013). The eastern phoebe's flight sounds were found to be broadband ( $>50 \mathrm{kHz}$ at $-20 \mathrm{~dB}$ ) with a peak frequency less than 1 
$\mathrm{kHz}$, which is well within the hearing range of the butterfly ear. These studies were conducted in a field environment, which meant some of the important preliminary data such as the distance from the microphone to the bird, as well as the direction of flight had to be estimated. Therefore, my first objective is to record and analyze passive sounds produced by the flight of a trained cockatiel in the laboratory. The purpose of this was two-fold: first, I was looking to measure the change in overall sound pressure level (the volume) of bird flight sounds at increasing distances and, second, I wanted to analyze how the flight sounds of this larger, tropical bird compare to those previously determined in smaller, local bird species.

\subsubsection{Insects are capable of hearing bird flight sounds}

Fournier et al. (2013) used sound play back recordings of bird flight and showed that noctuid moth ears, as well as M. peleides ears responded neurophysiologically to these sounds. Jacobs et al. (2008) demonstrated that a diurnal moth, Helicoverpa armigera, responded neurophysiologically to frequencies of rustling branches $(1-60 \mathrm{kHz})$ and also responded behaviourally, i.e. escape manoeuvres, to acoustic stimulation at similar acoustic levels as those produced by a bird during ground gleaning behaviour. I wished to take this one step further, to determine if a moth ear would respond to the passive flight sounds of a live bird flying (see below). Therefore, my second objective was to record the neurophysiological response of an eared insect to a bird. I chose to test these predictions using noctuid moths, rather than butterfly specimens, for their ready availability. This allowed me to conduct pilot studies without having to navigate the difficulties that arise when working with butterfly dissection and very limited specimens. First, I collected audiograms from the moth preps to determine whether bird flight 
sounds are within the hearing range of $T . n i$. Subsequently, I recorded the neural response of $T$. $n i$ to a live bird in the laboratory.

My final prediction is that moths in their natural environments can hear bird flight sounds. It is insufficient to test that moths physiologically respond to a trained bird in a laboratory setting. This is because it is generally agreed that insects experience their natural environments quite differently than they experience a laboratory setting (Romer 1993; Forrest 1994). Further, there are reported instances of insects that use other sensory organs to detect and to evade predatory birds, such as the descending contralateral movement detectors in the eyes of some locusts (Santer et al. 2012). It is therefore possible that multimodal stimuli (e.g., vision and hearing) are required to elicit the natural evasive response of an insect. As such, it is important to complement laboratory studies by conducting physiological and behavioural experiments outdoors (Rheinlaender and Romer 1986; Kostarakos and Romer 2010). For example, outdoor rigs have been used to answer specific questions concerning directional hearing in grasshoppers and field crickets that could not have been answered in a laboratory environment (Gilbert and Elsner 2000; Kostarakos and Romer 2010). Thus, my objective was to develop a portable electrophysiology rig and to collect measurements in a variety of locations and habitats, based on previous designs in the literature (Rheinlaender and Romer 1986; Romer and Bailey 1986; Kostarakos and Romer 2010). This work contains preliminary results collected on the constructed rig and discusses the possibility to use such a portable workstation to test whether eared insects in their natural environments hear bird flight sounds.

An earlier study (Fournier 2011) showed that moth ears responded to playbacks of bird flight. I attempted to determine if a moth prep would respond to a live bird flying in the lab. This represents a pilot study, and therefore, I am reporting mostly general observations. 


\subsection{Materials and Methods}

\subsubsection{Objective 1: Record bird flight sounds in the laboratory}

To determine whether birds produce sounds during flight, total sound pressure level measurements and audio recordings were collected from a live bird during flight. Because of the preliminary nature of this pilot, we chose a domesticated bird for the measurements. A 7-yearold male domestic cockatiel, Nymphicus hollandicus, "Nibbler," was obtained from Amanda Lindeman, a member of the Yack lab. The cockatiel was trained to fly in a straight path across the laboratory, on cue, by using food as a reward. The bird was released from a fixed position, marked with masking tape on the floor, and flew in a straight line toward its cage, where the food reward was placed. Several distances $(0.3,0.5,1,2$ and $5 \mathrm{~m})$ were measured perpendicular to the midpoint of the flight-path using a measuring tape. At each distance, the bird flight sound levels were measured during three separate flybys, for a total of fifteen measurements, with a Bruel and Kjaer Type 2239 sound pressure meter (A weighting - RMS, Naerum, Denmark).

Next, in order to characterize the audio characteristics of bird flight sounds, recordings were collected using an Earthworks Qtc40 (Milford, NH, USA) microphone (4 Hz- $40 \mathrm{kHz} \pm 1$ $\mathrm{dB})$. The microphone was placed $0.3 \mathrm{~m}$ perpendicular to the mid-point of the cockatiel's flight path. The microphone was attached to a Fostex FR-2 data recorder (Gardena, CA, USA) and recordings were collected using a sampling rate of $88.2 \mathrm{kHz}$ as waveform audio files (.wav). These files were later analyzed using Raven Pro v. 1.6 software (Charif et al. 2010) to characterize the temporal, spectral, and intensity features of bird flight sounds. During these recordings, video recordings were also collected. The video recording included an audio track (albeit of relatively low quality). The audio tracks of the two recordings (video and audio-only) 
were synchronized by examining, in slowed playback, a portion of the recording in which the experimentalists (i.e., my colleagues and I) were speaking. Once synchronized, the audio characteristics during the different components of the bird's flight (upstroke, downstroke, full flight cycles, approach, perpendicular flight and flight away from the microphone) could be analyzed. The bird flight sounds and chirps were converted from the time domain to the frequency domain by a Discrete Fourier Transform (DFT) using a temporal grid of 2.67 ms with a 50 per cent overlap, a frequency grid resolution of $188 \mathrm{~Hz}$, and a DFT size of 512 samples in a Hann window function.

\subsubsection{Objective 2: Neurophysiological response of moth ears to a bird in flight}

The purpose of these recordings is to determine whether the moth, Trichoplusi ni, can hear a live bird in flight. The purpose is additionally to consider the hearing threshold of the moth's hearing at different distances from the bird and at different frequencies. In this work, moths were dissected and mounted on a physiological rig in the laboratory. The domestic cockatiel Nibbler (the bird used in Section 3.2.1), was flown in a straight line past the physiology rig, at a distance of $0.3 \mathrm{~m}$ from the moth at the midpoint of the flight path. Audio recordings of the bird flight sounds were recorded using the same setup as described above, with the microphone positioned $<1 \mathrm{~cm}$ from the moth, to ensure the recording is sufficiently similar to the sound at the moth's position. Concurrently, the physiological response of the moth's auditory nerve was recorded. 


\section{Specimens}

Pupae of the moth Trichoplusia ni (Noctuidae) were obtained from the Insect Production Unit of the Canadian Forest Service in Sault Ste. Marie. I placed the pupae in large glass jars on moist paper towels laid over Vermiculite (Perlite Canada Inc., Montreal). The specimens were maintained at $25^{\circ} \mathrm{C}$ in a greenhouse (Nesbitt Building, Carleton University) on the building's natural light cycle until they were used for experimentation. The specimens were used within one week of emergence. Both sexes were used for electrophysiological recordings.

\section{Dissection}

Using the methods described by Roeder (1969) and the dorsal dissection technique described by Fullard (1984), T. ni moths were dissected to expose the auditory nerve (IIIN1b). After the legs were removed, the moths were placed dorsal-side-up, on a small block of modeling clay and restrained the wings and abdomen using staples. I made small grooves in the clay to accommodate the body and to allow sound stimuli to reach the tympanal organs. Using a paint brush, I removed the scales on the mesonotum (scutum and scutellum) and a shallow incision was made around the perimeter of the mesonotum. I then made two small incisions on each side of the thorax, medial to the forewing alula. The flight muscles were then removed to expose the thoracic ganglia and nerve branches, including the IIIN1b auditory nerve. The thoracic cavity was bathed in lepidopteran physiological saline to prevent desiccation (Paul 1973). 


\section{Electrophysiology}

Action potentials were recorded using an electrochemically etched stainless steel hook electrode. The IIIN1b nerve was hooked with the recording electrode and lifted slightly out of the saline bath. Once isolated, all excess saline was removed and the thoracic cavity was filled with silicone grease to prevent desiccation. Another stainless steel electrode was inserted into the moth's thoracic flight muscle to serve as reference electrode. Extracellular impulses were amplified with a Grass Instruments P-55 preamplifier (West Warwick, RI, USA), viewed on a Tectronix (Beaverton, ON, Canada) THS720A digital oscilloscope, and monitored using an A-M Systems, Inc. audio monitor (model 3300; Sequim, WA, USA). The electrical response of the auditory nerve and the audio recording of the bird flight sounds were collected with a Fostex FR2 data recorder (Gardena, CA, USA) on two channels in a waveform audio file (.wav) at a sampling rate of $88.2 \mathrm{kHz}$. By saving the data in a single file for each measurement, the neural response and the audio stimulus were synchronized. All files were later analyzed using Raven Pro (v. 1.6) software and Avisoft-SASLab Pro (v. 5.2). All neurophysiological recordings were performed within a Faraday cage lined with sound attenuating foam to reduce interference from electrical noise and echoing within the cage.

\section{Audiograms}

Auditory threshold curves (audiograms) were collected from $T . n i$ in order to confirm that our neurophysiological measurements were consistent with those reported by other researchers. Synthetic acoustic stimuli between $10-45 \mathrm{kHz}$ were broadcast as trapezoidal sound pulses (30 ms duration, $5 \mathrm{~ms}$ rise/fall, linear ramp). Broadcast sounds were shaped using PC Tucker Davis 
software (RPvdsEX, v. 5.4; Alachua, FL, USA) and synthesized by a Tucker Davis Technologies (TDT) digital signal processor (RX6 multifunction processor). Sound pulses were attenuated using a TDT PA5 programmable attenuator and broadcast from a calibrated Pioneer Ribbon Tweeter speaker (model ART-54F; Kanagawa, Japan), tested from $2-80 \mathrm{kHz}$. The speaker was placed $30 \mathrm{~cm}$ away from the preparation ipsilateral with the recording electrode. I tested the moths' hearing in the frequency range $5-45 \mathrm{kHz}$. The frequencies were broadcast in $5 \mathrm{kHz}$ intervals using a random order to prevent systematic bias. I measured the hearing threshold at each frequency by systematically attenuating the acoustic stimuli in $0.5 \mathrm{~dB}$ increments. The auditory threshold was defined as the lowest sound level at which neural spikes could be clearly heard through the audio speaker or seen on the oscilloscope in synchrony with the sound stimulus by two independent observers.

Analysis

The bird flight sounds were analyzed using the same method as described above for the recordings collected without moths. Nerve responses were analyzed using Avisoft SASS lab Pro. A neural burst was defined as the neural spikes elicited during one flight cycle (one downstroke and one upstroke), the interspike interval was the amount of time between two spikes within a burst, and the interburst interval was the amount of time between the final neural spike of a burst and the first neural spike of the subsequent burst. The relative latency was defined as the time period between the onset of the downstroke and the peak of the first neural spike. This measurement has reduced precision due to the nature of flight sounds beginning quietly and increasing to a maximum amplitude after a short rise time. 


\subsubsection{Objective 3: Constructing and testing a portable extracellular neurophysiology rig}

I developed a design for a portable electrophysiology rig based on an existing design in the Yack lab and from similar rigs in the literature (Rheinlaender and Romer 1986; Romer and Bailey 1986; Kostarakos and Romer 2010). The schematic diagram of my new rig design is shown in Figure 3.1. An adjustable tripod serves as the base of the rig. On top of the tripod, an aluminum base (18" x 6") supports two pieces of cold-rolled steel (4"). Two micromanipulators equipped with magnetic bases are mounted on the steel. Two battery powered LED lights (UltraBrite LED Booklights) with bendable necks are secured to the back of the aluminum base and provide illumination for dissections. A microscope is attached to the aluminum base by a metal rod and the preparation is placed under the microscope. Two micromanipulators are connected to a Grass P15 AC preamplifier via two BNC connectors. The signal from the preamplifier is split between a RadioShack mini amplifier/speaker (CAT.NO. 277-1008C), to aurally identify neural signals in real-time, and a portable oscilloscope, Syscomp GCR-101. The signal from the oscilloscope is then output to a laptop, HP Mini210-1000 to visualize and record the neural signals in the .csv file format. This visualization and data acquisition is done using the Syscomp Circuit gear software (v. 1.16). All components of the unit are in electrical contact, by copper wiring, with the ground. In the laboratory, this is achieved using the ground terminal in a building electrical circuit. In the field, this is achieved by connecting the ground wire to a 6 " steel rod inserted into the earth. Two Sony HandyCam HDR12 video cameras (Tokyo, Japan) are set on tripods approximately $3-5 \mathrm{~m}$ from the tripod and faced toward the preparation to capture the incoming and outgoing flight of the birds. A Sony ECM-MS907 $(100 \mathrm{~Hz}-15 \mathrm{kHz})$ microphone is connected to the video camera and clamped to the platform of the portable rig to record and monitor flight sound and behaviour simultaneously. An Avisoft CM16 microphone (2 
$-200 \mathrm{kHz}$ ) equipped with a windsock serves as the main recording microphone. This microphone is positioned as close to the preparation as possible in order to collect accurate recordings possible. The rig connects to a standard North American three-pronged power supply $(120 \mathrm{~V}, 60 \mathrm{~Hz})$. During early testing, the rig was powered in the laboratory using the local electrical utility (Hydro Ottawa) for convenience. During field testing, the rig was powered using a portable power unit (Motomaster Eliminator 300A Power Box). The portable rig was field tested in a clearing surrounded by trees and houses in Navan, Ontario. T. $n i$ specimens were dissected indoors and transferred to the portable rig. Black-capped chickadees were lured using bird calls and seeds. 


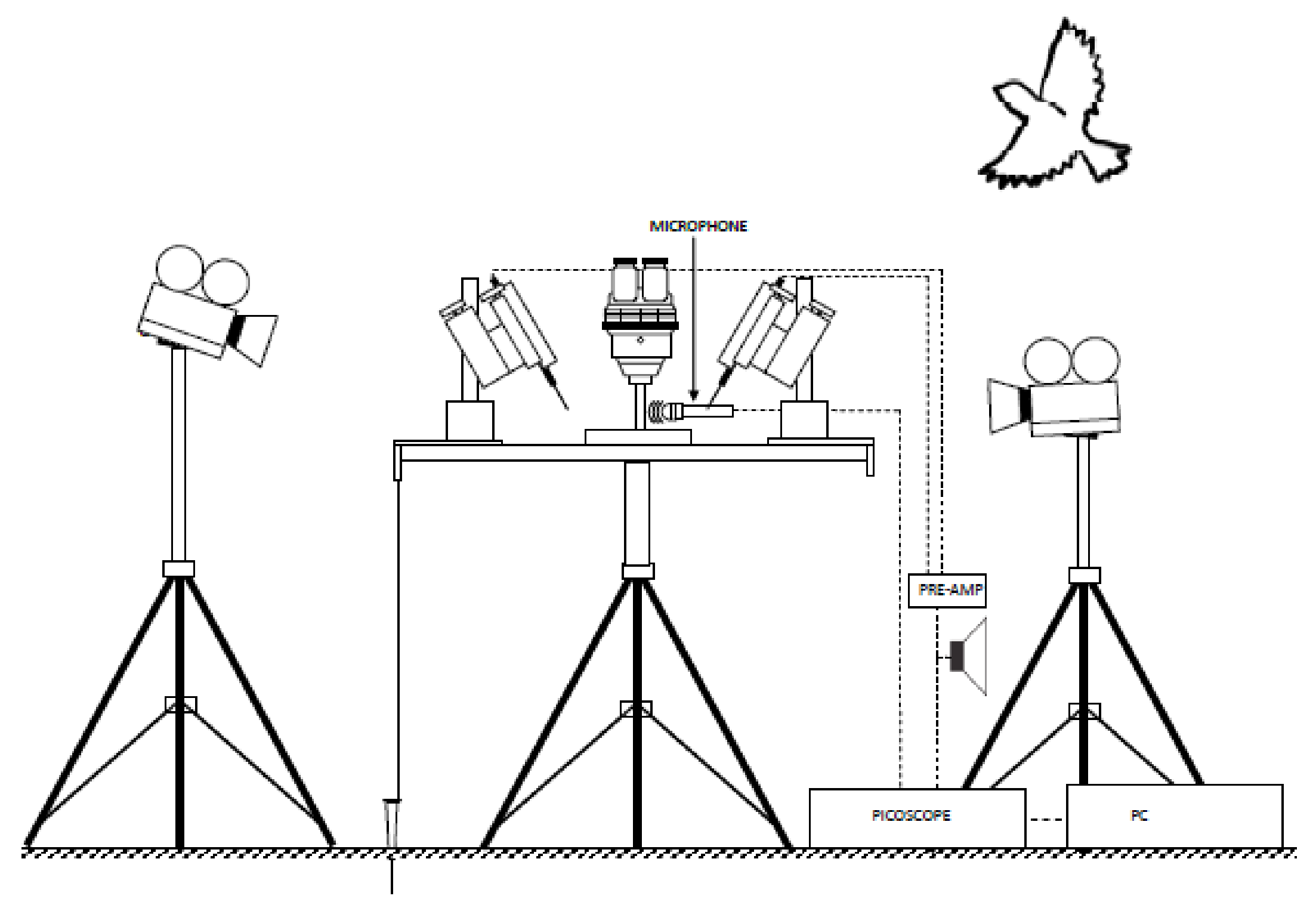

Figure 3.1 Schematic diagram of the portable electrophysiology rig. 


\subsection{Results}

\subsubsection{Recording bird flight sounds in the laboratory}

The results of sound level measurements of cockatiel flight collected at various distances $(0.3,0.5,1,2$ and $5 \mathrm{~m})$ are shown in Figure 3.2. The background sound levels in the laboratory were also measured at each of these distances for comparison. The average background sound level was $30.3 \mathrm{~dB}$ SPL ( $\mathrm{s}=0.4 \mathrm{~dB}$ SPL), which is shown as a noise threshold in Figure 3.2. These measurements show that cockatiel bird flight sound levels follow a linear trend with distance (when sound levels are plotted in $\mathrm{dB}$ SPL) with slope $-9.6 \mathrm{~dB} \mathrm{~m}^{-1}$. Further, the bird flight sound levels are above the background noise level, even at $5 \mathrm{~m}$, the largest distance in this study. 


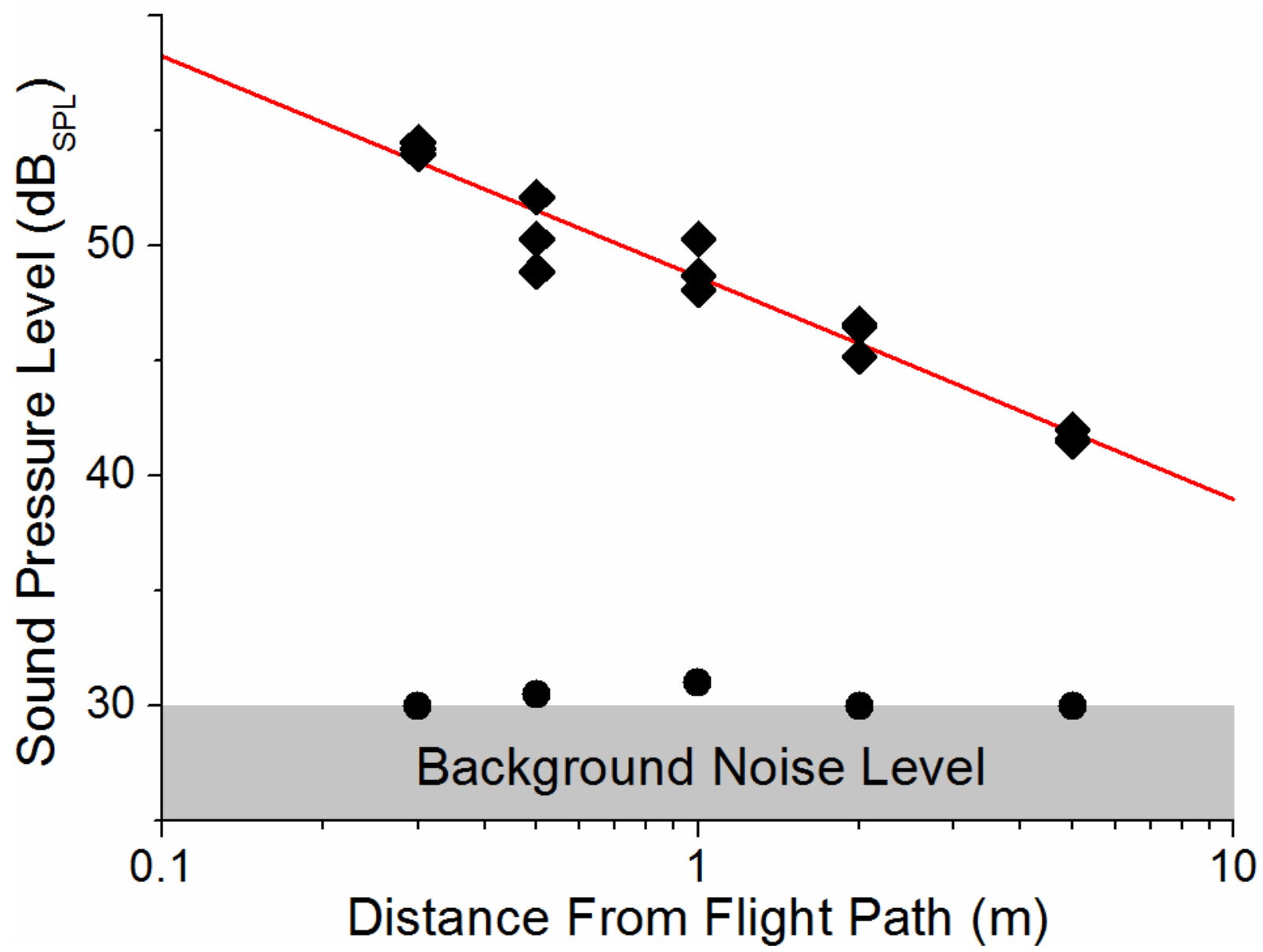

Figure $3.2 \quad$ Sound levels of cockatiel flight at various distances. Sound levels were measured during three separate flybys at each distance $(0.3,0.5,1,2$ and $5 \mathrm{~m})$ for a total of fifteen individual flybys. The background noise level was measured at each distance (black circles) and the median value is shown as a noise threshold. The bird flight levels were fitted using a linear regression, which is shown by a red line $\left(\mathrm{R}^{2}=0.946\right)$. 
Once the sound levels of bird flight were established to be well above the ambient noise levels, the audio characteristics were then examined. For these recordings, the microphone was placed $0.3 \mathrm{~m}$ perpendicular to the midpoint of the bird flight path. The waveform in Figure 3.3 shows that bird flight sounds are composed of short duration, broad-frequency pulses, similar to those reported by Fournier (2011) and Fournier et al. (2013). By synchronizing the video recording with the audio recording, it is observed that each cycle corresponds to one wingbeat cycle, composed of one complete downstroke followed by one complete upstroke. Using this definition, the average wing beat frequency is $9.9 \mathrm{~Hz}$ (standard deviation $=0.5 \mathrm{~Hz}, \mathrm{~N}=15$ ). The power spectrum (Figure 3.3) from isolated bird flight shows that the cues had a peak frequency of $1.0 \pm 0.5 \mathrm{kHz}$ (mean \pm s.d., $\mathrm{n}=5)$ and were broadband $(3.9 \pm 1.9 \mathrm{kHz}$ at $-10 \mathrm{~dB}$ below peak). Further, the cockatiel produces bird flight sounds at gradually decreasing intensity at frequencies $>20 \mathrm{kHz}$ (over the range $20-48 \mathrm{kHz}$, the intensity decreases by $16 \mathrm{~dB}$ ). 

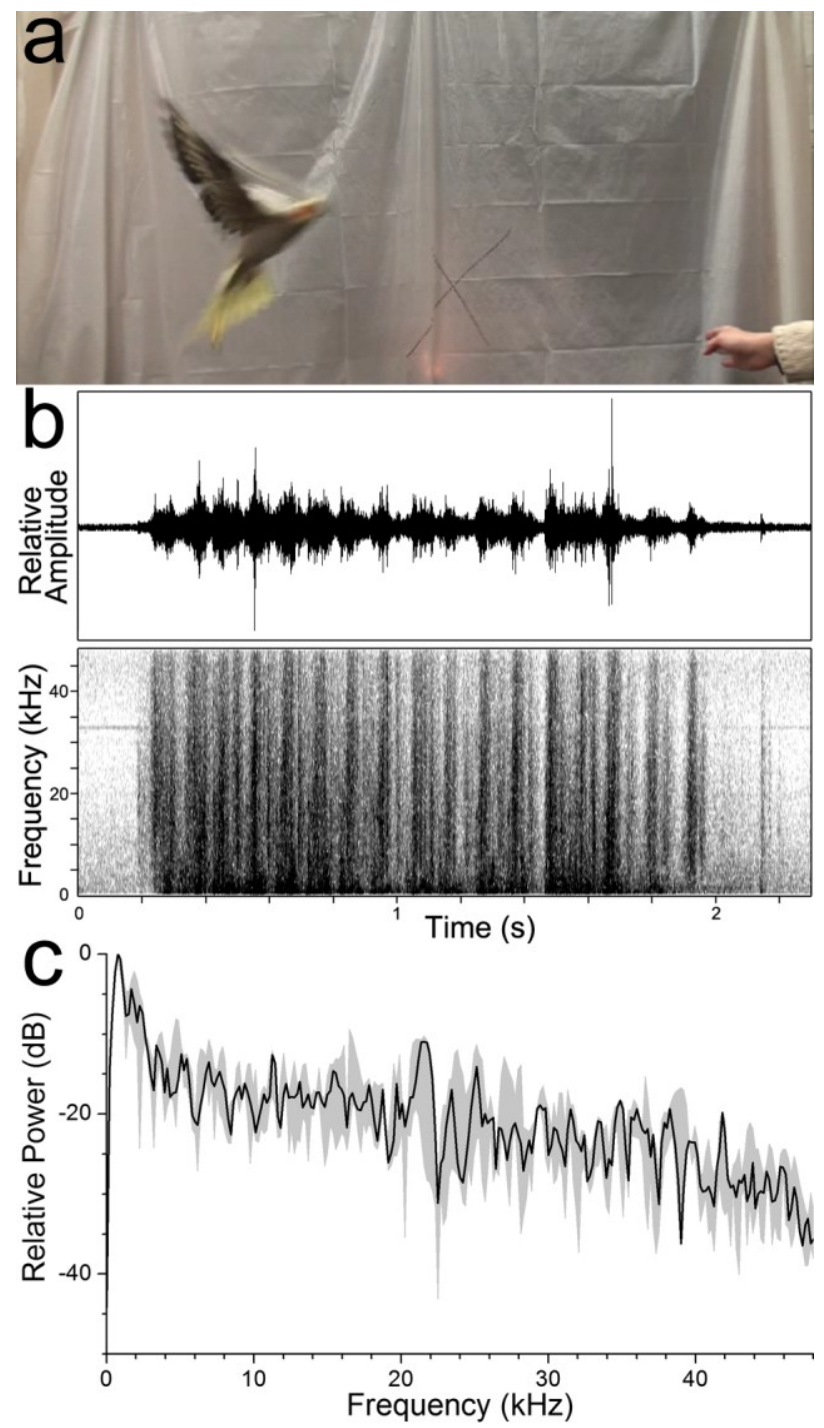

Figure $3.3 \quad$ (a) A frame-grab from the video of the cockatiel in flight, which was collected concurrently with audio recording. The microphone (out of frame) is $0.3 \mathrm{~m}$ perpendicular to the midpoint of the flight path. (b) The audio waveform of one flyby. (c) The power spectrum of cockatiel flight sounds. The solid black line shows the median value from five flybys and the shaded region indicates the first and third quartiles. 


\subsubsection{Neurophysiological responses of moth ears to a live bird in the laboratory}

The audiogram of $T . n i$ (Figure 3.4) shows that the hearing range of $T . n i$ overlaps with the frequency range of the bird flight sounds measured in the previous section (Figure 3.4). The hearing range of Morpho peleides is also shown for comparison, since it is a tropical species that is found in the same geographical region as wild cockatiels. 


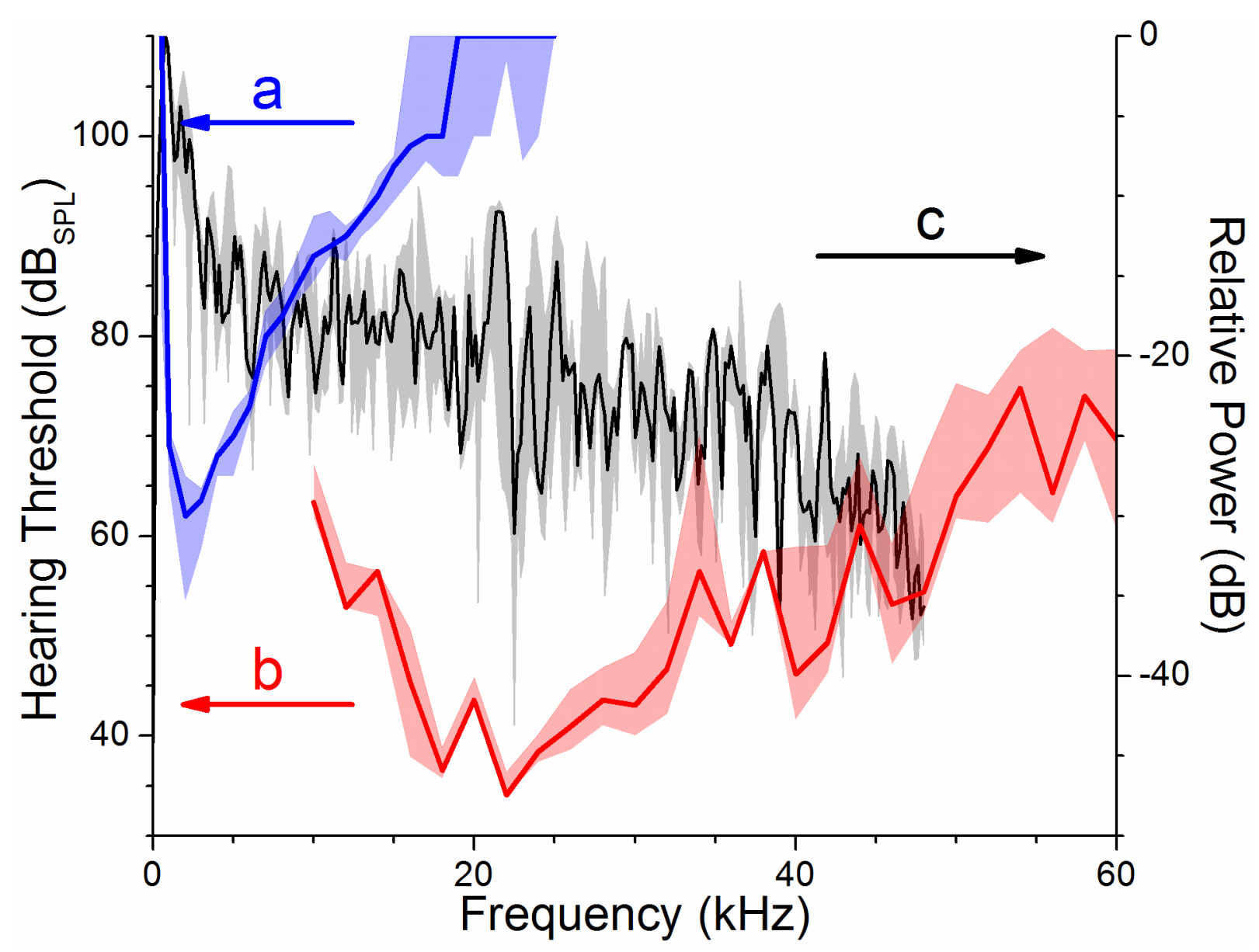

Figure $3.4 \quad$ (a) The hearing threshold of Morpho peleides is shown. The solid blue line shows the median values and the shaded blue region shows the first and third quartiles from 12 measurements (corresponds to left axis). This data is courtesy of A. Mikhail. (b) The hearing threshold of Trichoplusia ni. The solid red line shows the median values and the shaded red region shows the first and third quartiles from six measurements (corresponds to left axis). (c) The power spectrum of bird flight sounds (from Figure 3.3) is shown for comparison (corresponds to right axis). 
The audio waveform and the electrical response of the $T$. $n i$ auditory nerve during a cockatiel flyby is shown in Figure 3.5. From the synchronized video recording, the wing beat cycle components were matched to the audio waveform and are labelled on Figure 3.5(a). Following the onset of each downstroke, the moth response shows an average latency of $11 \mathrm{~ms}$ followed by a burst of neural spikes. On average, the nerve bursts are $33 \mathrm{~ms}$ in duration and composed of 6.6 spikes, as reported in Table 3.1. The neural response was only observed during downstrokes. 

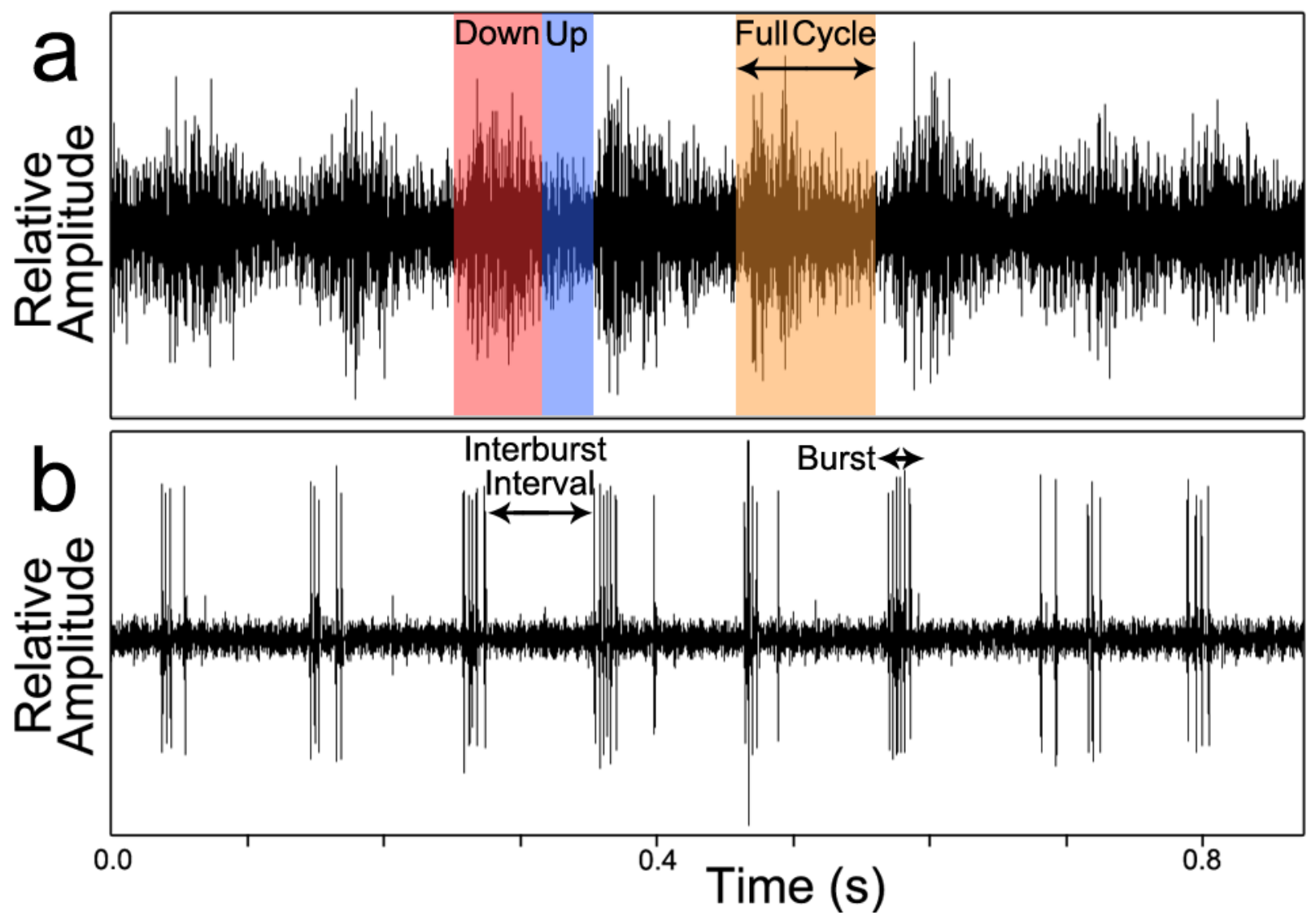

Figure 3.5 The cockatiel was flown such that the flight path's midpoint was $0.3 \mathrm{~m}$ from the physiological prep. (a) The wingbeat components (downstroke, upstroke and full cycle), as determined from the synchronized video, are labelled on the audio recording of the bird flight sounds. (b) The electrical signal from the auditory nerve of Trichoplusia ni. The spikes indicate the moth's response to the flight sounds of the cockatiel. The neural response components (interburst interval and neural burst) that are discussed in the text are labeled on the figure. 
Table 3.1 The neural response of the A1 cell of Trichoplusia ni was recorded during flybys $(30-100 \mathrm{~cm})$ of a cockatiel. The results were analyzed and are summarized below.

\begin{tabular}{|c|c|c|c|c|c|}
\hline Sex & $\begin{array}{l}\text { No. of } \\
\text { Flybys }\end{array}$ & $\begin{array}{c}\text { Mean Inter-Burst } \\
\text { Interval } \\
(\mathrm{ms})\end{array}$ & $\begin{array}{c}\text { Mean Inter-Spike } \\
\text { Interval } \\
(\mathrm{ms})\end{array}$ & $\begin{array}{c}\text { Mean Bursts } \\
\text { per Flyby }\end{array}$ & $\begin{array}{c}\text { Mean Spikes } \\
\text { per Burst }\end{array}$ \\
\hline q & 7 & 79 & 4.6 & 17 & 7 \\
\hline o & 8 & 100 & 5.1 & 14 & 5 \\
\hline$q$ & 10 & 73 & 4.7 & 15 & 8 \\
\hline$\sigma^{\lambda}$ & 7 & 86 & 5.2 & 14 & 6 \\
\hline$\widehat{0}$ & 7 & 85 & 5.3 & 12 & 7 \\
\hline Mean & & 84.6 & 4.98 & 14.4 & 6.6 \\
\hline Std. Dev. & & 10.1 & 0.31 & 1.8 & 1.1 \\
\hline
\end{tabular}


During our in-laboratory trials with a live cockatiel, the bird occasionally vocalized while it rested $3 \mathrm{~m}$ from the prep. In all of these cases it was later observed that the moth auditory nerve responded quite strongly to these vocalizations. There are no literature reports, to date, of the neural response of a moth to a bird chirp. Thus, I conducted frequency analysis of these chirps and show a preliminary look into the moths' responses to bird chirps (Figure 3.6). The chirps span 1-10 kHz, with harmonics at intervals up to $48 \mathrm{kHz}$ (which is the maximum I recorded). The associated power spectrum shows that most of the energy is found below $10 \mathrm{kHz}$. The moth response shows an average latency of $14 \mathrm{~ms}$ to the stimulus followed by 1-2 long bursts of nerve spikes. On average, the nerve bursts are $132.5 \mathrm{~ms}$ in duration and are composed of 54 spikes per burst.

The power spectrum (Figure 3.6b) from cockatiel chirps shows that the cues had a peak frequency of $5.6 \mathrm{kHz}$ (mean value, $\mathrm{n}=3$, s.d. $=0.0 \mathrm{kHz}$ from this limited number of measurements) and had bandwidth $=2.6 \pm 0.1 \mathrm{kHz}$ (mean \pm s.d. at $-10 \mathrm{~dB}$ below peak, $\mathrm{n}=3$ ), which is narrower than the wingbeat sounds discussed above $(c f .3 .9 \pm 1.9 \mathrm{kHz}$ at $-10 \mathrm{~dB}$ below peak). From the spectrogram in Figure 3.6b, there are several horizontal black bands, which are indicative of harmonic overtones. These bands are not perfectly straight and they are not perfectly horizontal. Therefore, the pitch of the chirp changes slightly with time. Consequently, the harmonic overtones are not clearly visible in the power spectrum in Figure 3.6b, which was calculated from the average of three entire chirps. Therefore, a power spectrum was calculated from only the very peak of a single chirp, as shown by the shaded region in Figure 3.7a. In this 'snapshot' power spectrum (Figure 3.7b), it is more apparent that cockatiel chirping consists of a fundamental frequency, the peak frequency at $\sim 5.6 \mathrm{kHz}$, and several overtones. 


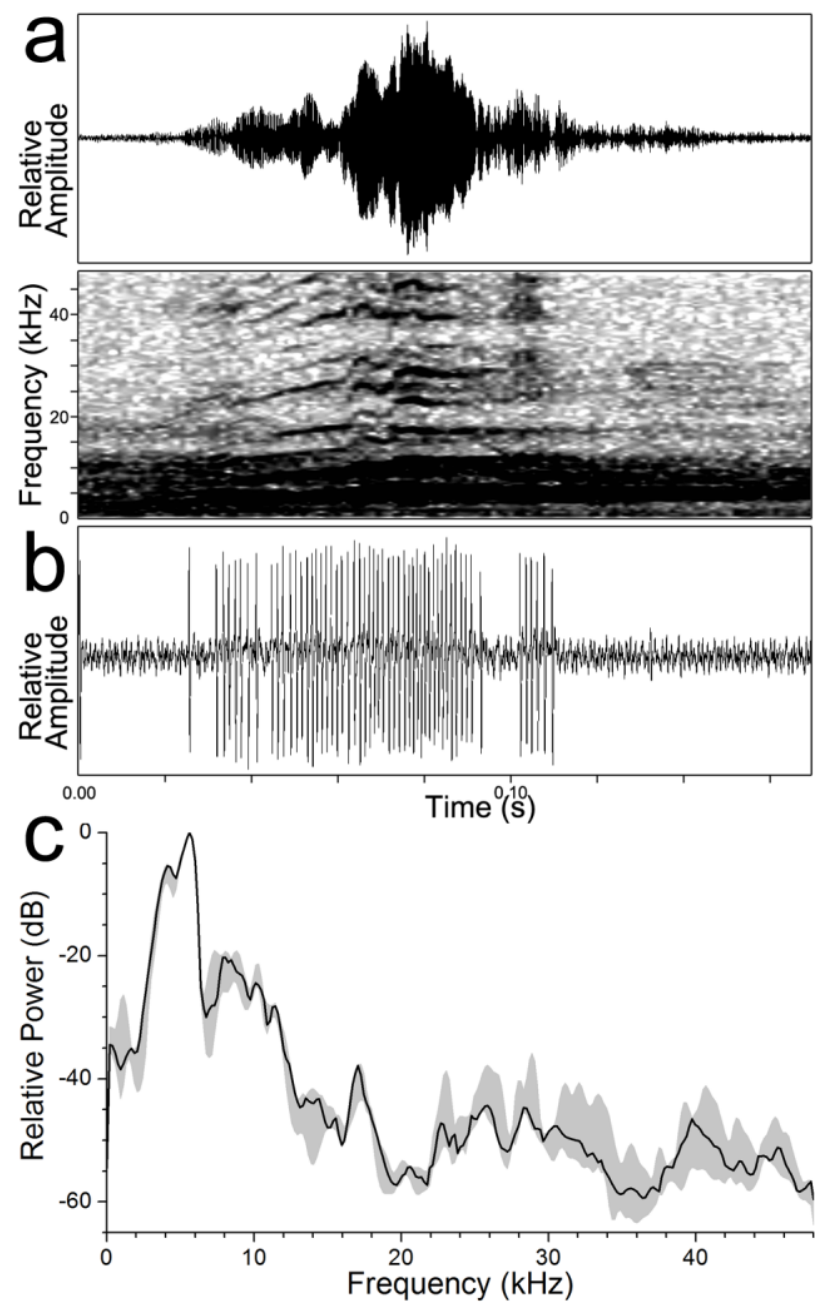

Figure 3.6 (a) The audio waveform of a single cockatiel chirp and the corresponding spectrogram are shown. (b) The neural response signal was recorded from the auditory nerve of Trichoplusia ni at $3 \mathrm{~m}$ from the bird. The spikes indicate the moth's response to the audible cockatiel chirp. (c) The power spectrum of cockatiel chirping. The solid black line shows the median values and the shaded grey region represents the maximum and minimum values from three chirps. 


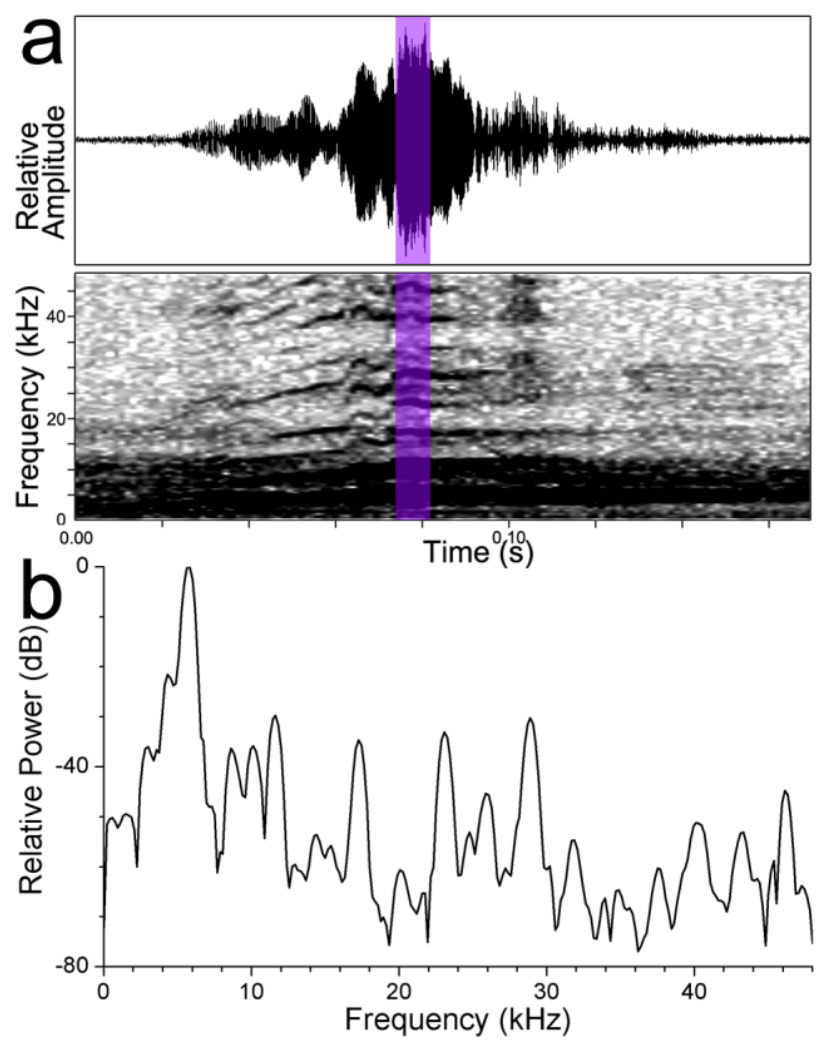

Figure $3.7 \quad$ (a) The audio waveform of a single cockatiel chirp and the corresponding spectrogram are shown. (b) The 'snapshot' power spectrum from the only peak of the chirp (highlighted region) is plotted to show the harmonics. 


\subsubsection{Portable physiology rig}

I successfully constructed a portable electrophysiology rig (Figure 3.8). The rig was tested in the laboratory by measuring the neural response of the Trichiplusia ni auditory nerve to a high-pitched whistle/hiss that I produced orally (Figure 3.9). However, some troubleshooting was necessary before the data in Figure 3.9 was collected. The first obstacle was that the data recorder/oscilloscope did not perform well during measurements. While I collected measurements the neural response was clearly audible from the speaker. However, the oscilloscope display time-lagged and jumped by several seconds at a time, preventing me from visualizing the moth's response in real-time. Further, upon examination of the recordings collected on the Picoscope, the audio was obscured by noise and the moth's response could not be clearly heard. The frequencies examined $(\leq 48 \mathrm{kHz})$ should have been within the instrument's sampling rate, which the manufacturer reports at $\leq 2 \mathrm{MHz}$. It is possible that the input signal amplitude was not great enough for the instrument's sensitivity, despite the amplifier. In the end, this data recorder/oscilloscope was inadequate for the measurements and was replaced with the Fostex data recorder and the TekTronics portable oscilloscope that were used in the permanent rig. Although these two instruments are larger and heavier, I found that they reliably recorded good data and displayed the moth's response with minimal time-lag. 


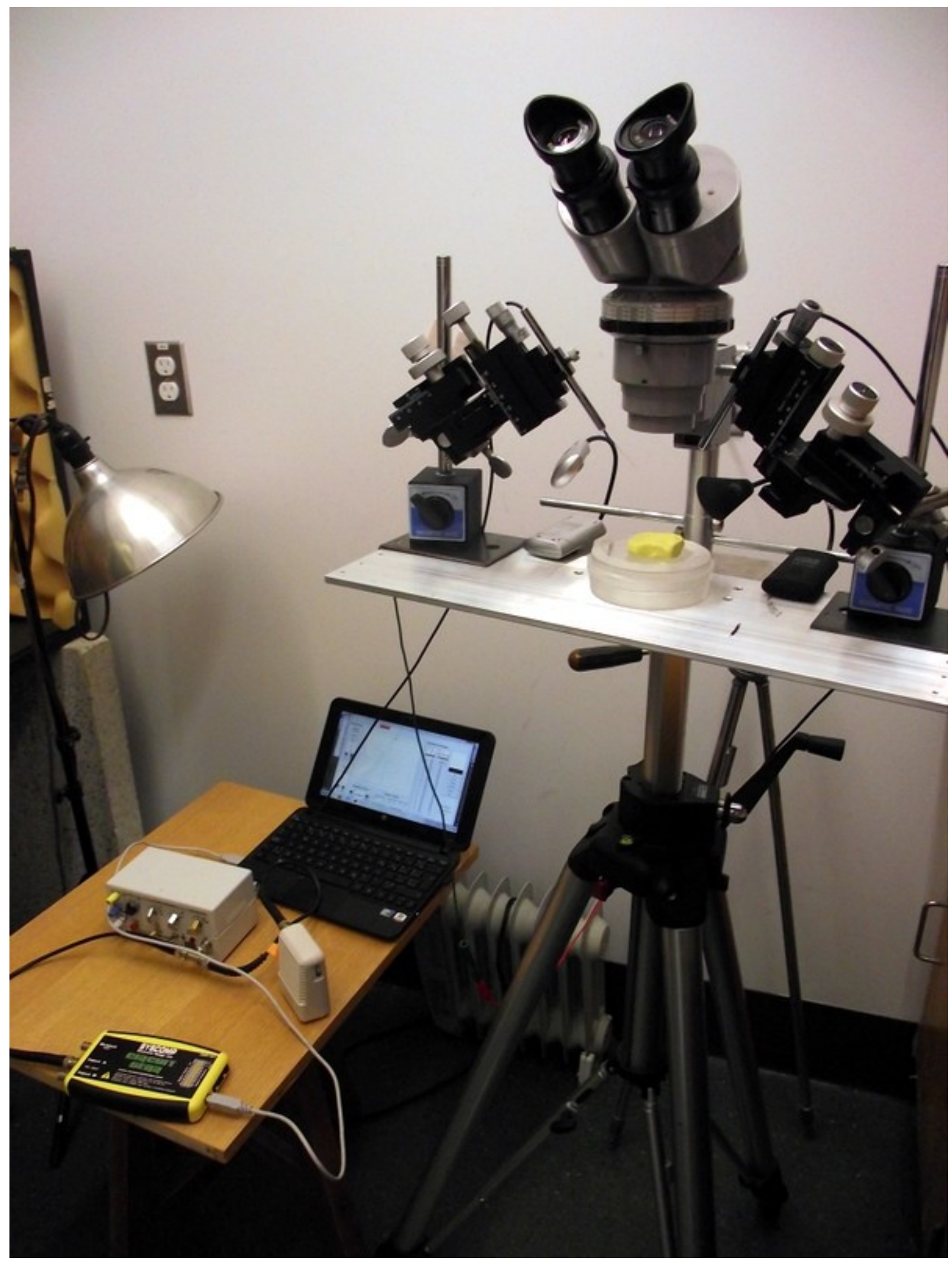

Figure $3.8 \quad$ The portable electrophysiology rig. 


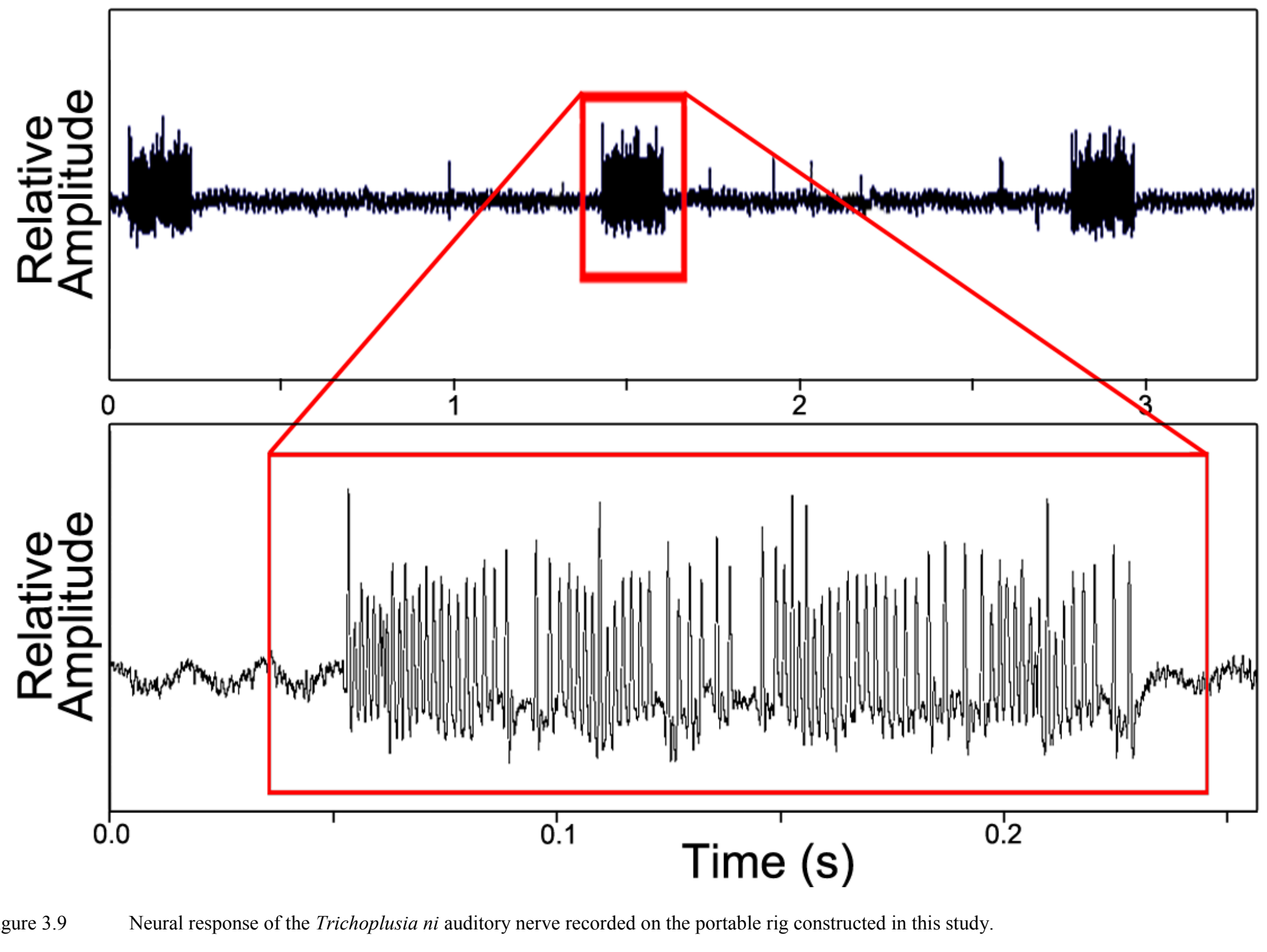


Having successfully tested the portable physiology rig in the laboratory, I attempted to measure the neural response of the Trichiplusia ni auditory nerve to live birds while outside. I found that the neural response was similar to that recorded indoors when the rig was powered using a three-pronged outlet connected to the municipal electrical utility. However, when I attempted to collect measurements using a portable energy source, which is composed of a battery and a voltage inverter, the recordings showed very high levels of electrical noise. I found that I could reduce the electrical noise by creating electrical contact between all parts of the rig, using alligator clips and wires, and grounding the entire rig using a $30 \mathrm{~cm}$ galvanized steel stake that I inserted into the earth. The results using the portable power supply were then usable, however they were never as good as I collected using the electrical utility.

I attempted to further reduce the electrical noise levels by enclosing the physiological prep and the electrodes in copper mesh, which was grounded. I was attempting to create a small Faraday cage around the prep and electrodes. However, I could not establish an observable difference from the unshielded and shielded experiments. Further, because the mesh had to be put in place after the physiological prep was already set up, the risk of damaging the prep, by breaking the moth's auditory nerve, was very high. Therefore, I find that the portable rig should be used without such shielding.

In order to test the portable physiology rig in the field, the response of $T . n i$ to the blackcapped chickadee was measured. This bird was selected because it is abundant in the Ottawa region, it is insectivorous and because it is generally curious. With regards to this last point, I found that these chickadees were not at all afraid of the portable physiology rig when I set it up outside. Indeed, they were easily lured by seeds to fly and land near the rig, occasionally landing on the rig itself. Although there was some difficulty with the signal-to-noise ratio, as outlined 
above, these preliminary measurements succeeded in obtaining a neural response of $T . n i$ to wild birds in a field setting.

\subsection{Discussion}

The fact that a wide variety of insectivorous birds prey upon butterflies and moths and, thus, impose a large selective pressure has been well documented (Marshall 1909; Chai and Srygley 1990; Chai 1996; Pinheiro 1996; Langham 2004, 2006; Jacobs et al. 2008). The selection pressure by birds is thought to influence butterfly colouration, wing morphology, and behaviours concerning flight and reproduction (Chai and Srygley 1990). Because birds utilize several predation strategies to hunt butterflies and moths, the insects are not safe from predation during flight or rest. A few known examples of neotropical birds that prey upon insects such as butterflies and moths are Jacamars (Genus: Galbula), Kingbirds (Genus: Tyrannus) and Neotropical jays (Genus: Cyanolyca) (Chai 1996; Pinheiro 1996; Langham 2006). There are many known species of insectivorous birds native to Canada, including Eastern Kingbirds (Genus: Tyrannus), the Eastern Phoebe (Genus: Sayornis), and the common tree swallow (Genus: Tachycineta) (Bird 2010). There have been quite a few studies reporting that some birds use wing sonation as communication signals, indicating that birds are capable of producing sounds with their wings, reviewed in (Bostwick 2006). Some of these studies conclude that the sounds produced by the feathers are distinct from flight, while others suggest they are also making use of incidental sounds being produced by locomotion (Larsson 2012). Further, there have been studies that looked at adaptations to feathers in a species of owl that effectively lessens the sound of their flight (Sarradj et al. 2011). An adaption like this would suggest that prey species are capable of detecting passive cues that are produced during bird flight. As a 
result of locomotion, all animals will produce vibrations in the substratum, be that water, ground, or air, this will result in sound waves being emitted (Larsson 2012). The question that remains to be answered is, can moths detect the passive sound waves being emitted by one of their predators, birds?

\subsubsection{Objective 1: Record bird flight sounds in the laboratory}

In this work, I studied the bird flight sounds of a trained cockatiel in the laboratory. The advantage of studying the bird flight sounds in the laboratory is that the experiment is very wellcontrolled and that there is very low ambient background noise, which is known to pose additional challenges during field studies (Bradbury and Vehrencamp 2011; Fournier 2011). First, the total sound levels produced during bird flight were measured at several distances over the range $0.3-5 \mathrm{~m}$. Sound ideally follows an inverse square law, so the sound level was expected to decrease by $6 \mathrm{~dB}$ every time the distance is doubled or, equivalently, by $20 \mathrm{~dB}$ per decade (Greenfield 2002). Thus, the recorded sound pressure levels in Figure 3.2 were plotted using a logarithmic scale for the $\mathrm{x}$-axis. Ideally, the slope of this figure should be $-20 \mathrm{~dB}$ per decade. However, the experimental slope is approximately half this value, at only $-9.6 \mathrm{~dB}$ per decade (equivalently, the sound level decreases by $2.9 \mathrm{~dB}$ every time the distance doubles). Thus, the sound levels do not follow the inverse square law. This demonstrates that the size and geometry of the laboratory had significant effect on the propagation of the bird flight sounds. Further, it demonstrates that using the inverse square law to estimate sound levels may introduce error, depending on the experimental environment. This confirms the additional level of control that utilizing a domestic bird in the laboratory offers. Studies conducted in the field are often required to estimate the sound levels of bird flight sounds with the idealized inverse-square law 
(Fournier et al. 2013). However, in our work we may more accurately determine the sound levels of bird flight through direct measurements.

Next, the audio characteristics of the bird flight sounds were examined. Similar to recordings obtained from recordings of wild chickadees and phoebes (Fournier 2011), cockatiel bird flight sounds are cyclic and consist of short pulses that correspond to the up- and downstrokes, although the flight cycles are longer and the peak frequency is lower. This is attributed to the larger size of the cockatiel, relative to the phoebes and chickadees. Most of the power in the bird flight sounds was in the $<5 \mathrm{kHz}$ range. These lower frequencies fall within the range of best hearing for certain butterflies, e.g., Morpho peleides (Lane et al. 2008; Lucas et al. 2009).

\subsubsection{Objective 2: Record the physiological response of moths to a bird in flight}

There are very few studies that have been conducted on a moth's response to bird predation (Jacobs et al. 2008; Fournier et al. 2013). The most likely reason for this being that the function of moth hearing is generally accepted to be for bat detection (Roeder 1964). But, what if that hearing organ in certain moths has been adapted to detect lower frequency sounds produced by another predator imposing pressures on moths? Previous literature has shown that certain moths react behaviourally to the sounds produced by birds foraging (Jacobs et al. 2008). Another study explores the physiological response of moths to a recording of bird flight sounds taken in the wild (Fournier et al. 2013). While this study provided invaluable information on characteristics of bird flight sounds and the corresponding neural response of the moth being tested, I wanted to take the experiments one step farther (Fournier et al. 2013). To test my prediction that moths can hear bird flight sounds, which would allow them to detect predatory 
birds, I collected audiograms for Tricoplusia ni. Cockatiel flight produces sounds that fall within the hearing range of $T . n i$. I then measured the electrophysiological response as the trained cockatiel flew nearby. The measured response of the auditory nerve demonstrates that $T . n i$ is able to hear bird flight sounds. Further, from the mean neural spike frequency $\left(0.407 \mathrm{~ms}^{-1}\right.$, see Table 3.1) the neural response of the moths to the bird flight falls within a range that is hypothesized to elicit a behavioural response $\left[c f .0 .625 \mathrm{~ms}^{-1}\right.$ in Roeder (1964)]. Thus, this result shows that the moths could clearly detect the bird flight sounds at $30 \mathrm{~cm}$ away. Further, the synchronized video, audio and neural recordings show that the moths could detect the bird flight sounds at $\sim 1 \mathrm{~m}$ away, during both the bird's approach and its flight away from the physiological prep. Since the bird flight sounds are well above background noise levels in the laboratory up to $5 \mathrm{~m}$ away, it is possible that these moths can detect bird flight sounds at even further distances. However, further studies are necessary to exactly establish the maximum distance at which $T . n i$ may detect bird flight sounds. These results support the avian hypothesis, i.e., that moths use their hearing organs to hear bird flight sounds. This work demonstrates the methods to measure the physiological response of moths to a bird in flight, which will later be used to similarly test whether butterfly species can hear bird flight sounds in the laboratory.

There are examples in nature of animals using their sense of hearing in order to "eavesdrop" on heterospecifics in order to know their whereabouts. For example, some caterpillars are capable of detecting the wing beats of a parasitoid wasps (Tautz and Markl 1978). Knowing this information could alert the caterpillar to danger and possibly alter the outcome of the encounter. On the parasitic point of view, some Ormia use their sense of hearing to eavesdrop on the calling song of crickets, their host species (Walker 1993). Eavesdropping is a method that is employed in other species in order to assist in survival, so it is my hypothesis that 
moths could be doing that very same thing. It is widely accepted that night-flying moths have their ears tuned to the echolocation frequencies of bats, which again is eavesdropping. Because of this, I suggest that moths have also adapted their hearing to eavesdrop on another predator, the vocalization and passive flight cues of birds. As a preliminary analysis the moths' auditory reactions to bird vocalizations was examined. Again, the frequency range falls definitively into the hearing range we have seen for both moths and butterflies. The moths' neural responses also support that they can detect these vocalizations. This suggests that moths and, perhaps, butterflies can use their hearing to detect more than just the passive cue of bird flight sounds. This shows that further work is necessary to consider what other sounds are within the hearing range, in terms of frequency and volume, of butterflies and moths.

\subsubsection{Objective 3: Construct and test an outdoor physiology rig}

The portable electrophysiology rig constructed in this work is capable of measuring the neural responses of $T$. ni. Therefore, the next step will be to conduct preliminary measurements in order to determine that neural responses can also be measured from butterflies. This will ultimately allow measurements in the field, rather than in a laboratory setting, that will determine whether butterflies can hear bird flight sounds in their natural environments. 


\subsection{Conclusions}

The first objective of this physiological investigation was to record and characterize bird flight sounds in a laboratory setting. The results show that bird flight sounds from a domestic cockatiel are well above ambient noise levels in the laboratory, up to $5 \mathrm{~m}$ away. The variation in bird flight sound levels with distance does not follow the inverse square law, which demonstrates the advantage of direct measurements over using this equation to estimate sound levels.

The second objective of this work was to record and analyze the physiological response of moths' ears to a bird in flight. From the audio characteristics of bird flight sounds and from audiograms that I collected from Trichoplusia ni, moths and other insects may be able to detect passive cues from birds. Therefore, the neural response to an in-flight cockatiel was measured. Bird flight sounds elicited a neural response up to $3 \mathrm{~m}$ away, the furthest distance tested in this study. From the characteristics of the neural response (interspike interval and burst length), this response could elicit behavioural response. I also recorded and characterized the auditory neural response of $T . n i$ to bird vocalizations, or chirps. This work demonstrates that the hearing organs in moths are physiologically capable of detecting bird flight sounds and bird vocalizations, which may have significance for behaviour, such as predator avoidance in the wild.

The third objective of this work was to construct and test an outdoor physiology rig, to ultimately measure the auditory neural response of moths and butterflies in their native habitats. A portable physiology rig was constructed and successfully used to measure the auditory neural response of $T . n i$ in the laboratory and to wild chickadees in a field setting. Therefore, the portable physiology rig constructed in this work is found to be suitable for use with butterflies. 


\section{References}

Ackery, P. R., R. de Jong, and R. I. Vane-Wright. 1999. The Butterflies: Hedyloidea, Hesperioidea and Papilionoidea in N. P. Kristensen, ed. Handbook of Zoology. Walter de Gruyter, Berlin.

Bailey, W. J. and H. Romer. 1991. Sexual differences in auditory sensitivity: mismatch of hearing threshold and call frequency in a tettigoniid (Orthoptera, Tettigoniidae: Zaprochiinae). Journal of Comparative Physiology 169:349-353.

Bennet-Clark, H. C. 1998. Size and scale effects as constraints in insect sound communication. Philosophical Transactions of the Royal Society of London. Series B: Biological Sciences 353:407-419.

Bird, D. M. 2010. Birds of Canada. Dorling Kindersley, Toronto.

Bostwick, K. 2006. Mechanisms of feather sonation in Aves: unanticipated levels of diversity. Acta Zool. Sin 52:68-71.

Bourgogne, J. 1951. Ordre des Lepidopteres in P. P. Grasse, ed. Traite de Zoologie. Masson et Cie, Paris.

Bradbury, J. W. and S. L. Vehrencamp. 2011. Principles of Animal Communication. Sinauer Associates, Sunderland, Massachusetts, USA.

Brussard, P. F. and P. R. Ehrlich. 1970. The population structure of Erebia epipsodea (Lepidoptera: Satyrinae). Ecology 51:119-129.

Cardas, G. 2006. Microphone diaphragms defined by logarithmic curves and microphones for use therewith, United States Patent \#US 2006/0090955 A1. 
Cardone, B. and J. H. Fullard. 1988. Auditory characteristics and sexual dimorphism in the gypsy moth. Physiological Entomology 13:9-14.

Chai, P. 1996. Butterfly visual characteristics and ontogeny of responses to butterflies by a specialized tropical bird. Biological Journal of the Linnean Society 59:37-67.

Chai, P. and R. B. Srygley. 1990. Predation and the flight morphology and temperature of neotropical rain-forest butterflies. The American Naturalist 135:749-765.

Charif, R., A. M. Waack, and L. M. Strickman. 2010. Raven 1.4 user's manual. Cornell Laboratory of Ornithology, Ithaca, New York.

Clayton, D. L. and D. Petr. 1992. Sexual differences in habitat preference and behavior of Oeneis chryxus (Nymphalidae: Satyrinae). Journal of the Lepidopterists' Society 46:110-118.

Cook, M. A. and M. J. Scoble. 1992. Tympanal organs of geometrid moths: a review of their morphology, function and systemic importance. Systematic Entomology 17:219-232.

Debaisieux, P. 1935. Organes scolopidiaux des pattes d'insectes. Cellule 44:271-314.

DeVries, P. J., ed. 1987. The Butterflies of Costa Rica and their Natural History. University of Chicago Press.

Faure, P. A., A. C. Mason, and J. E. Yack. 2009. Invertebrate Ears and Hearing. Pp. 2035-2042 in M. D. Binder, N. Hirokawa, U. Windhorst, and M. C. Hirsch, eds. Encyclopedia of Neuroscience. Springer, Berlin.

Fenton, M. B. and J. H. Fullard. 1979. The influence of moth hearing on bat echolocation strategies. Journal of Comparative Physiology 132:77-86.

Fonseca, P. J. and T. Correia. 2007. Effects of temperature on tuning of the auditory pathway in the cicada Tettigetta josei (Hemiptera, Tibicinidae). Journal of Experimental Biology 210:1834-1845. 
Forrest, T. G. 1994. From sender to receiver: Propagation and environmental effects on acoustic signals. American Zoologist 34:644-654.

Fournier, J. P. 2011. If a bird flies in the forest, does anyone hear it?: Avian flight sound cues and hearing in Lepidoptera. Pp. 106. M.Sc. Thesis. Biology. Carleton University, Ottawa.

Fournier, J. P., J. W. Dawson, A. Mikhail, and J. E. Yack. 2013. If a bird flies in the forest, does an insect hear it? Biology Letters 9.

Frederiksen, R. and E. J. Warrant. 2008. Visual sensitivity in the crepuscular owl butterfly Caligo memnon and the diurnal blue morpho Morpho peleides: a clue to explain the evolution of nocturnal apposition eyes? Journal of Experimental Biology 211:844-851.

Frings, H. and M. Frings. 1956. Reactions to sounds by the wood nymph butterfly, Cercyonis pegala. Annals of the Entomological Society of America 49:611-617.

Fullard, J. H. 1984. Listening for bats: pulse repetition rate as a cue for defensive behaviour in Cycnia tenera (Lepidoptera: Arctiidae). Journal of Comparative Physiology 154:249-252.

Gilbert, F. and N. Elsner. 2000. Directional hearing of a grasshopper in the field. Journal of Experimental Biology 203:983-993.

Gingerich, P. D. 1984. Primate evolution: evidence from the fossil record, comparative morphology and molecular biology. American Journal of Physical Anthropology 27:5772.

Greenfield, M. D. 2002. Signalers and receivers: Mechanisms and evolution of arthropod communication. Oxford University Press Oxford.

Hartley, J. C. and R. O. Stephen. 1992. A paradoxical problem in insect communication: Can bush crickets discriminate frequency? Journal of Experimental Biology 163:359-365. 
Heikkilä, M., L. Kaila, M. Mutanen, C. Peña, and N. Wahlberg. 2012. Cretaceous origin and repeated tertiary diversification of the redefined butterflies. Proceedings of the Royal Society B: Biological Sciences 279:1093-1099.

Heinrich, R., M. Jatho, and K. Kalmring. 1993. Acoustic transmission characteristics of the tympanal tracheae of bushcrickets (Tettigoniidae). II: Comparative studies of the tracheae of seven species. The Journal of the Acoustical Society of America 93:3481-3489.

Hoy, R. and D. Robert. 1996. Tympanal hearing in insects. Annual Review of Entomology 41:433-450.

Jacobs, D. S., J. M. Ratcliffe, and J. H. Fullard. 2008. Beware of bats, beware of birds: the auditory responses of eared moths to bat and bird predation. Behavioral Ecology.

Kalmring, K., W. Rössler, E. Hoffmann, M. Jatho, and C. Unrast. 1995. Causes of the differences in detection of low frequencies in the auditory receptor organs of two species of bushcrickets. Journal of Experimental Zoology 272:103-115.

Kennel, J. V. and F. Eggers. 1933. Die abdominlen Tympanalorgane der Lepidopteran. Zool. Jahrb., Abt. Anat. u. Ont. Tiere 57:1-104.

King, J. D. 2007. Butterfly hearing: a comparative study. B.Sc. Thesis. Biology. Carleton University, Ottawa.

Kostarakos, K. and H. Romer. 2010. Sound transmission and directional hearing in field crickets: neurophysiological studies outdoors. Journal of Comparative Physiology, A 196:669-681.

Kristensen, N. P., ed. 2003. Lepidoptera, Moths and Butterflies. de Gruyter, Berlin, Germany.

Kristensen, N. P., M. J. Scoble, and O. Karsholt. 2007. Lepidoptera phylogeny and systematics: the state of inventorying moth and butterfly diversity. Zootaxa 1668:699-747. 
Kristensen, N. P. and A. W. Skalski. 1999. Phylogeny and Palaeontology in N. P. Kristensen, ed. Handbook of zoology: Lepidoptera, Moths and Butterflies Walter de Gruyter, Berlin.

Lane, K. A., K. M. Lucas, and J. E. Yack. 2008. Hearing in a Diurnal, Mute Butterfly, Morpho peleides (Papilionoidea, Nymphalidae). The Journal of Comparative Neurology 508:677686.

Langham, G. M. 2004. Specialized avian predators repeatedly attack novel color morphs of Heliconius butterflies. Evolution 58:2783-2787.

Langham, G. M. 2006. Rufous-tailed jacamars and aposematic butterflies: do older birds attack novel prey? Behavioral Ecology 17:285-290.

Larsson, M. 2012. Incidental sounds of locomotion in animal cognition. Anim Cogn 15:1-13.

Layberry, R., P. Hall, and D. Lafontaine. 1998. Butterflies of Canada. University of Toronto Press Incorporated, Toronto.

LeCerf, F. 1926. Contribution a l'etude des organes sensoriels des Lepidoptere in P. Lechevalier, ed. Encyclopedie entomologique, Paris.

Lucas, K. M. 2008. Hearing in two tropical butterflies, Morpho peleides and Caligo eurilochus (Nymphalidae: Satyrinae). Pp. 67. M.Sc. Thesis. Biology. Carleton, Ottawa.

Lucas, K. M., J. F. C. Windmill, D. Robert, and J. E. Yack. 2009. Auditory mechanics and sensitivity in the tropical butterfly Morpho peleides (Papilionoidea, Nymphalidae). Journal of Experimental Biology 212:3533-3541.

Mahony, S. J. 2006. Hearing in the speckled wood butterfly, Pararge aegeria (Nymphalidae: satyrinae). Pp. 86. M.Sc. Thesis. Biology. Carleton, Ottawa.

Marshall, G. A. K. 1909. Birds as a factor in the production of mimetic resemblances among butterflies. Transactions of the Royal Entomological Society of London 57:329-384. 
Michelsen, A. 1998. Biophysics of Sound Localization in Insects. Pp. 18-62 in R. Hoy, A.

Popper, and R. Fay, eds. Comparative Hearing: Insects. Springer New York.

Minet, J. and A. Surlykke. 2003. Auditory and sound producing organs in N. P. Kristensen, ed. Handbook of zoology: Lepidoptera, Moths and Butterflies. Walter de Gruyter, Denmark. Monge-Najera, J., F. Hernandez, M. I. Gonzalez, J. Soley, J. Araya, and S. Zolla. 1998. Spatial distribution, territoriality and sound production by tropical cryptic butterflies (Hamadryas, Lepidoptera: Nymphalidae): impications for the "industrial melanism" debate. Revista de Biologia Tropical 46:297-330.

Murillo-Hiller, R. 2006. A noise producing butterfly, Yphthimoides castrenesis (Nymphalidae, Satyrinar) from south Brazil. Journal of the Lepidopterists' Society 60:61-63.

Nocke, H. 1975. Physical and physiological properties of the tettigoniid ("grasshopper") ear. Journal of Comparative Physiology 100:25-57.

Oldfield, B. P. 1988. The effect of temperature on the tuning and physiology of insect auditory receptors. Hearing Research 35:151-158.

Otero, L. D. 1990. Estudio de algunos caracteres para su uso en la clasifiaccion de Eurytelinae (Lepidoptera: Nymphalidae). Boletin de Entomologia Venezolana 5:123-138.

Paul, D. H. 1973. Central projections of the tympanic fibres in noctuid moths. Journal of Insect Physiology 19:1785-1792.

Peña, C. and N. Wahlberg. 2008. Prehistorical climate change increased diversification of a group of butterflies. Biology Letters 4:274-278.

Pinheiro, C. E. G. 1996. Palatability and escaping ability in neotropical butterflies: tests with wild king birds (Tyrannus melancholicus). Biological Journal of the Linnean Society 59:351-365. 
Pough, F. H. and L. P. Brower. 1977. Predation by birds on great southern white butterflies as a function of palatability, sex, and habitat. American Midland Naturalist 98:50-58.

Rajaraman, K., N. Mhatre, M. Jain, M. Postles, R. Balakrishnan, and D. Robert. 2013. Low-pass filters and differential tympanal tuning in a paleotropical bushcricket with an unusually low frequency call. Journal of Experimental Biology 216:777-787.

Reid, D. G. 1989. The comparative morphology, phylogeny, and evolution of the gastropod family Littorinidae. Philosophical Transactions of the Royal Society of London. Series B. $324: 1-10$.

Rheinlaender, J. and H. Romer. 1986. Insect hearing in the field. Journal of Comparative Physiology, A 158:647-651.

Ribaric, D. and M. Gogala. 1996. Acoustic behaviour of some butterfly species of the genus Erebia (Lepidoptera: Satyridae) Acta Entomologica Slovenica 4:5-12.

Robert, D. 2005. Directional Hearing in Insects. Pp. 6-35 in A. Popper, and R. Fay, eds. Sound Source Localization. Springer New York.

Roeder, K. D. 1964. Aspects of the noctuid tympanic nerve response having significance in the avoidance of bats. Journal of Insect Physiology 10:529-546.

Roeder, K. D. 1969. Brain interneurons in noctuid moths: Differential suppression by high sound intensities. Journal of Insect Physiology 15:1713-1718.

Romer, H. 1993. Environmental and biological constraints for the evolution of long-range signalling and hearing in acoustic insects. Philosophical Transactions of the Royal Society of London, Series B: Biological Sciences 340:179-185.

Romer, H. and W. J. Bailey. 1986. Insect hearing in the field. Journal of Comparative Physiology $159: 627-638$. 
Romer, H. and J. Tautz. 1992. Invertebrate auditory receptors. Advances in Comparative and Environmental Physiology 10:185-212.

Rydell, J., S. Kaerma, H. Hedelin, and N. Skals. 2003. Evasive response to ultrasound by the crepuscular butterfly Manataria maculata. Naturwissenschaften 90:80-83.

Santer, R. D., F. C. Rind, and P. J. Simmons. 2012. Predator versus prey: Locust loomingdetector neuron and behavioural responses to stimuli representing attacking bird predators. PLoS ONE 7:e50146.

Sarradj, E., C. Fritzsche, and T. Geyer. 2011. Silent owl flight: bird flyover noise measurements. AIAA journal 49:769-779.

Scoble, M. J. and A. Aiello. 1990. Moth-like butterflies (Hedylidae: Lepidoptera): a summary, with comments on the egg. Journal of Natural History 24:159-164.

Shen, J. X. 1993. A peripheral mechanism for auditory directionality in the bushcricket Gampsocleisgratiosa: Acoustic tracheal system. The Journal of the Acoustical Society of America 94:1211-1217.

Spangler, H. G. 1988. Moth hearing, defense and communication. Annual Review of Entomology 33:59-81.

Stephen, R. O. and W. J. Bailey. 1982. Bioacoustics of the ear of the bushcricket Hemisaga (Sagenae). The Journal of the Acoustical Society of America 72:13-25.

Sueur, J., J. F. C. Windmill, and D. Robert. 2006. Tuning the drum: the mechanical basis for frequency descrimination in a Mediterranean cicada. Journal of Experimental Biology 209:4115-4128.

Tautz, J. and H. Markl. 1978. Caterpillars detect flying wasps by hairs sensitive to airborne vibration. Behavioral Ecology and Sociobiology 4:101-110. 
Troubridge, J. T. and D. K. Parshall. 1988. A review of the Oeneis polixenes (Fabricisu) (Lepidoptera: Satyrinae) complex in North America. The Canadian Entomologist 120:679-696.

Vogel, R. 1912. Uber die chordotonalorgane in der wurzel der schmetterlingsflugel. Z. Wiss. Zool. 100:210-244.

Wahlberg, N., M. F. Braby, A. V. Z. Brower, R. De Jong, M. M. Lee, S. Nylin, N. E. Pierce, F. A. H. Sperling, R. Vila, A. D. Warren, and E. Zakharov. 2005. Synergistic effects of combining morphological and molecular data in resolving the phylogeny of butterflies and skippers. Proc. R. Soc. Lond. B. 272:1577-1586.

Walker, T. J. 1993. Phonotaxis in female Ormia ochracea (Diptera: Tachinidae), a parasitoid of field crickets. Journal of Insect Behaviour 6:389-410.

Windmill, J. F. C., M. C. Gopfert, and D. Robert. 2005. Tympanal travelling waves in migratory locusts. Journal of Experimental Biology 208:157-168.

Yack, J. E. 2004. The structure and function of auditory chordotonal organs in insects. Microscopy Research and Technique 63:315-337.

Yack, J. E. and J. W. Dawson. 2008. Insect Ears. Pp. 35-54 in R. Hoy, G. M. Sheperd, A. I. Basbaum, A. Kaneko, and G. Westheimer, eds. The Senses.

Yack, J. E. and J. H. Fullard. 1993a. Proprioceptive activity of the wing-hinge stretch receptor in Manduca sexta and other atympanate moths: a study of the noctuoid moth ear B cell homologue. Journal of Comparative Physiology 173:301-307.

Yack, J. E. and J. H. Fullard. 1993b. What is an insect ear? Annals of the Entomological Society of America 86:677-682. 
Yack, J. E. and J. H. Fullard. 2000. Ultrasonic hearing in nocturnal butterflies. Nature 403:265266.

Yack, J. E. and R. Hoy. 2003. Insect Ears. Pp. 498-505 in V. H. Resh, and R. Carde, eds. The Encyclopedia of Insects. Academic Press, San Diego.

Yack, J. E., E. K. V. Kalko, and A. Surlykke. 2007. Neuroethology of ultrasonic hearing in nocturnal butterflies (Hedyloidea). Journal of Comparative Physiology, A 193:577-590.

Yack, J. E., L. D. Otero, J. W. Dawson, A. Surlykke, and J. H. Fullard. 2000. Sound production and hearing in the blue cracker butterfly Hamadryas feronia (Lepidoptera, Nymphalidae) from Venezuela. Journal of Experimental Biology 203:3689-3702.

Yager, D. D. 1990. Sexual dimorphism of auditory function in praying mantises. Journal of Morphology 221:517-537.

Yager, D. D. 1999. Structure, develepment, and evolution of insect auditory systems. Microscopy Research and Technique 47:380-400.

Zavadad, M. S. 1983. Comparative morphology of monocot pollen and evolutionary trends of apertures and wall structures. Botanical Review 49:331-379. 


\title{
5. Appendix
}

\subsection{Full List of Qualitative Descriptions of the Vogel's Organs}

\author{
Biblidini - Biblis hyperia
}

Biblis hyperia has a well-defined VO with a rigid cuticular ring and a transparent membrane with a clearly defined convex tholus. Its forewing veins are not inflated. $\mathrm{n}=1$

Epicaliini - Myscelia cyaniris

Myscelia cyaniris has a well-defined VO that is composed of a slightly ovular cuticular ring with a transparent outer membrane. The tholus takes up a large amount of surface area proportionally to the outer membrane and is defined both by its colour and elevation. The forewing veins are not inflated. Protective fusiform scales protruding from the anal and cubital vein hide the VO in its undisturbed state. $\mathrm{n}=6$ 


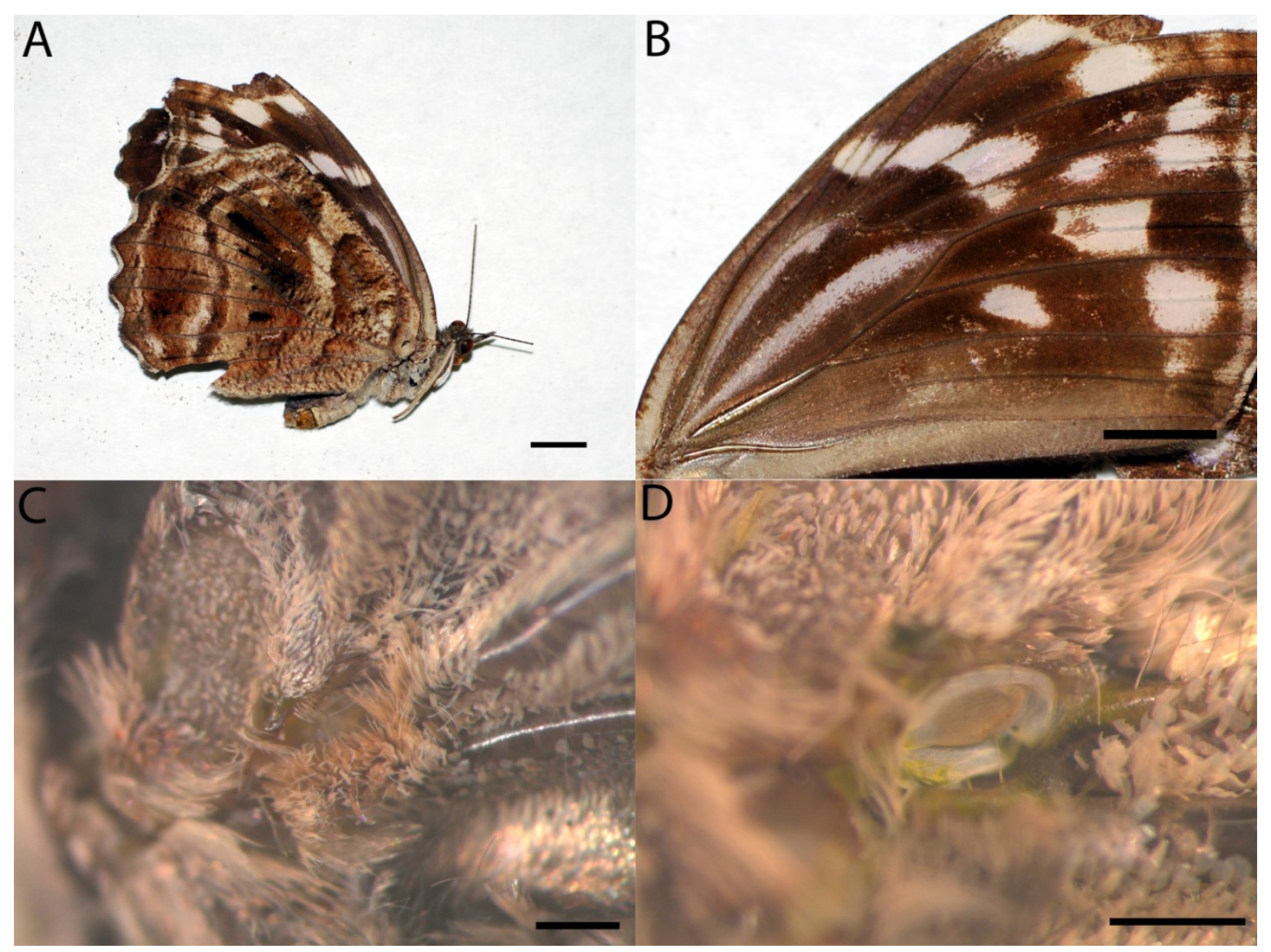

Figure 5.1 External morphology of the VO in Mycelia cyaniris. (A) View of ventral wing surface of intact specimen. Scale bar: $5 \mathrm{~mm}$. (B) Photograph of the ventral surface of the forewing of Myscelia cyaniris illustrating the forewing venation. Scale bar: $5 \mathrm{~mm}$. (C) Light micrograph of the base of the forewing on the ventral side of the specimen with hindwing removed, but protective scales intact. Scale bar: $500 \mu \mathrm{m}$. (D) Light micrograph of the base of the forewing on the ventral side of the specimen with hindwing removed and scales surrounding the Vogel's organ removed. Scale bar: $500 \mu \mathrm{m}$. 


\section{Junoniini - Hypolimnas bolina}

Hypolimnas bolina has a poorly-developed VO that does not has a structure in its cuticular ring that is less rigid than I observed in other species. The shape of this structure is difficult to state with certainty because the margins are not well-defined, however, it roughly appears ovular. There is no tholus present and the outer membrane varies from translucent to opaque in appearance. The forewing veins are not inflated in this species. In its natural, undisturbed state, there are large fusiform scales that protrude from three forewing veins (subcostal, cubital and anal) to cover and protect the VO. $\mathrm{n}=3$

\section{Victorinini - Siproeta stelenes}

Siproeta stelenes has an intermediately-developed VO with a cuticular ring that has some rigidity. Since the cuticular ring does not completely surround the VO, its shape is non-uniform. The outer membrane itself verges on opaque and its tholus does not have clear margins. The tholus itself is also not uniformly shaped, although there is a colouration difference present. Forewing vein inflation is not present in this species. The $\mathrm{VO}$ is protected by fusiform scales.

\section{Victorinini - Siproeta epaphus}

The VO of S. epaphus is quite similar to that of S. stelenes, from the same genus. The outer ring is clearly definined and lacks continuous structure, which gives rise to an irregular $\mathrm{VO}$ shape. The outer membrane is opaque and there is not much definition between the tholus and the outer membrane, although heterogeneity of colour is present. The tholus is proportionally 
small compared to the outer membrane. There is no forewing vein inflation present in this species. The VO is protected by fusiform scales that protrude from the anal vein and flattened scales from the cubital vein. 


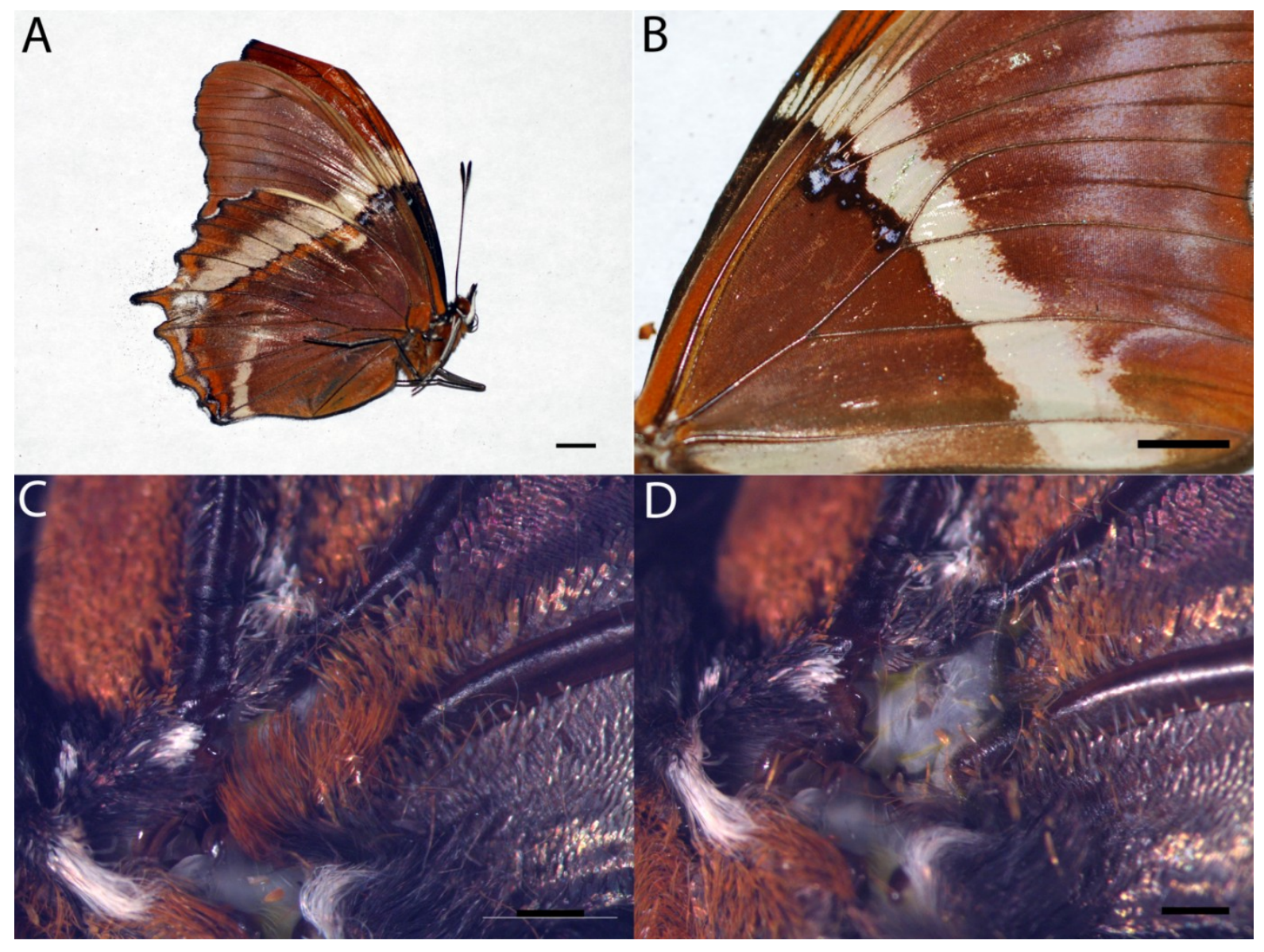

Figure 5.2 External morphology of theVO in Siproeta epaphus. (A) View of ventral wing surface of intact specimen. Scale bar: $5 \mathrm{~mm}$. (B) Photograph of the ventral surface of the forewing of Siproeta epaphus illustrating the forewing venation. Scale bar: $5 \mathrm{~mm}$. (C) Light micrograph of the base of the forewing on the ventral side of the specimen with hindwing removed, but protective scales intact. Scale bar: $500 \mu \mathrm{m}$. (D) Light micrograph of the base of the forewing on the ventral side of the specimen with hindwing removed and scales surrounding the Vogel's organ removed. Scale bar: $500 \mu \mathrm{m}$. 


\section{Brassolini - Caligo memnon}

Caligo memnon was one of the largest specimen looked at in this study. Its VO is intermediately-developed and has an irregularly shaped chitinous ring. The outer membrane is translucent and there are no clear margins defining the outer membrane from the tholus, although colour heterogeneity is observed. There is no forewing vein inflation in this species. Large, fusiform scales protrude from the three forewing veins and serve as protection for the VO. 


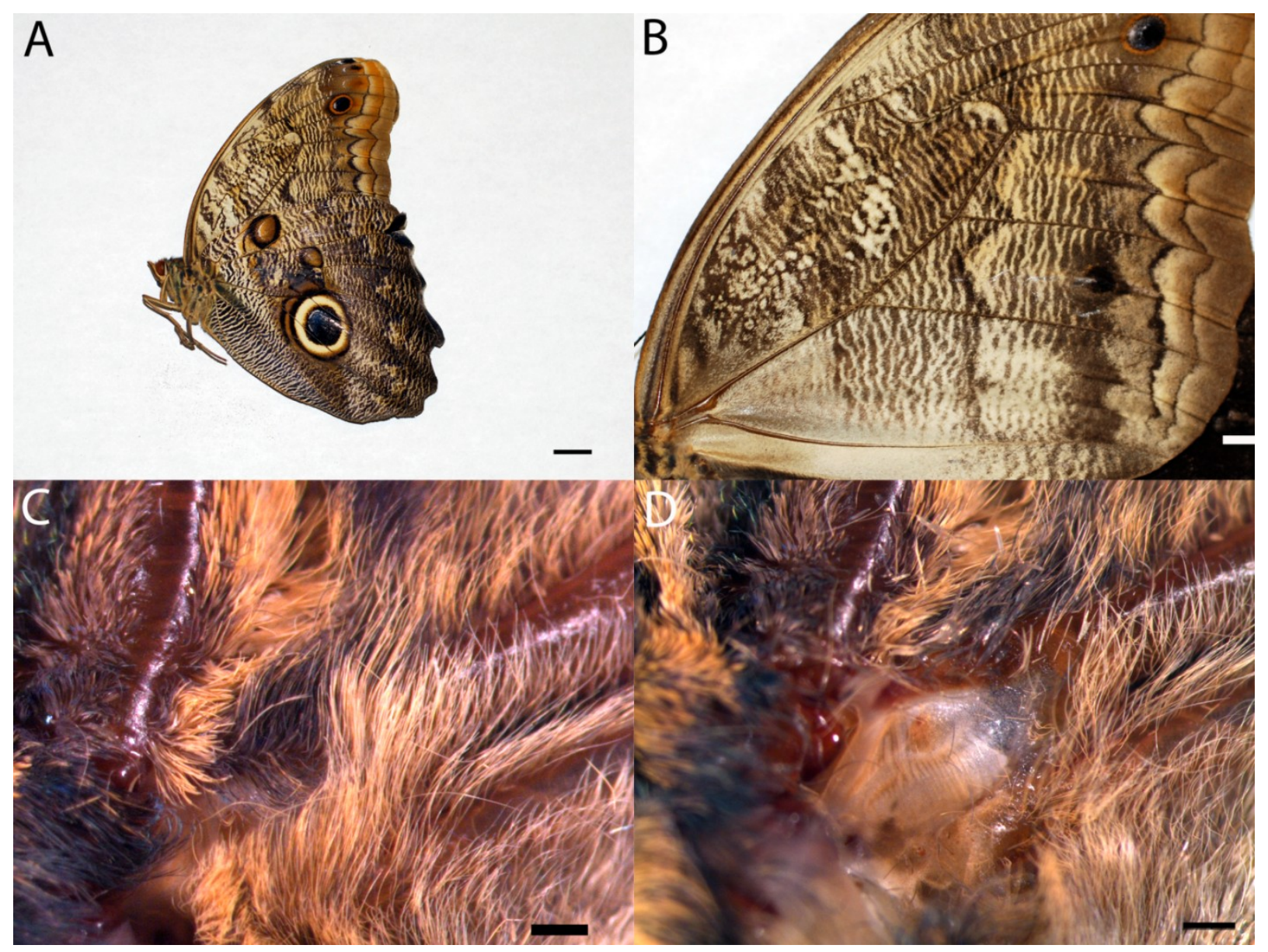

Figure 5.3 External morphology of the VO in Caligo memnon. (A) View of ventral wing surface of intact specimen. Scale bar: $1 \mathrm{~cm}$. (B) Photograph of the ventral surface of the forewing of Caligo memnon illustrating the venation. Scale bar: $1 \mathrm{~cm}$. (C) Light micrograph of the base of the forewing on the ventral side of the specimen with hindwing removed, but protective scales intact. Scale bar: $500 \mu \mathrm{m}$. (D) Light micrograph of the base of the forewing on the ventral side of the specimen with hindwing removed and scales surrounding the VO removed. Scale bar: 500 $\mu \mathrm{m}$. 


\section{Brassolini - Caligo eurilochus}

Caligo eurilochus has a VO that is very similar to that of $C$. memnon. The outer membrane is translucent in nature and is not clearly defined from the tholus. Striations of different colouration are observed to run through the outer membrance. The forewing veins are not inflated. 


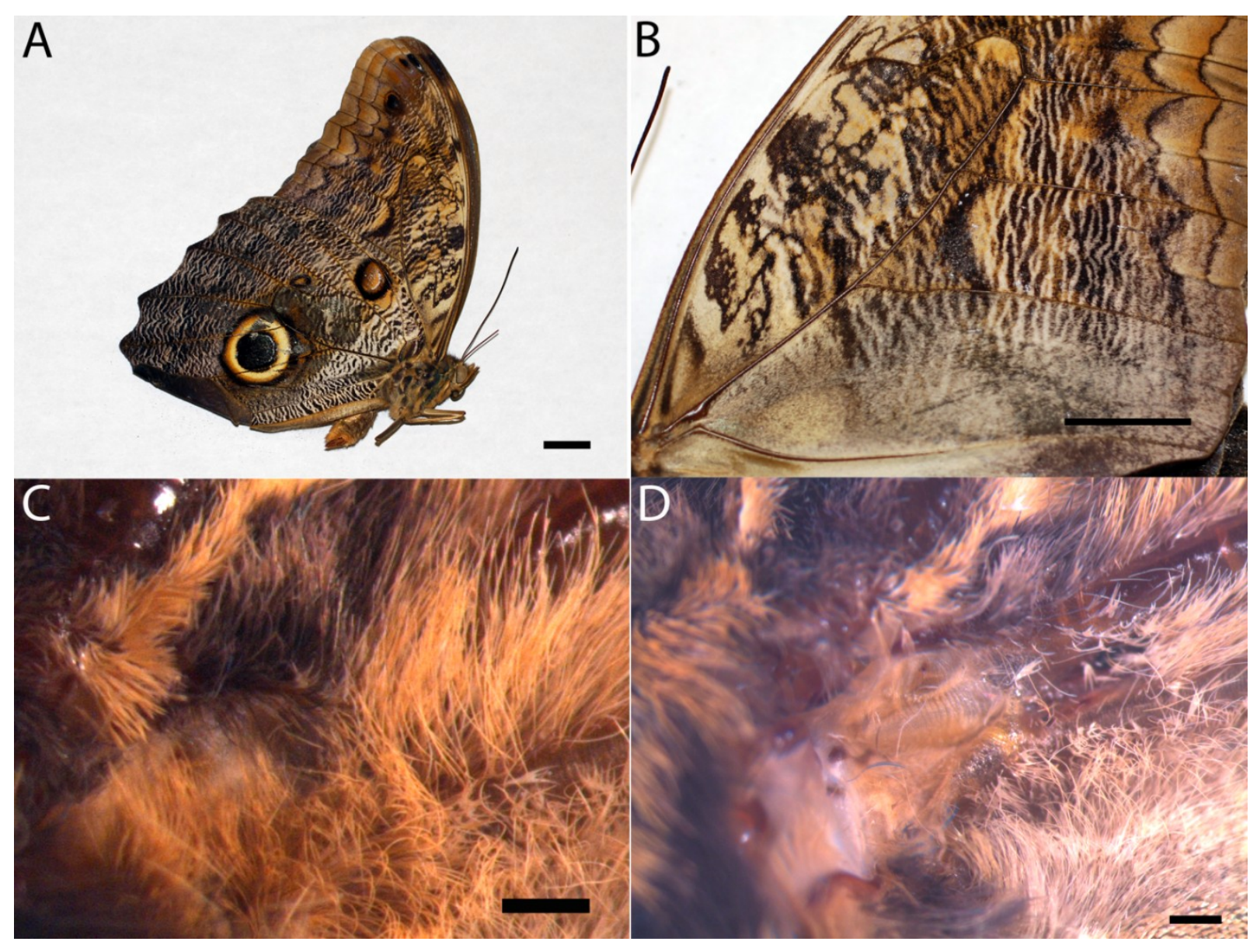

Figure 5.4 External morphology of the VO in Caligo eurilochus. (A) View of ventral wing surface of intact specimen. Scale bar: $1 \mathrm{~cm}$. (B) Photograph of the ventral surface of the forewing of Caligo eurilochus illustrating venation. Scale bar: $1 \mathrm{~cm}$. (C) Light micrograph of the base of the forewing on the ventral side of the specimen with hindwing removed, but protective scales intact. Scale bar: $500 \mu \mathrm{m}$. (D) Light micrograph of the base of the forewing on the ventral side of the specimen with hindwing removed and scales surrounding the VO removed. Scale bar: 500 $\mu \mathrm{m}$. 


\section{Brassolini - Opsiphanes tamirindi}

Opsiphanes tamirindi has an intermediate VO with poor definition of the cuticular ring. The shape of the ring appears irregular. The outer membrane is translucent and there is a small, poorly-defined region of heterogeneous colouration that might be the tholus. Forewing veins are not inflated in this species. Small tufts of fusiform scales from the anal vein serve as protection to the VO under natural conditions.

\section{Morphini - Morpho microthalmus}

Morpho microthalmus has a VO that is very similar to that previously described in Morpho peleides. It has a very rigid and clearly margined cuticular ring, a semi-transparent membrane and a convex, elevated tholus. A small tuft of scales arises from the anal vein and provides some protection to the VO under normal conditions. 


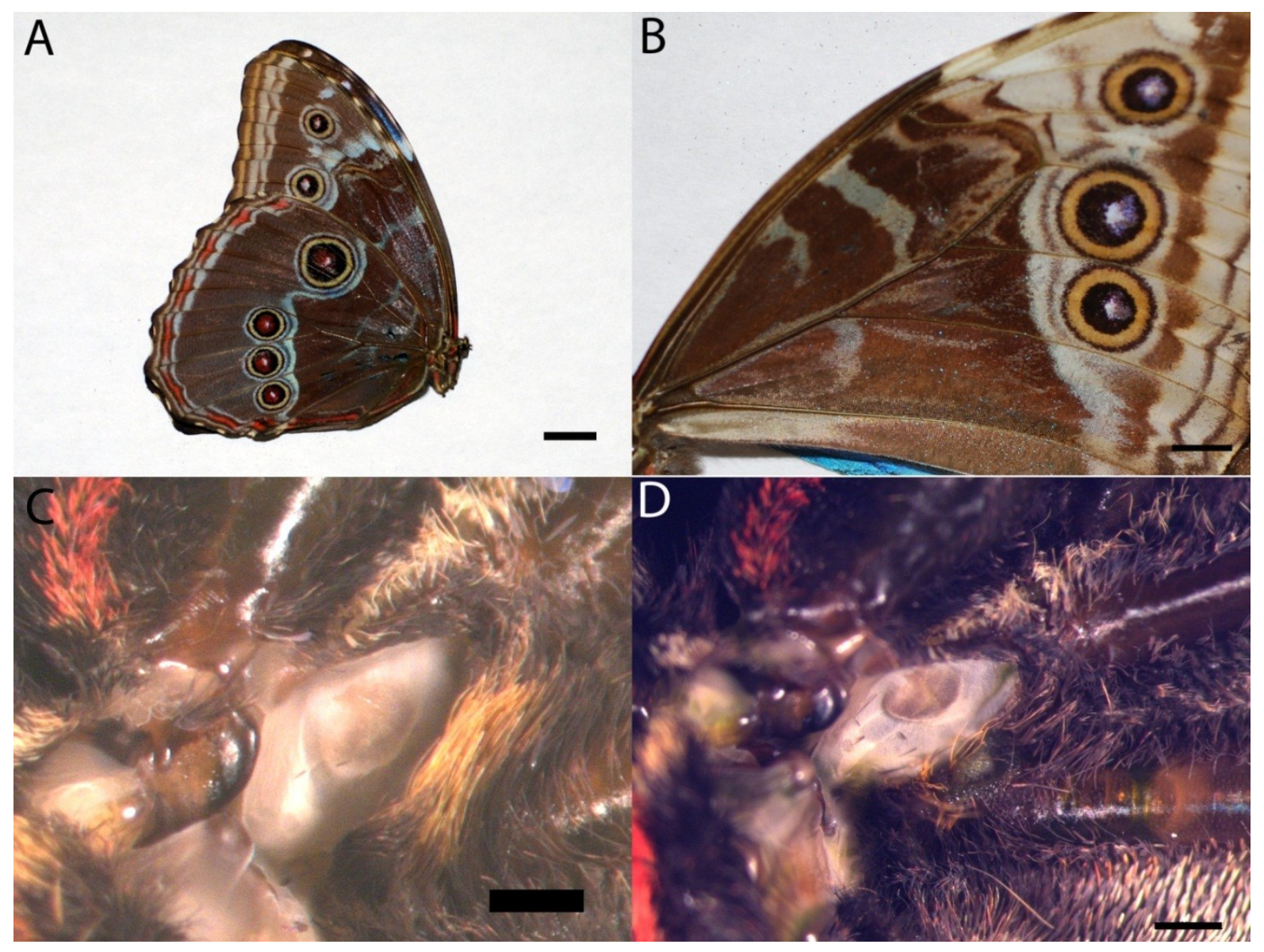

Figure 5.5 External morphology of the VO in Morpho microthalmus. (A) View of ventral wing surface of intact specimen. Scale bar: $5 \mathrm{~mm}$. (B) Photograph of the ventral surface of the forewing of Morpho microthalmus illustrating the venation. Scale bar: $5 \mathrm{~mm}$. (C) Light micrograph of the base of the forewing on the ventral side of the specimen with hindwing removed, but protective scales intact. Scale bar: $500 \mu \mathrm{m}$. (D) Light micrograph of the base of the forewing on the ventral side of the specimen with hindwing removed and scales surrounding the VO removed. Scale bar: $500 \mu \mathrm{m}$. 
Morphinii-Morpho polyphemus

Morpho polyphemus has an intermediate VO that is quite different from both M. peleides and M. microthalmus. The tholus is absent both in terms of elevation and distinct colouration. The outer membrane appears translucent. There is no forewing vein inflation present in this species. A tuft of scales from the anal vein protects the membrane, although the VO is visible without removal of these scales. 


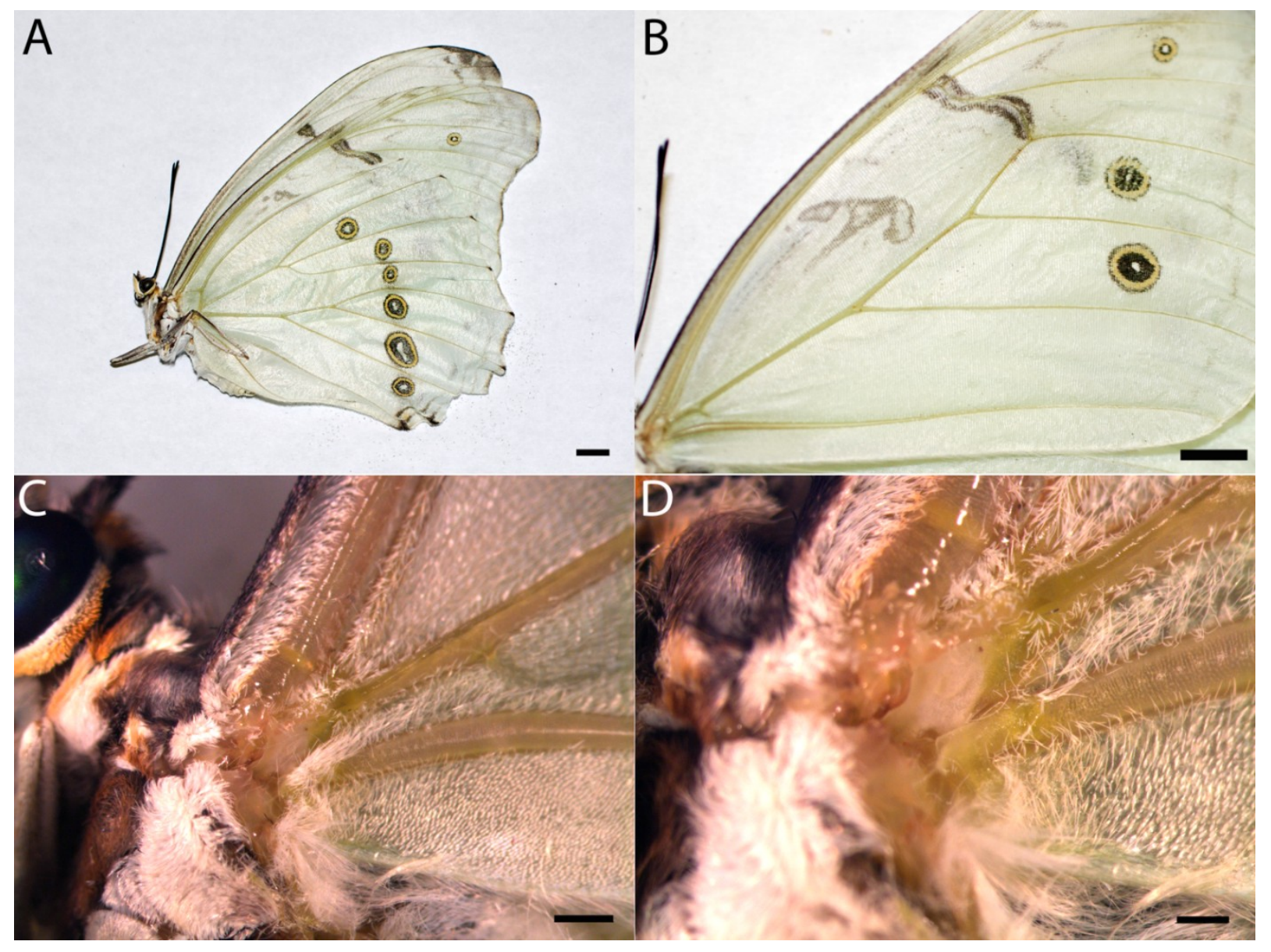

Figure 5.6 External morphology of the VO in Morpho polyphemus. (A) View of ventral wing surface of intact specimen. Scale bar: $5 \mathrm{~mm}$. (B) Photograph of the ventral surface of the forewing of Morpho polyphemus illustrating the venation. Scale bar: $5 \mathrm{~mm}$. (C) Light micrograph of the base of the forewing on the ventral side of the specimen with hindwing removed, but protective scales intact. Scale bar: $500 \mu \mathrm{m}$. (D) Light micrograph of the base of the forewing on the ventral side of the specimen with hindwing removed and scales surrounding the VO removed. Scale bar: $500 \mu \mathrm{m}$. 


\section{Satyrini - Megisto cymela}

Megisto cymela has a very narrow VO with a rigid, well-defined cuticular ring over which a transparent outer membrane is stretched. The tholus is distinct with very clear definition from the outer membrane both in terms of colouration and elevation. The tholus is very large relative to the outer membrane, which it mostly covers. The subcostal vein in $M$. cymela is very inflated and a series of trachea are visible through the cuticle. Both fusiform and flattened scales arising from the cubital and anal veins offer protection to the VO. The scales completely obscure the VO from view. 


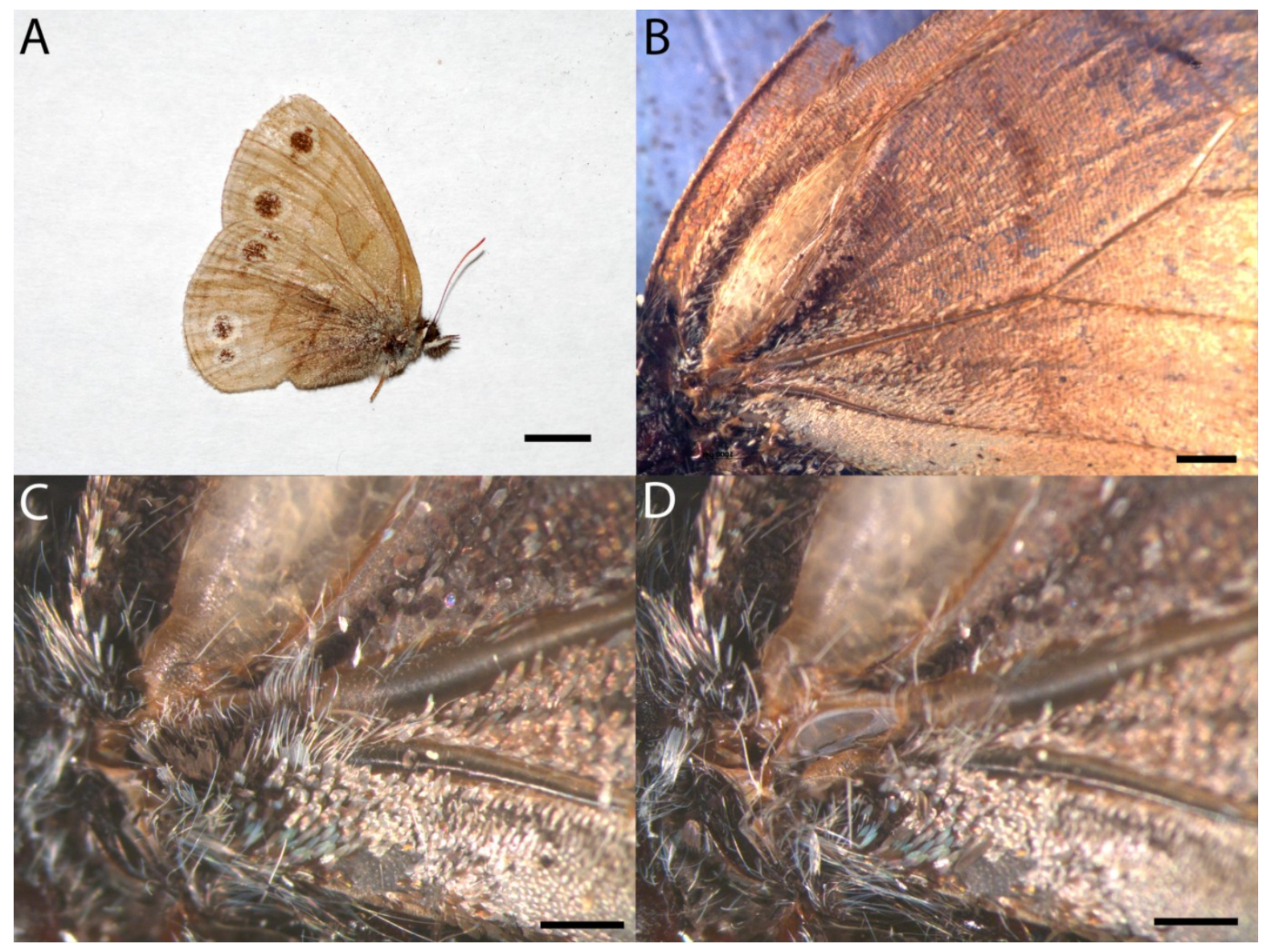

Figure 5.7 External morphology of the VO in Megisto cymela. (A) View of ventral wing surface of intact specimen. Scale bar: $5 \mathrm{~mm}$. (B) Photograph of the ventral surface of the forewing of Megisto cymela illustrating the venation. Scale bar: $1000 \mu \mathrm{m}$. (C) Light micrograph of the base of the forewing on the ventral side of the specimen with hindwing removed, but protective scales intact. Scale bar: $500 \mu \mathrm{m}$. (D) Light micrograph of the base of the forewing on the ventral side of the specimen with hindwing removed and scales surrounding the VO removed. Scale bar: $500 \mu \mathrm{m}$. 


\section{Satyrini - Coenonympha nipisquit}

Coenonympha nipisquit has a well-defined VO surrounded by a rigid cuticular membrane that forms an oval-shaped structure. The outer membrane is transparent and the tholus has welldefined margins and colouration. All three forewing veins are inflated in C. nipisquit. Fusiform and flattened scales arising from the three inflated veins completely obscure the VO from view. 


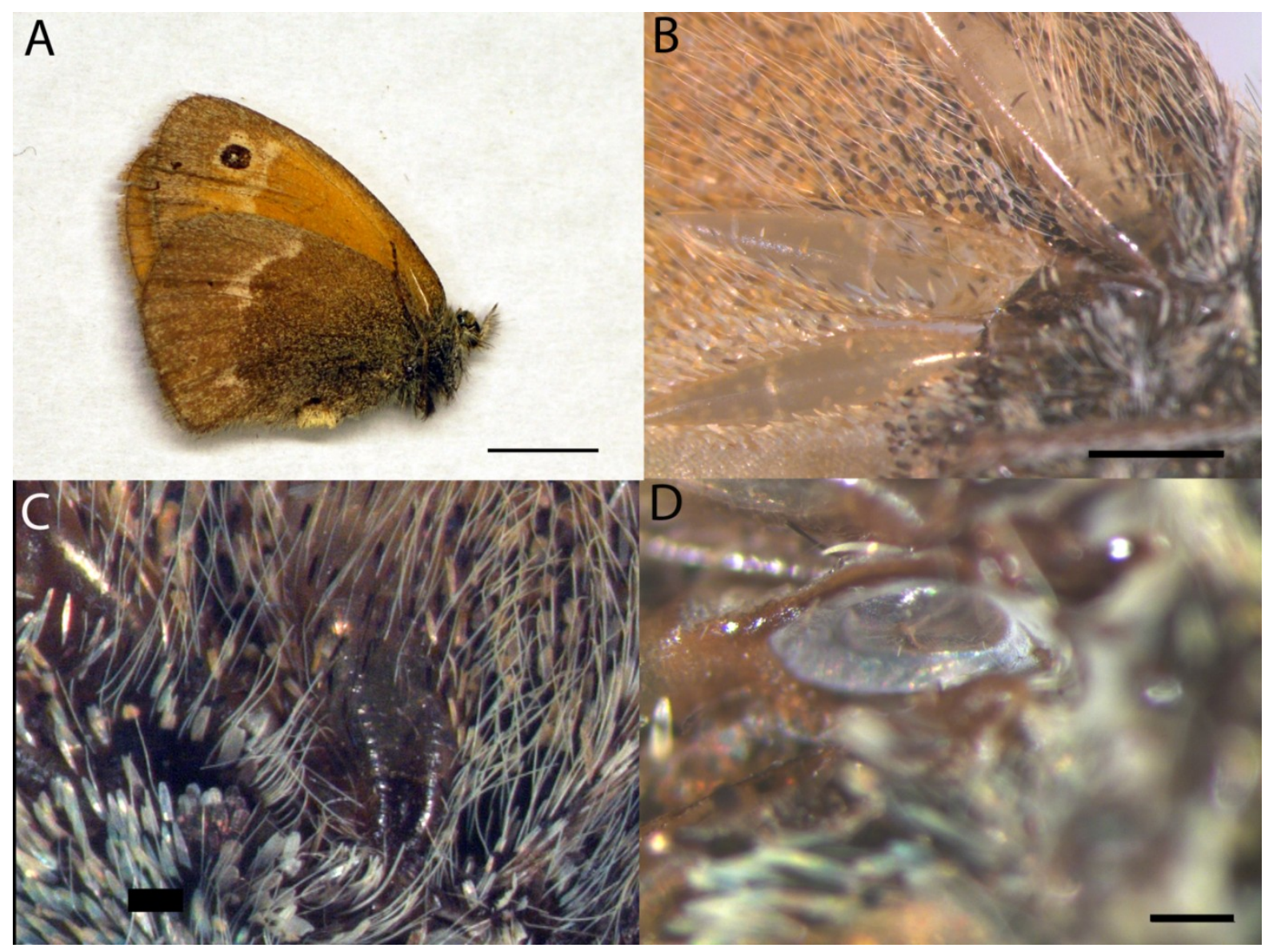

Figure 5.8 External morphology of the VO in Coenonympha nipisquit. (A) View of ventral wing surface of intact specimen. Scale bar: $5 \mathrm{~mm}$. (B) Photograph of the ventral surface of the forewing of Coenonympha nipisquit illustrating the venation. Scale bar: $1000 \mu \mathrm{m}$. (C) Light micrograph of the base of the forewing on the ventral side of the specimen with hindwing removed, but protective scales intact. Scale bar: $200 \mu \mathrm{m}$. (D) Light micrograph of the base of the forewing on the ventral side of the specimen with hindwing removed and scales surrounding the VO removed. Scale bar: $200 \mu \mathrm{m}$. 


\section{Satyrini - Enodia anthedon}

Enodia anthedon has a relatively less rigid cuticular membrane, which results in a slightly less uniform shape surrounding the VO. The outer membrane is transparent. Although the tholus is clearly present, the colouration of the tholus is not as distinct as is observed for other species and it appears to be proportionally smaller than in other species of the Satyrini tribe. The subcostal forewing vein appears inflated in this species. Fusiform scales from the cubital and anal vein serve as protection for the VO, but do not block it completely from view. 


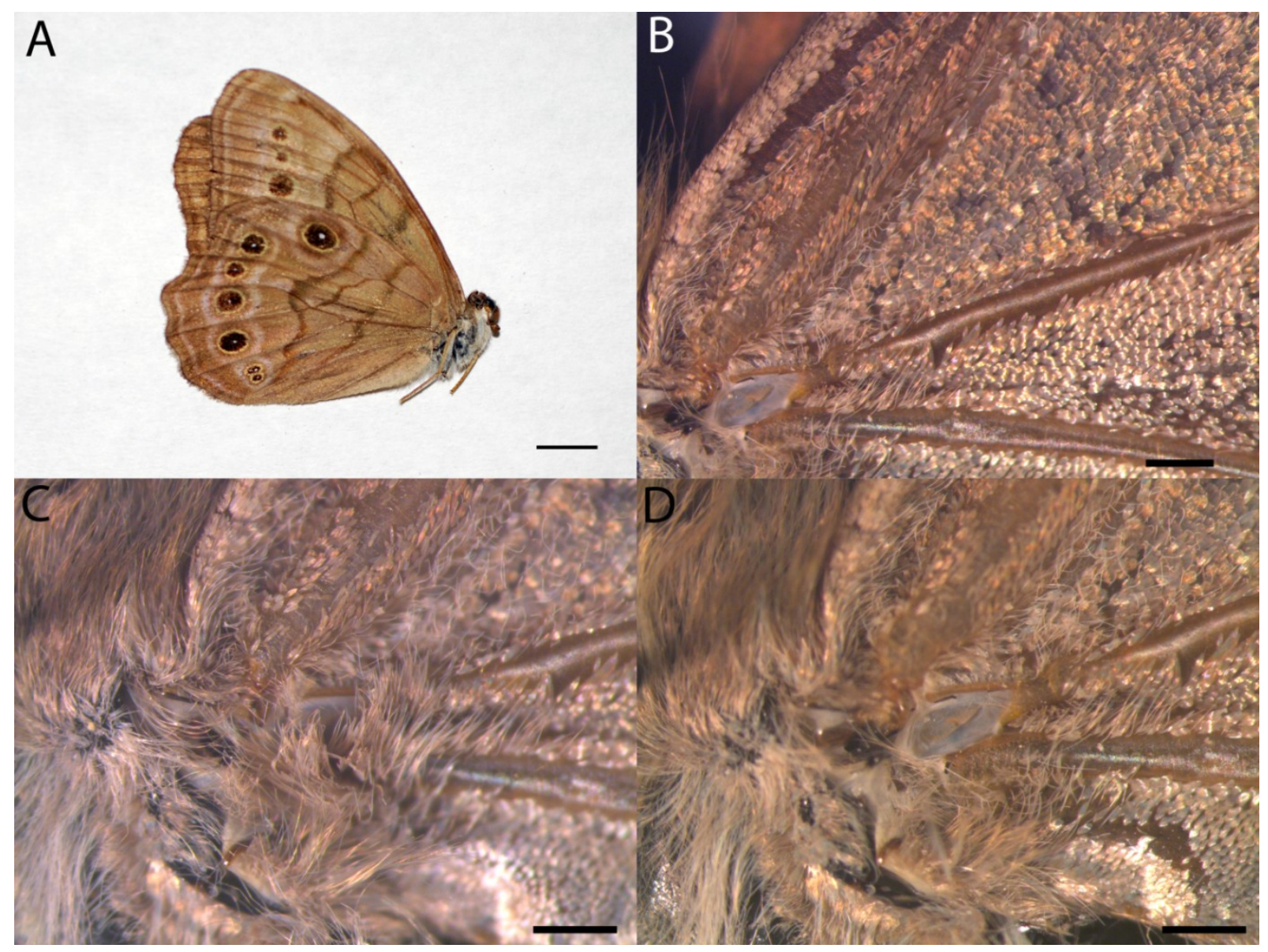

Figure 5.9 External morphology of the VO in Enodia anthedon. (A) View of ventral wing surface of intact specimen. Scale bar: $5 \mathrm{~mm}$. (B) Photograph of the ventral surface of the forewing of Enodia anthedon illustrating the venation. Scale bar: $500 \mu \mathrm{m}$. (C) Light micrograph of the base of the forewing on the ventral side of the specimen with hindwing removed, but protective scales intact. Scale bar: $500 \mu \mathrm{m}$. (D) Light micrograph of the base of the forewing on the ventral side of the specimen with hindwing removed and scales surrounding the VO removed. Scale bar: $500 \mu \mathrm{m}$. 


\section{Satyrini - Satyrodes appalachia}

Satyrodes appalachia has a rigid well-defined cuticular ring that forms an ovular structure. The outer membrane of the VO is transparent and the tholus is poorly defined from it. The convex nature of the tholus is difficult to determine and the colouration change is subtle. None of the forewing veins appeared inflated in this specimen. Long fusiform scales arising mostly from the anal vein, and some from the cubital protect and obscure the VO from view in natural conditions. 


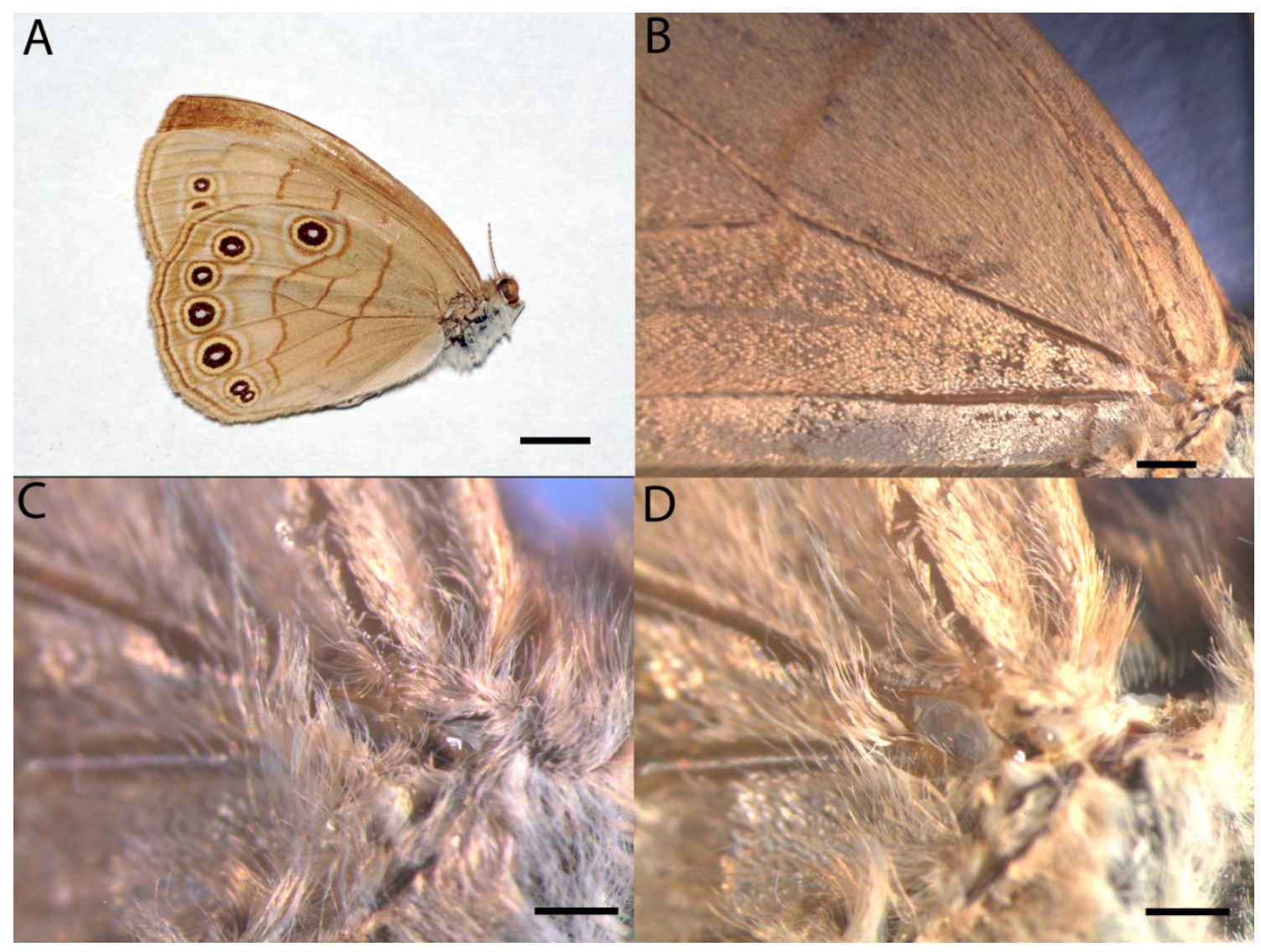

Figure 5.10 External morphology of the VO in Satyrodes appalachia (A) View of ventral wing surface of intact specimen. Scale bar: $5 \mathrm{~mm}$. (B) Photograph of the ventral surface of the forewing of Satyrodes appalachia illustrating the venation. Scale bar: $1000 \mu \mathrm{m}$. (C) Light micrograph of the base of the forewing on the ventral side of the specimen with hindwing removed, but protective scales intact. Scale bar: $500 \mu \mathrm{m}$. (D) Light micrograph of the base of the forewing on the ventral side of the specimen with hindwing removed and scales surrounding the VO removed. Scale bar: $500 \mu \mathrm{m}$. 


\section{Satyrini-Oeneis bore}

Oeneis bore bas a rigid, ovular cuticular membrane over which its thin transparent outer membrane is stretched. The tholus is quite dark in colour and convex from the outer membrane. The forewing veins of $O$. bore are not inflated. Fusiform scales from the anal vein partial cover the $\mathrm{VO}$ offering some protection to the membrane, but even when these scales remain undisturbed the VO is still visible. 


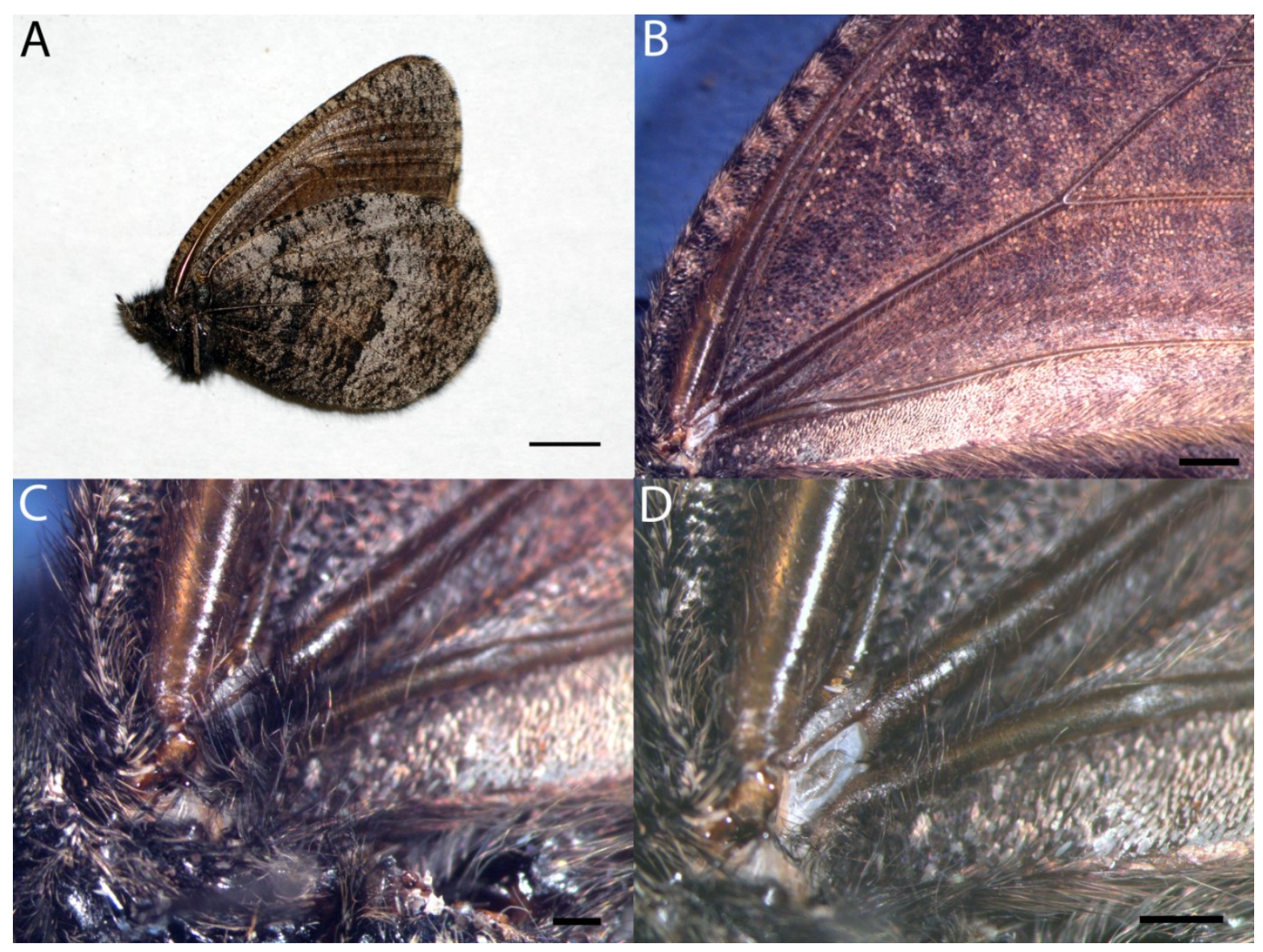

Figure 5.11 External morphology of the VO in Oeneis bore. (A) View of ventral wing surface of intact specimen. Scale bar: $5 \mathrm{~mm}$. (B) Photograph of the ventral surface of the forewing of Oeneis bore illustrating the venation. Scale bar: $1000 \mu \mathrm{m}$. (C) Light micrograph of the base of the forewing on the ventral side of the specimen with hindwing removed, but protective scales intact. Scale bar: $500 \mu \mathrm{m}$. (D) Light micrograph of the base of the forewing on the ventral side of the specimen with hindwing removed and scales surrounding the VO removed. Scale bar: $500 \mu \mathrm{m}$. 


\section{Satyrini - Oeneis chryxus}

Oeneis chryxus has a rigid cuticular membrane forming an ovular structure. The outer membrane is slightly more opaque than those seen in most satyrines. The tholus is well-defined in both colouration and elevation from the outer membrane. None of the forewing veins in this species are inflated. Fusiform scales from the anal vein partial cover the VO offering some protection to the membrane, but even when these scales remain undisturbed the VO is still visible. 


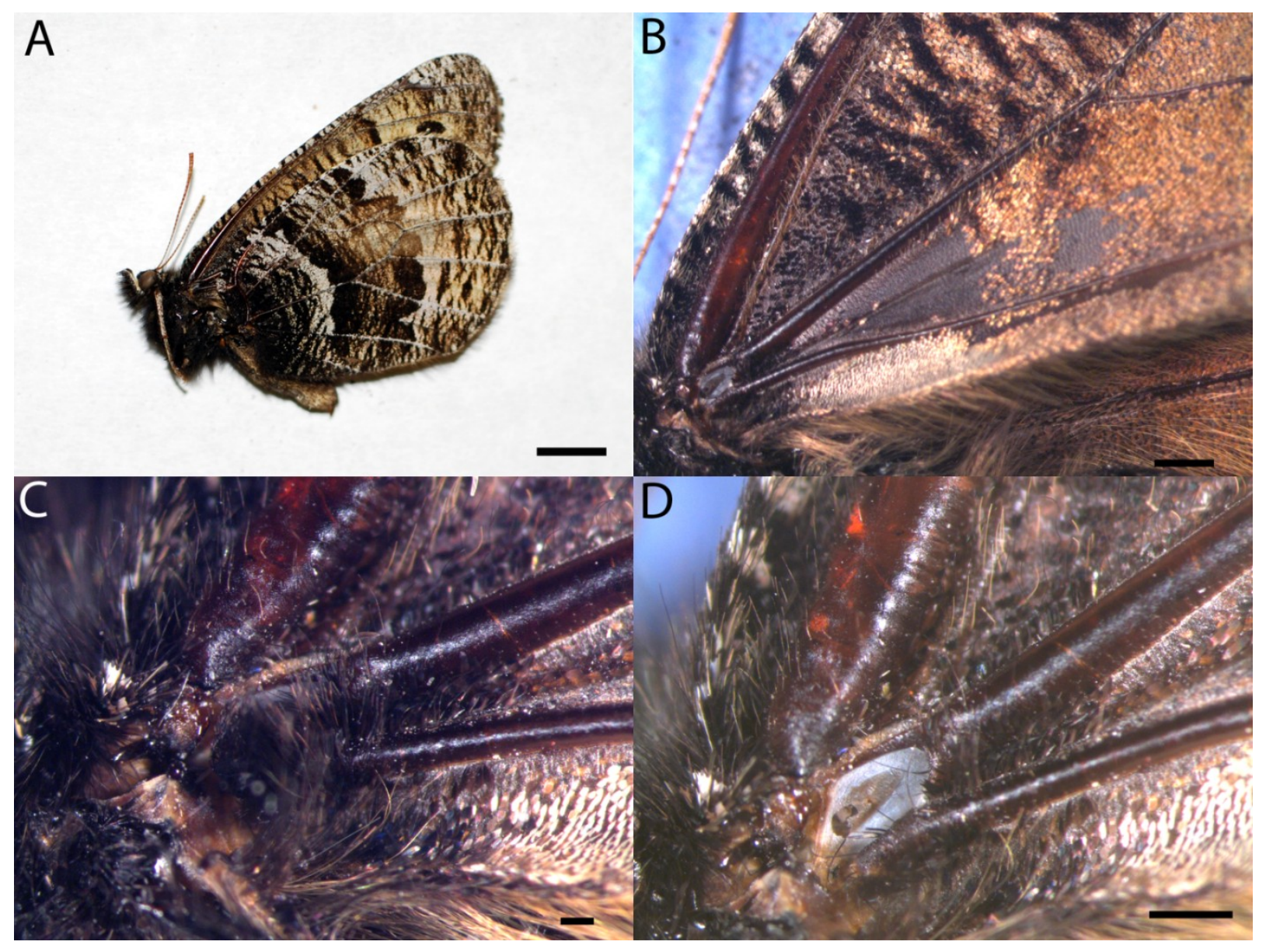

Figure 5.12 External morphology of the VO in Oeneis chryxus. (A) View of ventral wing surface of intact specimen. Scale bar: $5 \mathrm{~mm}$. (B) Photograph of the ventral surface of the forewing of Oeneis chryxus illustrating the venation. Scale bar: $1000 \mu \mathrm{m}$. (C) Light micrograph of the base of the forewing on the ventral side of the specimen with hindwing removed, but protective scales intact. Scale bar: $200 \mu \mathrm{m}$. (D) Light micrograph of the base of the forewing on the ventral side of the specimen with hindwing removed and scales surrounding the VO removed. Scale bar: $500 \mu \mathrm{m}$. 


\section{Satyrini - Oeneis jutta}

Oeneis jutta has a similar VO to the other species in its genus. The cuticular ring forms a rigid oval and the outer membrane is translucent. The tholus has a distinct colouration and elevation from the outer membrane. The subcostal vein in this species is inflated. Fusiform scales from the anal vein partial cover the VO offering some protection to the membrane, but even when these scales remain undisturbed the VO is still visible. 


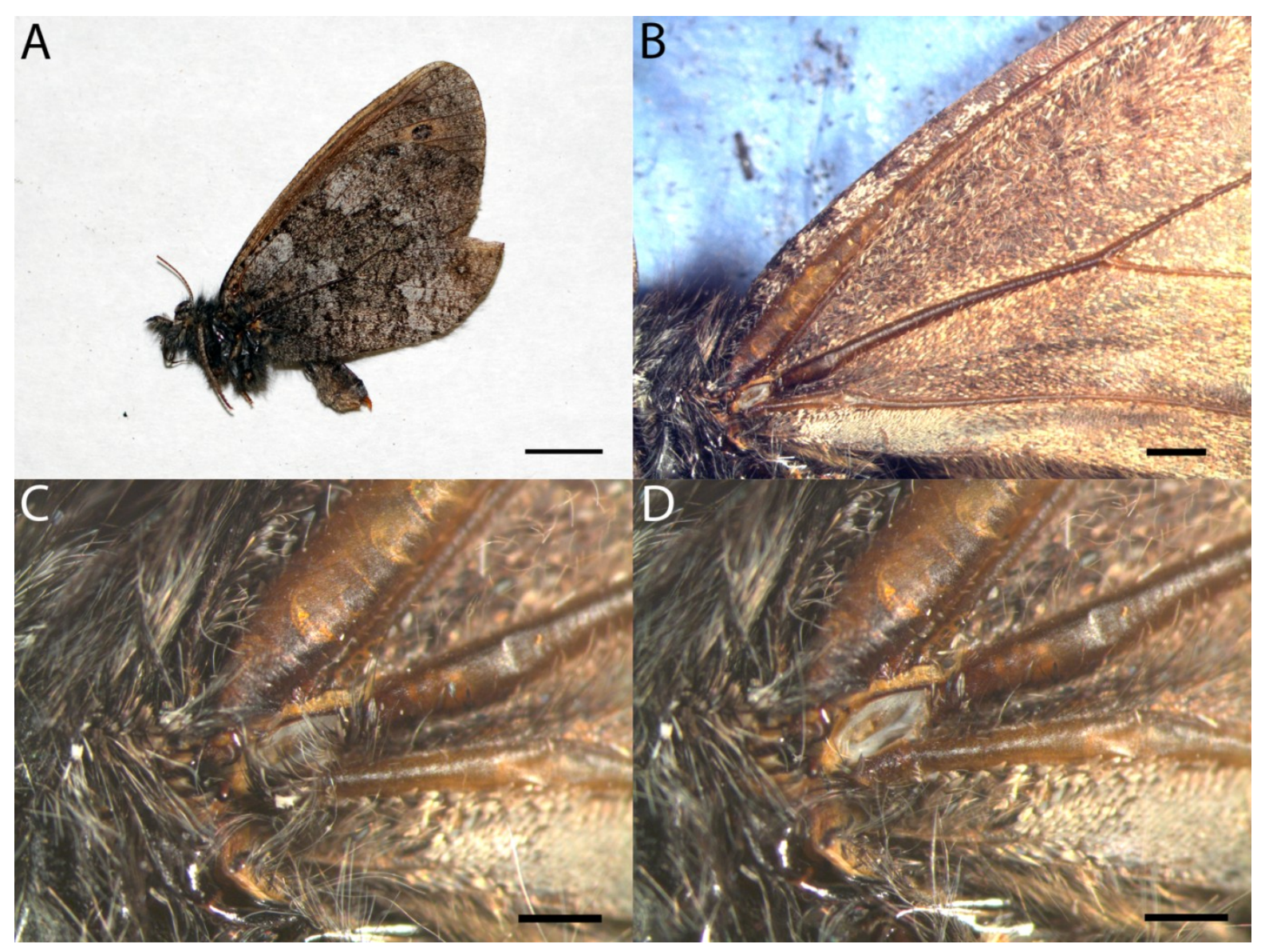

Figure 5.13 External morphology of the VO in Oeneis jutta. (A) View of ventral wing surface of intact specimen. Scale bar: $5 \mathrm{~mm}$. (B) Photograph of the ventral surface of the forewing of Oeneis jutta illustrating the venation. Scale bar: $1000 \mu \mathrm{m}$. (C) Light micrograph of the base of the forewing on the ventral side of the specimen with hindwing removed, but protective scales intact. Scale bar: $500 \mu \mathrm{m}$. (D) Light micrograph of the base of the forewing on the ventral side of the specimen with hindwing removed and scales surrounding the VO removed. Scale bar: $500 \mu \mathrm{m}$. 


\section{Satyrini - Oeneis polixenes}

Oeneis polixenes has a rigid cuticular membrane that surrounds the outer membrane and forms an oval with clear definition. The outer membrane is more opaque and the tholus is welldefined with regards to its colouration and its elevation from the outer membrane. There is no forewing vein inflation present in this species. Fusiform scales from the anal vein partially cover the $\mathrm{VO}$ and offer the membrane some protection, although the $\mathrm{VO}$ is naturally visible behind the scales. 


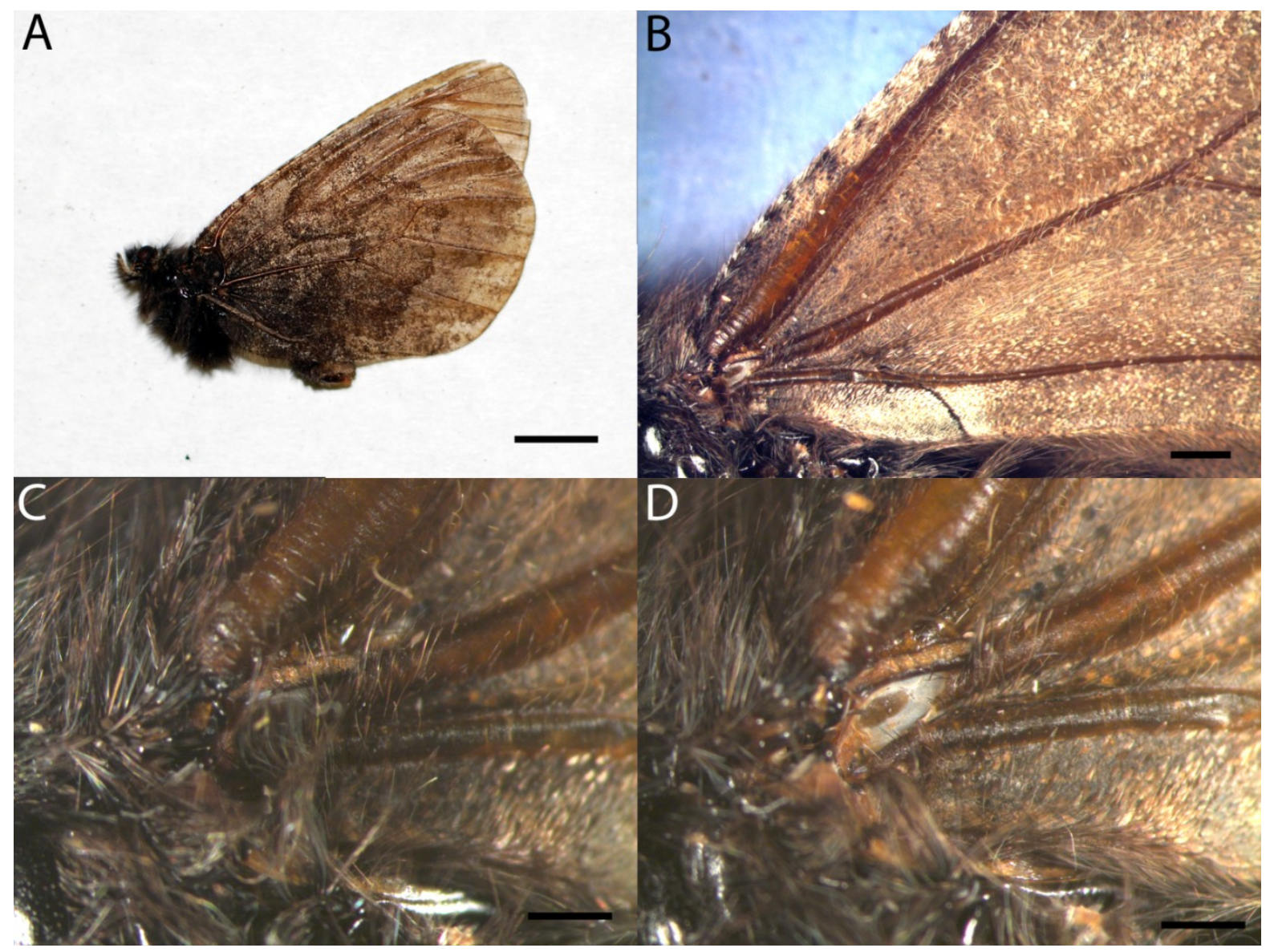

Figure 5.14 External morphology of the VO in Oeneis polixenes. (A) View of ventral wing surface of intact specimen. Scale bar: $5 \mathrm{~mm}$. (B) Photograph of the ventral surface of the forewing of Oeneis polixenes illustrating the venation. Scale bar: $1000 \mu \mathrm{m}$. (C) Light micrograph of the base of the forewing on the ventral side of the specimen with hindwing removed, but protective scales intact. Scale bar: $500 \mu \mathrm{m}$. (D) Light micrograph of the base of the forewing on the ventral side of the specimen with hindwing removed and scales surrounding the VO removed. Scale bar: $500 \mu \mathrm{m}$. 


\section{Satyrini - Erebia mackinleyensis}

Erebia mackinleyensis has a well-defined cuticular ring that surrounds the entire outer membrane. The tholus is easily differentiated by its colour and convexity from the outer membrane. The subcostal vein is inflated in this species, but the cubital and anal veins are not. Long, but sparse, fusiform scales arise from the anal vein and partially cover the VO in this species. The VO is naturally mostly visible behind the scales. 


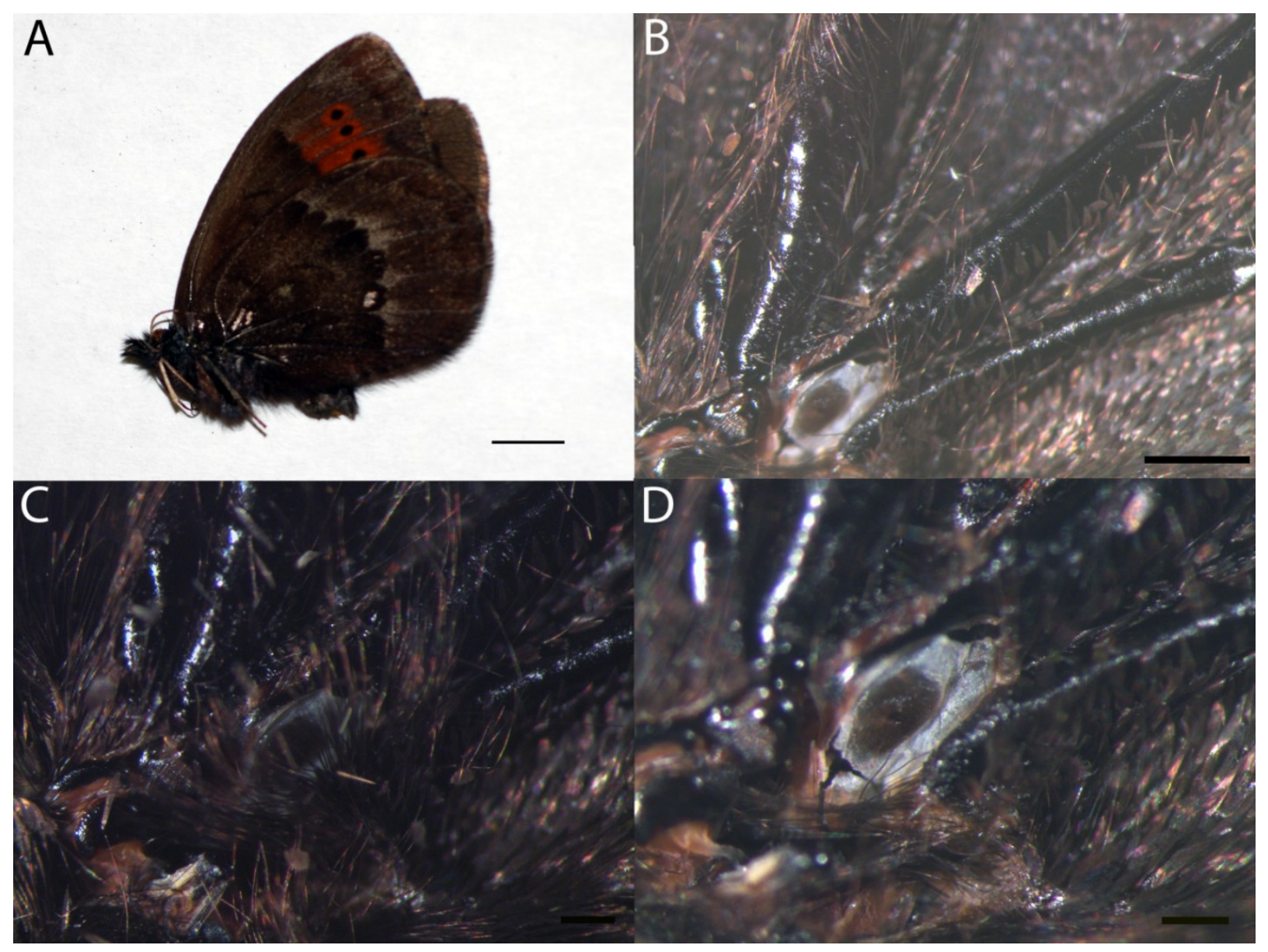

Figure 5.15 External morphology of the VO in Erebia mackinleyensis. (A) View of ventral wing surface of intact specimen. Scale bar: $5 \mathrm{~mm}$. (B) Photograph of the ventral surface of the forewing of Erebia mackinleyensis illustrating the venation. Scale bar: $500 \mu \mathrm{m}$. (C) Light micrograph of the base of the forewing on the ventral side of the specimen with hindwing removed, but protective scales intact. Scale bar: $500 \mu \mathrm{m}$. (D) Light micrograph of the base of the forewing on the ventral side of the specimen with hindwing removed and scales surrounding the VO removed. Scale bar: $500 \mu \mathrm{m}$. 
Satyrini - Erebia manicus

Erebia manicus has a firm cuticular ring forming an ovular structure. The outer membrane is translucent with a clearly defined tholus. There is no forewing vein inflation present. Long, but sparse, fusiform scales arise from the anal vein and partially cover the VO in this species. The VO is naturally mostly visible behind the scales. 


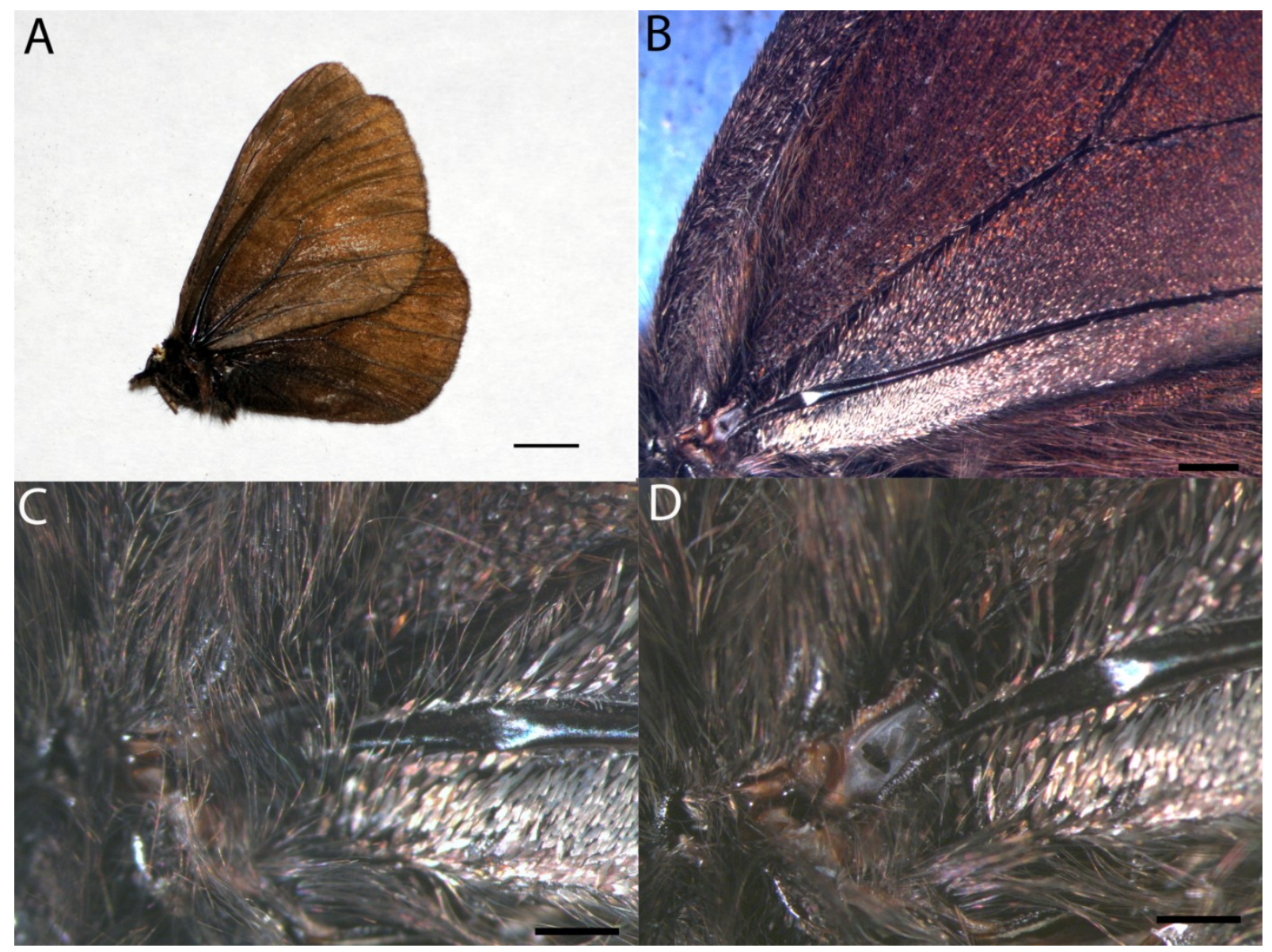

Figure 5.16 External morphology of the VO in Erebia manicus. (A) View of ventral wing surface of intact specimen. Scale bar: $5 \mathrm{~mm}$. (B) Photograph of the ventral surface of the forewing of Erebia macinus illustrating the venation. Scale bar: $500 \mu \mathrm{m}$. (C) Light micrograph of the base of the forewing on the ventral side of the specimen with hindwing removed, but protective scales intact. Scale bar: $200 \mu \mathrm{m}$. (D) Light micrograph of the base of the forewing on the ventral side of the specimen with hindwing removed and scales surrounding the VO removed. Scale bar: $200 \mu \mathrm{m}$. 


\section{Satyrini - Erebia rossi}

Erebia rossi has a cuticular ring that is ovular in nature surrounding the outer membrane which is translucent. The tholus has clear margins with regards to its colouration and elevation. The forewing subcostal vein in this species is inflated. Long, but sparse, fusiform scales arise from the anal vein partially covering the $\mathrm{VO}$ in this species. Even if the scales remain undisturbed the VO is still mostly visible. 


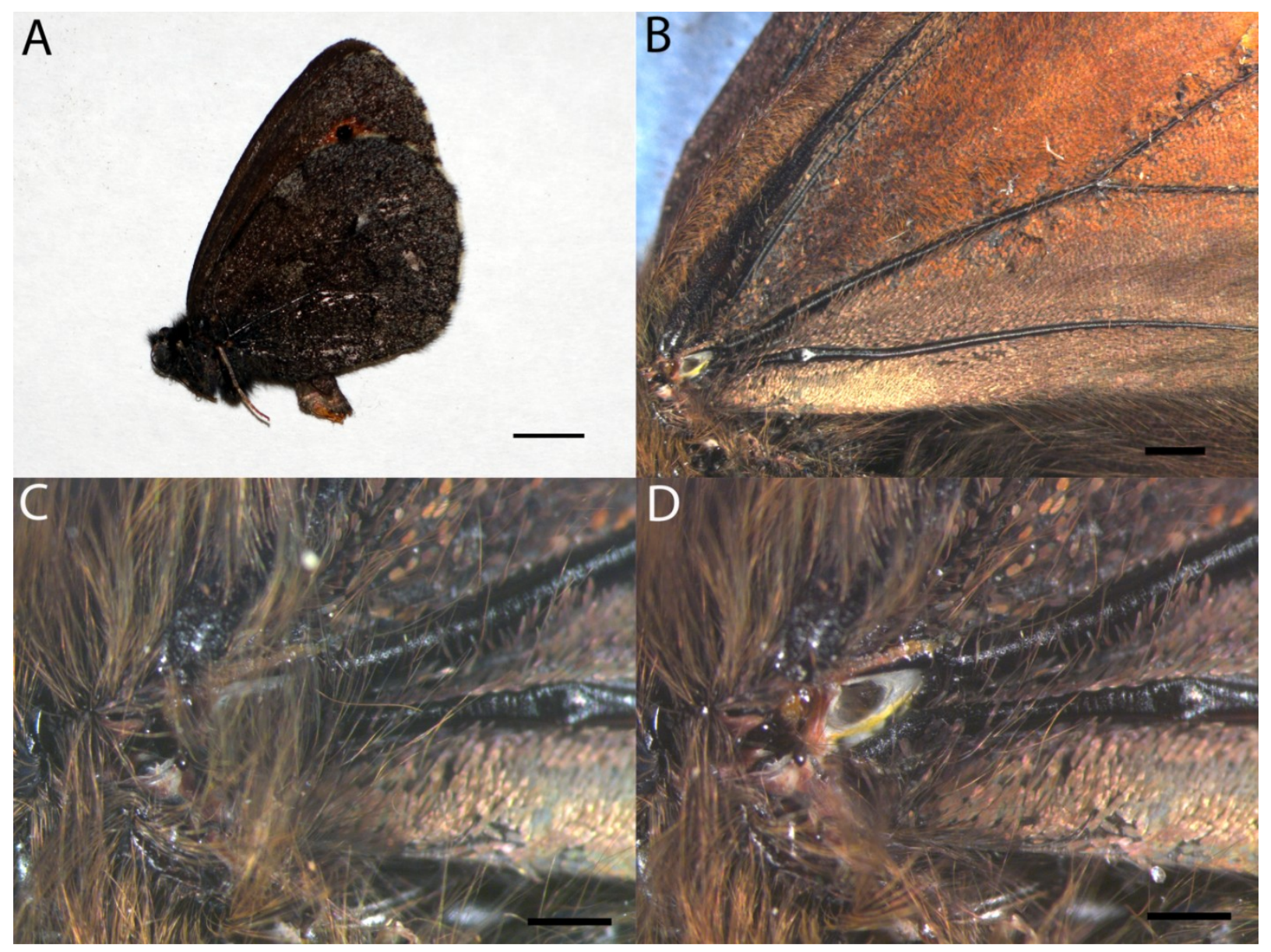

Figure 5.17 External morphology of the VO in Erebia rossii. (A) View of ventral wing surface of intact specimen. Scale bar: $5 \mathrm{~mm}$. (B) Photograph of the ventral surface of the forewing of Erebia rossii illustrating the venation. Scale bar: $1000 \mu \mathrm{m}$. (C) Light micrograph of the base of the forewing on the ventral side of the specimen with hindwing removed, but protective scales intact. Scale bar: $500 \mu \mathrm{m}$. (D) Light micrograph of the base of the forewing on the ventral side of the specimen with hindwing removed and scales surrounding the VO removed. Scale bar: $500 \mu \mathrm{m}$. 


\section{Satyrini - Erebia youngii}

Erebia youngii has a rigid cuticular ring making the $\mathrm{VO}$ ovular in shape. The outer membrane is translucent and the tholus is well defined from it. The forewing subcostal vein is inflated in this species, but the cubital and anal are not. Long, but sparse, fusiform scales arise from the anal vein and partially cover the $\mathrm{VO}$ in this species. Even if the scales remain undisturbed the VO is still mostly visible. 


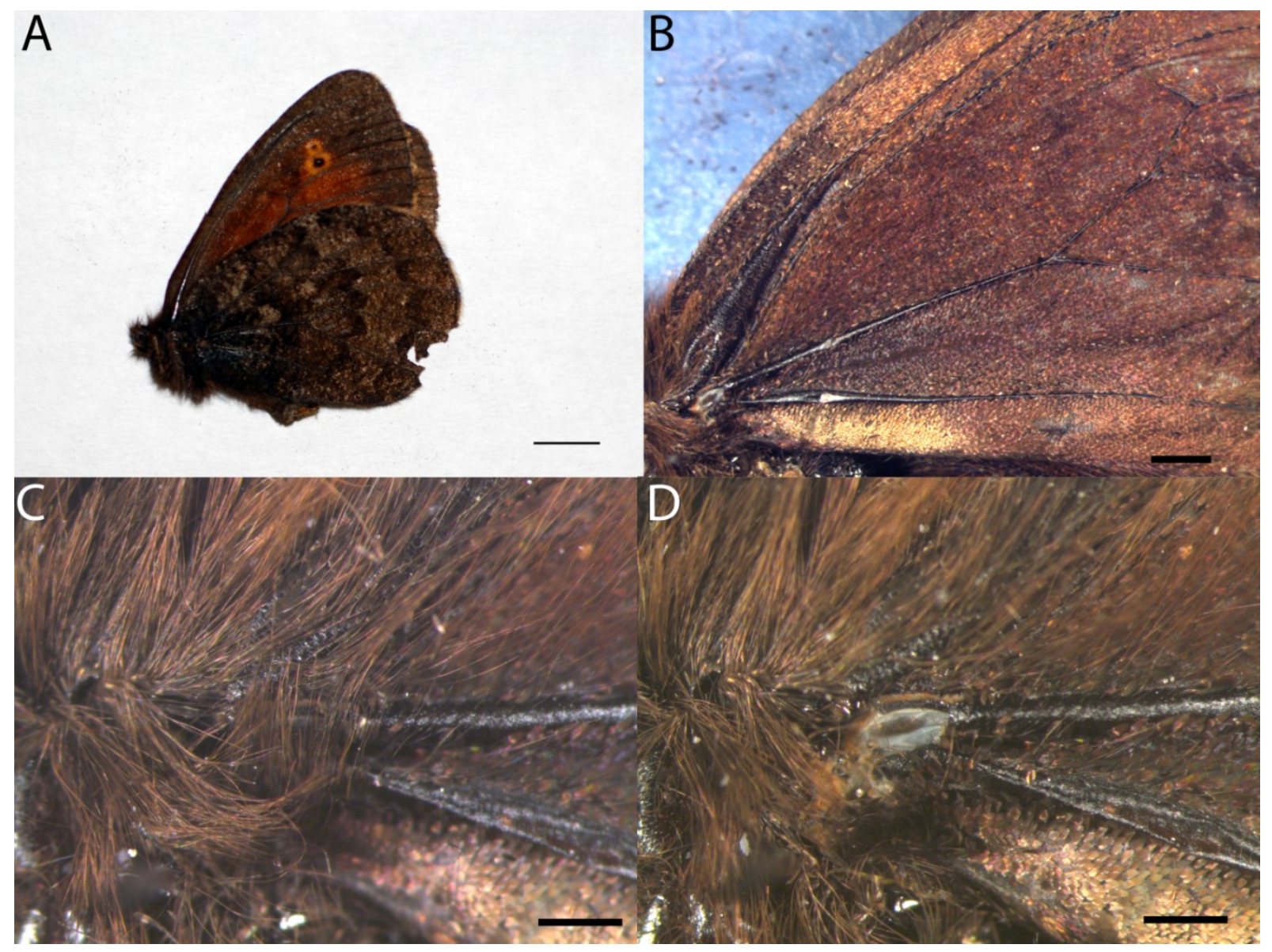

Figure 5.18 External morphology of the VO in Erebia youngi. (A) View of ventral wing surface of intact specimen. Scale bar: $5 \mathrm{~mm}$. (B) Photograph of the ventral surface of the forewing of Erebia youngi illustrating the venation. Scale bar: $1000 \mu \mathrm{m}$. (C) Light micrograph of the base of the forewing on the ventral side of the specimen with hindwing removed, but protective scales intact. Scale bar: $500 \mu \mathrm{m}$. (D) Light micrograph of the base of the forewing on the ventral side of the specimen with hindwing removed and scales surrounding the VO removed. Scale bar: $500 \mu \mathrm{m}$. 


\section{Satyrini-Cercyonis pegala}

Cercyonis pegala has a very rigid cuticular ring forming a narrow oval in shape. The outer membrane is extremely transparent with some of the attachment sites of chordotonal organs clearly visible. The tholus is well-defined and transparent. The subcostal vein is inflated in this species. Fusiform and flattened hairs arise from the anal and cubital veins in this species and protect the VO. Under natural conditions, these hairs obscure the VO. 


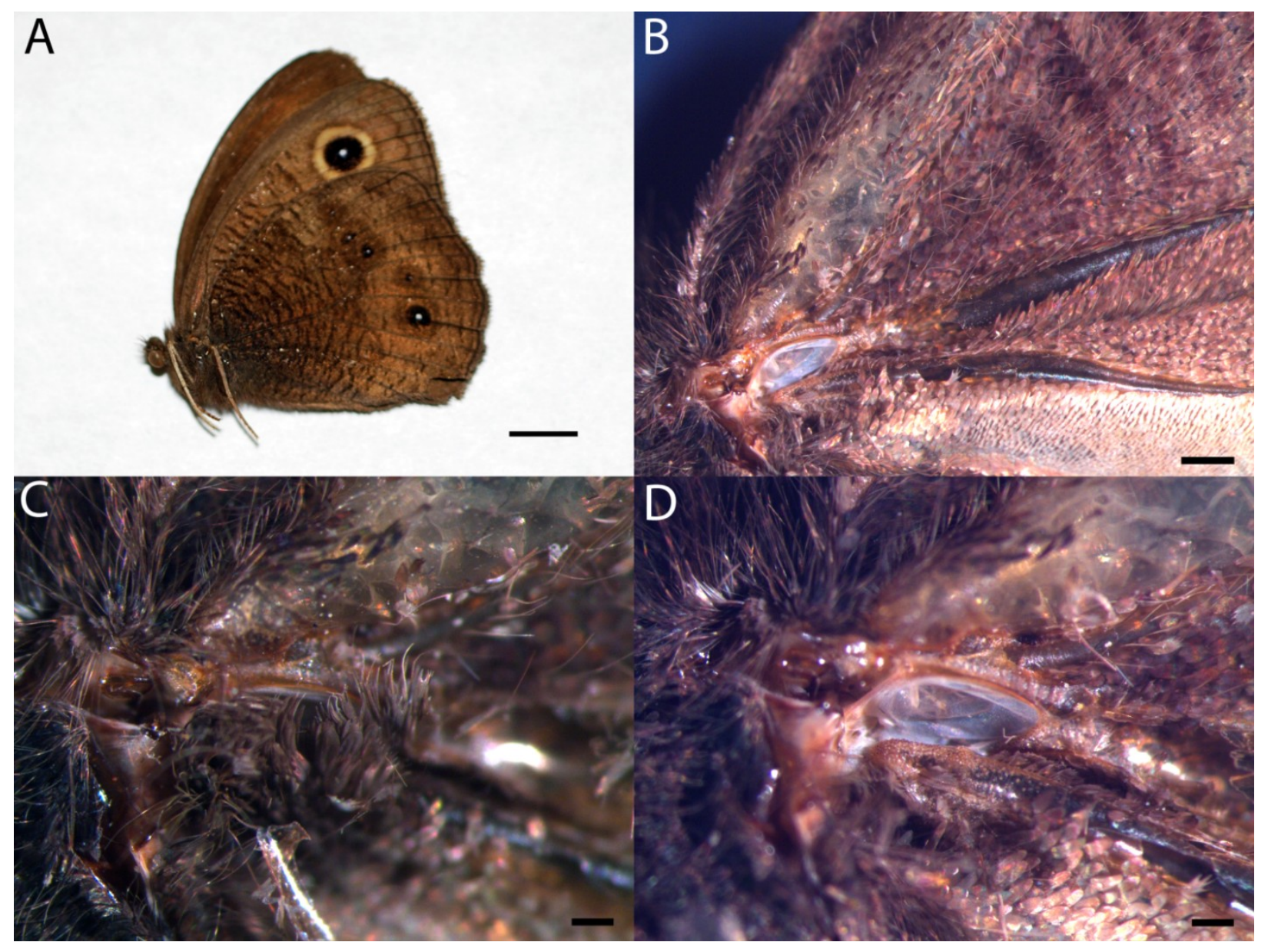

Figure 5.19 External morphology of the VO in Cercyonis pegala. (A) View of ventral wing surface of intact specimen. Scale bar: $5 \mathrm{~mm}$. (B) Photograph of the ventral surface of the forewing of Cercyonis pegala illustrating the venation. Scale bar: $500 \mu \mathrm{m}$. (C) Light micrograph of the base of the forewing on the ventral side of the specimen with hindwing removed, but protective scales intact. Scale bar: $200 \mu \mathrm{m}$. (D) Light micrograph of the base of the forewing on the ventral side of the specimen with hindwing removed and scales surrounding the VO removed. Scale bar: $200 \mu \mathrm{m} . \mathrm{m}$. 